aldibraxy of the attruseum

OF

\section{COMPARATIVE ZOÖLOGY,}

AT HaRVARD COLLEGR, CAIIBRIDGE, MLSS.

founder by pribate subscription, in 1861.

DR. L. DE KONINCK'S LIBRARY.

No. /(1 41). 




\section{SPECIMEN}

\section{ZOOPHYTOLOGIE DILUVIAN $Æ$}

A UCT ORE

\section{IOANNE MICHELOTTI}

I. U. D.

\section{AUG. TAURINORUM}

EDID. HEREDES SEB. BOTTA 


\author{
MCZ LIBRARY \\ HARVARD UNIVERSITY \\ CAMBRIDGE. MA USA
}

\title{
PROSTAT
}

Lugduni, penes Terver, naturaliste, rie neuve, $n .{ }^{\circ} 36$. Parisiis, penes F. G. Levrault, rue de la harpe, $n .{ }^{\circ} 8 \mathrm{r}$. Argentinæ, penes cit. Levrault, rue des juifs, n. 33. Sturgardiæ, penes E. Schweizerbart. 


\section{AVGVSTINO LASCARIS}

MARCHIONI COMITI ALBINTIMILII

EQVITI TORQVATO MAVRITIANO ET LEOPOLDIANO

$\mathrm{R} \cdot$ ACADEMIAE SCIENTIARVM PRAESIDI

QVI SVMMAM AVORVM ATAVORVMQVE

ET SPLENDIDISSIMI GENERIS DIGNITATEM

INGENIO DOCTRINA COMITATE BENEFICENTIA

SVSTINVIT AMPLIFICAVIT

VIRO ILLVSTRI

BONARVM ARTIVM COMMERCIORVM REI AGRARIAE

TVTORI AC VINDICI

EGREGIO LITTERARVM FAVTORI

IOANNES MICHELOTTI

IN MEMORIAM BENEFICIORVM

D. D. C 


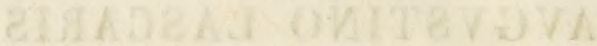

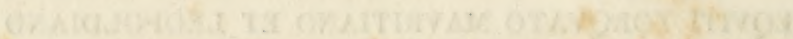

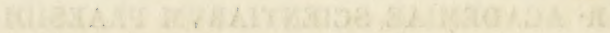

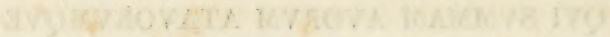

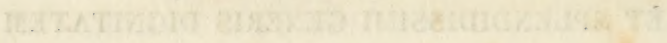

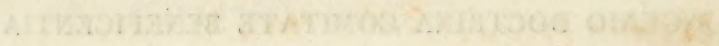

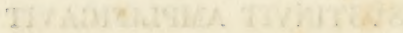

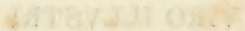

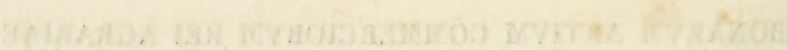

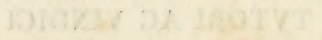

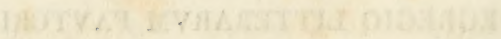

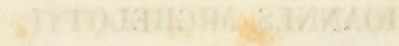

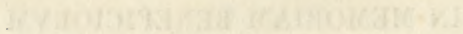

a 
Ea naturalis historiæ pars, quæ zoophytorum naturam, seriem, historiamque inquirit, atque demonstrat, communi, probatoque Zoophytologice nomine venire solet, eodemque vocabulo polypi, et polyparia comprehenduntur.

Polypos ea animantia cum Blainville dicimus, quæ nequeunt in duas æquas partes dividi, quæque circum punctum unum, uti centrum, disposita sunt, et radiatam formam habent vel in tota corporis forma vel in tentaculorum ordine, in quorum vim animantia radiata plerique eos appellant. Polyparia dicimus tegumenta quorundam polyporum, qui iisdem insident, atque vivunt, nec non multiplicantur, atque constant non ex transudatione polyporum, quemadmodum in testaceis contingit, sed ex intima eorum essentia, cujusmodi est cernere in crustaceis.

Mirifica sane de polypis ab auctoribus, qui hac de re scripserunt, afferuntur documenta; corpora enim habes in hac re, quæ obtruncata reviviscunt, quæve compressa in tot alias mutantur figuras quot 
impedimenta; voracitate insigni ac propemodum incredibili pollent, sensibilitate prædita, communi omnibus aliis animantibus nervorum systemate carent; sensus ferme omnes in plerisque desiderantur ( $\mathrm{r}$ ), ovula e parenchymate emergentia præbent (2). Nec minoris ponderis sunt quæ exhibent nobis tegumenta ipsa, seu polyparia; quod cum effusa sint ubique, et varietates, pulcherrimasque formas, ac colores induant, cumque solida eorum textura apprime in nonnullis eorum conservationi decorique inserviat, ornatus, artiumque causa non infrequens eorum est usus; uti in medicina pluries adhiberi posse, hac arte periti contendunt.

Dupliciter igitur præclarissimam hanc historiæ naturalis partem commendatam velim, maxime quia hac nostra ætate ad Geologiæ formationes, strataque cognoscenda, ab iis exordiendo, quæ primæva fossilifera dixerunt, ad ea perveniendo, quæ subfossilia nuncupantur, plurimi intersit (3).

Quum tamen impar sim universam Zoophytologiam complecti, cumque multi referat singillatim potiores species investigare, quæ in unoquoque strato geologico adsunt; hinc brevitatis causa unam

(1) Mémoire d'un genre de polypes par M. Trembley. Opuscul. de physiq. par M. Spallanzani. Tom. 2.

(2) Polipi di mare. Mem. di Filippo Cavolini.

(3) Manuel du géol. par M. Henri de-la-Beche.

Guide du géolog. voyag. par M. Ami Bové.

Mém. du géolog. par M. B. Studer. 
tantum ejusdem partem eligam, quæ pertinet ad supracretaceam cetatem, et quæ etiam in America septemtrionali sui indicium præbet, uti testes locupletes sunt Conradus, et Lea (r), et duabus, uti perbene notat Elie de Beaumont, respondet revolutionibus, quas conspicimus in Alpibus orientalibus, et occidentalibus in Sabaudia late patentibus, e monte dicto Div.Gothard, ad montem vulgo Mont-Blanc.

De Zoophytologice historia brevia dicenda sunt, cum jam de eadem ex professo egerint tum Pallas in Elencho Zoophrtorum, tum Blainville et in naturalis historiæ dictionario et in manuali suo de actinologia: adnotamus tantummodo Aristotelem quædam attulisse, quæ sarta, tectaque ex rhetorum cultu ad nos pervenerunt; qua in re ducem Plinium habuerunt, cui alioquin non minima laus tribuenda foret.

A græco scriptore usque ad annum millesimum quingentesimum nonagesimum nonum circiter inculta remansit tanti momenti scientia; quo tempore Gesner, et italicus Imperato, dein Ellis, Marsilius, Laflingius, Pallas, Esper eam colere coeperunt, et postremis temporibus Lamark, Litmoroux, Ehremberg, Blainville, Milne.Edwards, aliique de ea benemeriti sunt.

Licet autem eø pervenerimus, ut plura in hac scientia veteribus incognita, perspecta habeamus

(I) Fossis shells of the tertiary format of north. America bi Conrad. Philadelphia.

Contributions to geology bi M: J. Lea. Philadelphia. 
speciatim circa polypos proprios alicui generi, uti esset flustrce, vel escharce; attamen gravissima dubia adhuc supersunt, ex quibus primum tenet locum quæstio de ordine magis idoneo ad componendam Zoophytologiam; quumque maximi momenti sit, ut hujus operis dispositio pateat, hanc unam peculiariter diluendam aggredior: aliis quæstionibus alioquin servatis.

Polyparium constat ex polyporum opera, atque eisdem quousque vivunt, communem rationem habet; ubi igitur hæc polyporum corpora cognoscantur, quemadmodum naturalis rei ordo postulat, ex iisdem eorum tegumenta componenda sunt. Modo vero quum Milne-Edwards (1), Grant (2), atque Ehremberg (3), Delle Chiaje plura detexerint circa series quorumdam Zoopliytorum, quæ non modo Linnceo, sed et ipsi Lamarck latebant, atque novam dividendi hæc polyparia methodum induxerint, non renuo hanc servare, quam probabiliter modo laudati viri secuti essent, si illam agnovissent: exceptis tamen iis, quæ jam antea firmis argumentis innixa, subsistere videntur.

Alacri autem animo hane novam methodum miki proposui, quia ceteroquin multo simpliciori via huic scientiæ disposilioni consultum est: duas enim

(1) Ann. des Scienc. natur., I ser., t. 15, par Milne-Edivards ct Audouin. Paris 1828 .

(2) Olsservat. of on the structure and natura of flustra. Edinburgh, new philosoph. journ. Vol. 3, pag. 107.

(3) Beitrage sur phys. kenntiss der corall. im allgemeinen und besonters des Rothen meeres ec. Auct. Elivemberg. 
habemus sectiones experimentis probatas, quarum altera Antozoa, altera Briozoa a recentissimo scriptore appellantur. Hinc prior corpus animantis tibi offert unicam aperturam in cavitate digestiva, atque intus generatim lamellis radiatis munitam; altera corpus exhibet, quod canali digestivo completo, ore, anoque saltem gaudet: campanularia prioris, ocellaria posterioris, divisionis exemplum indicat.

Hisce positis, nemo non videt hanc methodum multo potiori inniti fundamento, quam quæ ducitur tantummodo ex polypariorum materia, vel flexibilitate, vel loculorum natura; licet enim prima fronte videatur, admissa materiæ, vel flexibilitatis ratione, sensim ex uno in aliud genus transire; tamen ubi certo definiri nequeat, an polypi respondeant polypariis, quibus adnexi creduntur; si pleraque polyparia, ut continuo docemur, maximopere differunt, prout in mari adhuc reperiuntur, et vivunt, vel paulo post ab eodem deducta, ac denique post aliquod temporis intervallum vel in undis ipsis; si quodque pejus arbitrarium omnimodo est judicium ex polypariis, imo et quoad cellulas, et quoad flexibilitatem, quæ variant pro locorum, temporis, ac ætatis adjunctis, non video, cur admissas utique, sed obvolutas, neque prolatas dividendi rationes sequi debeam.

Adde, quod si hæc vera sunt, in Zoophytologia ætatis nostræ geologicæ sunt verissima, quia ex professo eorum temporum documenta investiga- 
mus, quorum origo incerta, ac incognita necessario manere debet; necessario siquidem deducendum ex deductione foret, quod alioquin similitudinis causa obtinere possúmus.

Hanc ferme viam monstravit recentissimus testaceorum illustrator Deshayes, qui inter cætera ad cythereas notat: "Si genera ad id compa" rantur, ut memorix juvandæ causa inserviant; ) ubi veri characteres deficiant, nullius momenti ) distinctiones ex hac unica causa ductas habendas " esse : " quod in controversiam deduci nequit; ignorabatur v. g. an sertularice polypus magis ne compositus esset, ac polypus carioporce, ideo falso ex unica materia polypariorum deduximus posteriorem polypum priore simpliciorem præbere naturam.

Gravissina adhuc quæstio apud Zoophytologice cultores oritur de origine ipsius polyparii; hac in re putabat Lamarck, quemadmodum jampridem Cavolini ( I) licet adnexum polyparium polypo sit, tamen nihil commune cum eo habere, atque ex transudatione instar testaceorum constare, uti et Linnceus ipse docebat (2), unde per intus susceptionem, sicuti Cuvier in egregio suo opere (Tableau élém. d'hist. nat., pag. 66) sentiebat, minime crescere.

Nostra hac ielate insignes virtute viros con-

(x) Polipi di mare. Mem. cit. pag. 40 et pag. 56.

(2) Mem. Academ. auct. C. Linn, , ann. 1710, pag. 477. 
trarium sensisse cum Cuvier, eorum probant exprimenta (Ann. des scienc. nat., 3 ann., tom. 6, pag. 28). Quoad priorem doctrinam primitus evulgatam fuisse novimus a Peysonello; Linnceus eam recepit, atque adeo Lamarck placuit, ut iterum atque iterum eam firmare studuerit (1).

Primum enim fatetur ex corporum observatione omne polyparium semper extraneum esse animanti

(1) Histoire des animaux sans vertebr. I et 2 édit. pag. 88 , 9' et 97 . On peut encore assurer, d'après l'examen des objets, que tout polypier quelconque est toujours extérieur à l'animal, toujours inorganique, toujours sans communication intime avec lui, quoiqu'il y adhère; que tantôt le polypier forme, autour du corps des polypes, une enveloppe simple, et tantôt une enveloppe compliquée ou divisée latéralement.

.... La croûte gélatino-terreuse qui recouvre l'axe est encore le résultat des matières excrétées et déposées, mais d'une autre sorte que cclle de l'axe: elle ne tient rien de l'organisation, soit vasculaire, soit cellulaire; car ce n'est que dans son état de dessèchement qu'elle est poreuse, et, sous aucune considération, elle ne peut être comparée à une écorce végétale.... L'axe de leur polypier, ainsi que la croùte qui le recouvre, sont donc tout-à-fait extérieurs aux polypes....

Un naturaliste des plus distingués qui a fait faire à la zoologie de grands progrès par ses recherches, s'exprime ainsi dans un de ses ouvrages: "La partic dure, ou du moins la croùte qui revêt les polypes, paraît faire partie de leurs corps, et croître avec eux: en sorte que les branches qui naissent çà et là du tronc, dans les espèces qui ne restent pas simples, sont de véritables végétations, et non des additions que les habitants construiraient contre celles qui existaient déjà.... Rien de tout cela n'est fondé; ce dont il est facile de se convaincre en examinant attentivement la structure des polypiers. Les faits bien constatés attestent que les polypes à polypier sont aus hydres ce que les mollusques testacés sont aux moilusques nus. De part et d'autre, ceux, qui ont des enveloppes solides. les forment par des excrétions de leurs corps, et ces, enveloppes ne croissent pạs comme cux par intus-susception. Elles sont inorganiques et torjouss complétement extérieures aux animaux qu'clles conticunent. " 
ipsi, seu polypo, inorganicum semper, absque communione cum polypo licet eidem adhæreat.

Axem, qui in centro reperitur, testatur constitutum evidenter esse substantia continua absque organorum indicio, ejusve fracturas vitreas ferme esse; crustam autem, quæ axem tegit, affirmat conslare ex materiis sepositis, atque adnexis, nihilque propterea et axem, et crustam, quæ reperiuntur in polypariis, commune habere cum polypo.

Denique animadvertit polyparia ita se habere quemadmodum molluscha testacea; utroque in casu transudationem corporum animantium esse causam, cur eorum tegumenta originem habeant.

Contra sentientibus multa favent argumenta: hinc cum Milne-Edwards respondeo, cellulam non esse simplex depositum materiæ transudatce, quo modo evenit in testaceis, verum conditionem peculiarem generalis tegumentariæ membranæ ad eum modum compositæ, quo composita est in crustaceis, insectisque. Id ex analysi deducitur habita in gorsoniis; quodque in tegumento incipiat incrementum minutorum polyporum, ejusque texturam tunc temporis augere, uti notat Pallas ad sertularias, statuto loco, quin nova strata adjiciantur; paulo post polypos prodire ex hac membrana. Ergo necesse est concludere per intus-susceptionem constare polyparium; hac ratione Cavolini difficultatem in obtinendis, deducendisque polypis facillime explicabimus. Firmior hæc opinio manet, si addamus Lamarck sensisse polypos simplicissimæ 
naturæ esse, atque hoc tantum de polypis lamelliferis probatum est. Insuper non animadvertit multo magis implexos polypos esse si non adhæreant polypariis, quam si iisdem adhæreant; nam sic musculorum saltem seriem evitare ulla ratione non possumus, ex quo physiologiæ aliquod systema demonstretur oportet; implexam magis autem esse naturam molluschortum testaceortum et ipse fatetur. Illud denique adjiciendum polypos plares simul semper prodire, itidemque se abscondere, si agatur de polypariis compositis, uti vocant; quod ut contingat, oportet, ut vasculare adsit systema, quod in rudi materia locum habere nequit.

Non novam tamen hic opinionem habemus: raro enim contingit, ut quod probabile sit vel apud veteres $\sin$ explicatione, saltem indicatione aliqua refertum occurrat, sis licet Pallas alioquin de polyparii natura senserit eodem ferme modo ac Linnaus, Cavolini, Lamarck, tamen dum skeleton memoravit, et uti insectis polypos polypariis insidere non obscure, non ambigue Cusierii, atque Milne-Edwardii opiniones præcesserat.

Hæe necessario præmittenda videbantur, ut ordo, cui innitor, palam fiat cum eo temperamento instructus, ut veram polyparii originem sequamur, eos auctores generum initio indicando, qui potissimum in unoquoque speciales observationes contulerunt: peculiaria quædam occurrunt procul dubio et de polypis, et polypariis; sed quæ pertinent ad documenta geologize in Zoophrtologia 
I 0

saltem pro parte explere studebo; cætera reliquis scriptoribus, quorum non pauci, virtuteque præstantissimi nostris temporibus adsunt, committam.

$\mathrm{Tu}$ denique, historiæ naturalis cultor, humanitatem, sapientiamque tuam hisce conatibus adjungere dignare, quæque addenda, vel immutanda sint nota, meque monitum redde, gratumque animum tibi servabo. 
IMPERATO, LEFLINGIUS, CAVOLINI.

Polyparium phitoideum, corneum; surculis gracilibus, tubulosis, simplicibus aut ramosis ad latera dentatim celluliferis. Axi perforato.

Cellulce calyciformes, distincto, dentatim prominulce sessiles, vel subpedicillatce, bifaria, vel sparsce. Vesiculae gemmiferce.

Polypus corona simplici tentaculorum subsiliatorum monitus; os proboscidiforme simplex.

Sertulariam primum vere, accurateque clarus Laflingius investigare coepit ( 1 ), cujus rei abundans est testis Pallas (2), nec non italicus Cavolini (3), quem ducern sectando Peysonellus (4) passim postea hujus generis vera cognitio recepta fuit.

In definitione autem a Pallas tradita " animal vegetans plantæ habitu " cernere adhuc est inveteratæ opinionis, et rationum comparationis vim; unde ipse ajebat, sertulariam summam cum plantis affinitatem habere præter habitum, fructificationem; elongari in tubulum simplicem medulla repletum, ex eoque gemmulas protrudere, quie in solitos calyculos, polypiformes flosculos continentes efllo-

(1) Laflingius. Act. Accad. Stocklm. Germ. 1792. Vol. I4.

(2) Pallas. Elenchus zooph. Hagæ. conit. 1766. Sertul.

(3) Mem. cit, auct. Cavolini Philippi. pag. ig6.

(4) De corallis, trans, of London. Vol. 47, pag. 445 . 
rescunt; in quibusdam sertulariis non caulescentibus extrema ramulorum in tubos vermiculares, calyculis destitutos, obviis corporibus se se adfigentes, quasique radicantes degenerare; regerebat, ramulos, et calyculos semper sursum assurgere, et ipsos semper deorsum tendere: quid simile invenimus eliam apud Linnceum in editione decimatertia systema nature dum ait, sertularias et plures affines radicatas esse more plantarum, radiculis extra se dispersis.

Hisce sepositis, quæ non omni fundamento destituuntur, quemadmodum nostra ætate etiam exploratum est; puta inter cxtera effectus lucis et motus in polypis, quod eruimus ex scriptis insignis historiæ naturalis cultoris ( $\mathrm{r}$ ), facile probatu erit non modo polyparia, sed et polypos sertularia cognitos vel ab ipsis auctoribus remotioribus fuisse; jamdiu omne dubium memoratum genus cum hydris confundere evanuisse. Quasi hydram habes, inquit Pallas, ramosam, tubulo inclusam (2), cujus poris coronatis, seu calyculis capita sua cirrhis instructa exerit; in singularibus vesiculis profert germina viva, decidua, novasque stirpes animatas productura; turbata quiete horum polyporum, contrahuntur se se polypi, inque calyculos corneæ indolis, et ramosæ se recipiunt vel universo simul ramo, vel propria cellula.

(1) Blainville. Diction. des scienc. natur., tom. 6o, pag.. 76.

(2) Vid. Præfat. quam posuimus initio. 
Non pauca etiam habemus apud eumdem auctorem circa ovaria; docet siquidem verno in primis tempore vesiculas peculiares a calyculis polypifloribus diversissimas proferri, continuo adhærere earum membranam tubulo corneo; situ et figura differre; indiscriminatim nasci (I).

Aliqua etiam nobis Cavolini adjunxit de diversa quidem sertularice polypi, ac hydrce natura; nec non de horum polyporum affinitate (2).

Ipse tradidit variis in observationibus comparationem quxsivisse cum hydra, de qua meminit Tremblejus, cujusve proprietates, naturam, habitationem, ætatemque summa patientia, et elaboratione laudatus vir investigavit, et regerit non affuitatern tantum habere, sed omni versu congruere sertulariam cum polypo tremblejano, a qua tamen sententia adamussim servanda repugnat vel ipsa polyparii, vel ipsa corporis polypi indoles, alia in polypo hydrce, ac in polyposertularice; hoc ideo magis probat, quod polypi sertularice naturam minime assecutus, putabat organum in polypario inclusum esse, ex quo prodiret pedicillus, uti loqui amat, modo brevis, modo longior, qui cum se restituat, tentacula, quibus coronatus est, cum eo revolvuntur ad ejus similitudinem, atque in polypario includuntur.

Qua in re videmus accuratiorem tradidisse Pallas ejus definitionem Leflingii insistentem restigia,

(1) Pallas. Elenchus zooph. cit., pagy. пाо, IIx et 112.

(2) Cavoli 2 . Mem. polipe marini, pag. I1 


\section{4}

qui considerabat reapse proboscidem caput polypi esse, non pedicillum, et jam antea tentaculorum ordines, proprietatesque scripserat.

Non spernenda tamen quæ addidit italicus scriptor, qui præter innumeras de motu,vitaque experientias, nec non accuratissimas specierum sertulariarum quæ in mediterraneo reperiuntur enucleationes, animadvertit minutis granis corpus compositum esse; hæc minuta grana modo hic, modo illic agitari ignota, sed certa lege, licet et ipse polypus propria cellula consignatus appareat. Didicimus insuper ab eodem Cavolini plurima ova ad latera prodiri;itidem hre ova triplici modo fieri aliquando ad latera; aliquando in ipso polypo; aliquando cum propria cellula ostendi; de quo tamen postremo gravis quæstio futura foret, ni diceremus adultos polypos pro recenter-natis accepisse.

Primam propositionem ita eam explicare cupit, ut, quum omnia ova minime consistere possint in matrice, ita hæc tegumenta exteriora componantur, ut propagationi sertulariarum consulatur.

Multa itaque vel ab elapsi sæculi historia polyporum cultoribus allata sunt de polyporum indole, qui sertularius habitant; mirum itaque videri debet quod Lamarck, atque Blainville ne mentionem quidem habuerint de polypo sertularice, qui non infirnum locum, ubi de zoophytis agitur, obtinere debet. Cæterum ubi teneas ita polyparium sert:llarice esse compositum, ut tibi similitudinem præbeat minutæ plantæ scopulis, vel aliis corpo- 
ribus fixam, vel convolutam ima ex parte, unde passim alii trunculi ex eadem prodeant ferme recti quique ramuli non inepte comparati sunt ad minuta folia; en tibi exterior sertularice figura.

Ramuli autem vel bifurcati sunt et lateraliter componuntur, aliquando tamen summam ramulorum utrimque congeriem exhibet sertularia, ut nemus, ut ita dicam, præbeat, sylvulasque ex hisce sertulariis plures, ut ait Pallas, efficiat. Præterea truncus, et rami corneæ naturæe sunt flexibiles, unde Lamoroux, qui huic flexibilitati maxime attendit; inter polyparia flexibilia sertulariam retulit.

Colorem nec unum præbent sertularice; nam sertularia purpurea tota quanta est atro-purpureum colorem induit: sertularia nigra, quem indicat colorem habet; sunt nonnullæ, quæ truncum habent coloris ambra, ramos coloris albi, ut et aliæ eodem ubique colore pollent. Anni tempestates quum mutantur, nec non in procellis, quæ passim obveniunt in mari, evolvuntur sertularice,sæpeque trunci urice manent, vita destituti, atque passæ revolutionis testes.

Merito propterea, ut ex dictis liquet, Edwards inter antozoa provocavit sertularice locum, nam anatomiæ hujus polypi præsidiis freti, quibusnam modis hydris conveniat, quo sensu ab iisdem vitalitatis potissimum contemplatione recedat, cognovimus. Oris enim, tentaculorum, canalis digestivi speciatim dispositio hisce animantibus communis est. Hanc rem certa ex parte assecutum fuisse novimus Blainville solius met cellulie dis- 
positione innixum. Placuit insuper eodem ex sertularice genere novam familiam, divisionemque inducere, Sertularicea semel atque iterum nomine inclicata, cujus characteres in eo potissimum reponere maluit, quod corpus polypi corneum implexum exhibet, liquorem motu preditum, quique in omni polypo continuatur, ostendat. In ordine autem, quem statuit, hanc tribuit sertulariis definitionem, ut sit polyparium corneum, sxpe flexuosum, atque radicibus filiformibus addictum; ut cellulæ sessiles, urceolatx sint, atque binubo oblique dispositx. Polypum dixit hydriformem tentaculis ciliatis munitum. Creterum quousque melius cognoscamus hoc genus, eas tantum species inter sertularias recensebimus, qux axem perforatum exhibent. Ea denique nobis arridet opinio, vi cujus cum eodem Blainville genus idice a Lamoroux inventum inter sertularias reponimus.

Si vero ad geologiam te convertas, extra controversixe aleam positum est in primevis organici regni documentis haudquaquam reperiri, ita ut fossilifera strata inferiora, ea quæ transitionis, jurassica, oolitica dicimus, perquirere possis quin sertularice indicium habeas: videtur siquidem ex iis generibus esse, quæ recentioribus tantum temporibus sui indicia relinquere potuerunt una cum tot aliis animantibus quorum modo adeo utilis, laudabilisque investigatio in tota ferme Europa suscepta fuit.

Quæe sane documenta deficiunt, cur sertulariam 
habeamus tanquam primæræ ætatis incola, cujusve rei quoad geologiam maximopere optanda foret contraria sententia, quum ea ad antozois pertineat, alioquin vero non deficiunt documenta in polypariis insita ad hanc classem pertinentia; eam tamen non desideramus in cataclysmis posterioribus geologiæ; nam certum est eam extitisse in diluviano ævo atque cretaceo, uti docent exempla, quæ habemus in Svetia, in Germania, et alibi.

In diluviana ætate autem certe litora populasse nos docent strata geologica in Dania extensa quxque memoratam cretaceam formationem tegunt, quarum sertuluriarum aliquot fragmenta milhi commisit præclarissimus vir Forchlammer in hoc specimine relata.

Numero sane plures esse debent sertularice quæ in geologicis documentis adsunt, sed quum earum fragilitas conservationem impediat vel eas corrumpat, ut pluries, quid hoc nomine veniat cognosci nequeat, aliunde vero quum nec una stratcrum indoles, quæ modo magis, modo minus, modo niliil omnino sertularice conservationi favet, pronum est concludere iis tantummodo in locis, atque adjuactis perfici posse specierum accuratam descriptionem ubi memoratus concurrat, stratorum atque numeri favor. 
Stirpe ramosa, dichotoma, paniculata, intus perforata.

Frustra perquirere contendis species ab auctoribus recensitis, ut, qua de agimus, invenias speciem; nam in omnibus speciebus in statu viventi descriptis cellularum, vesicularum, et pinnarum, nec non articulorum, aliorumque similium dispositionem iidem præe oculis habuerunt; in hac quum unice possimus inspicere minutos ramulos circumcirciter velutino spinosos, frustra, repetam, inter descriptas, eam quæ eidem in statu viventi conveniat, quæras.

De sertulariis disserens Milne-Erlwards notat priorem sectionem sertulariarum posse Laomedcas dici: sed illico subjungit " mirum quod in eodem polypario utriusque generis dispositio invenitur " profecto si hoc probaretur, evanesceret omne fundamentum Laomedcas servandi, ideoque unde deductie sunt reverti debent, et sertularia gemus proprie dictum augere.

Multo poliori ratione servandum esse putarem genus Thoa; nam quod cellula sint ferme nulla, polypi ascendentes, ovaria irregulariter ovoidca vix attendendum; tamen negare nulla ratione possumus quoad tubulos qui se se implicantes atque conjuncti hanc massam constitumnt, quae sertularis altinis videur, aliud polyparium imblicare, cui alia quoque suffigatur polyporum natura. 
Ad hanc speciem sufficiat adhuc notare, antipathis indolem congruere, rigidam esse, et cellulas pedicillos exhibere. Reperitur in Dania in stratis supracretaceis nec non in insulis illius regionis propinquioribus. Mus. R. IIaplanice. Collectio Michelotti. 


\section{CORALLIUM}

\section{BOCCONE, MARSILI, DONATI.}

Polyparium fixum, dendroideum, inarticulatum, rigidum . Axis caulescens, ramosus, lapideus solidus, stratis, concentricis compositus, ad superficiem longitudinaliter striatus.

Crusta corticalis in vivo mollis, ramosa, polypifera; in sicco indurata, porosa; duobus stratis constans, cellulis sparsis.

Tentaculis 8 pinnatis, albis, interiori canali prceditis et ad os polyporum radiantibus, conicis; ovariis internis.

A sertulariis gradum nunc faciamus ad corallium, cujus quidem sin investigationem saltem, pretium cognitum jamdiu novimus.

Re enim vera præter Aristotelem memorat illud Ovidius ( $\mathbf{I}$ ), nec non Plinius in historia mundi, et inter recentiores Conradus, Gesner, Aldrovandi: posterioribus temporibus Boccone, Marsili, oculatus Donati, ut Linnci verbis utar, Pallas, Cavolini, Blainville, Milne-Edwards, Ehremberg, aliique hujus generis investigationem sedulo susceperunt. Talis autem est hujusce polyparii color, indoles, ut usibus quotidianis artis, ornamentique causa inserviat (2): imo etiam medicamentorum vicem obtinet, uti et veteres aliqui (3), et hodie

(1) Ovid. Metam. Libro 14 et 15.

(2) Diction. teckn. des arts et métiers. Tom.6, pag. 18.

(3) Vater Christ. De corallis nat. prxp. et usibus.

Garencieres, On the virtues and effets of the corall. 
zonnulli contendunt; quorum tamen opinionem alii tamquam pro aris et focis certantes acerrime rejiciunt (1).

Nos, iis relictis ambagibus, notamus eam esse materiam hujusmodi polyparii ut vix, excogitari quid possit, quod lævigationis et industriæ adjumentis in tot tamque varios usus convertatur, unde aptissimum nomen, gloria maris a græcis excogitatum eidem apprime congruit. A polypo ordientes, habemus corpus rubri coloris, et tentacula gerens alba, translucida, ita ut aperta, et effusa nobilissimam syderis formam exhibeat, mari autem deductum flacidum, et tamquam candidi lactei gutta cadit.

Os autem tentaculis coronatum, quæ canalem internum quoque ostendunt, rotundatum est, neque lineæ longitudinem excedit: ad latera adsunt duodecim striæ, quæ corpus in tot partes secernere videntur: ita denique polypi conjuncti apparent, ut unusquisque ad perpendiculum instet axi, ejusque abdominalis cavitas, communis portionis corticale involucrum constituens, latius interius pateat. Sulci ex pedicillo originem ducunt, atque vicissin sunt perpendiculares; in adultioribus ramis, quam in recentioribus sunt potiores, ii plani non sunt, sed inæqualiter respondent systemati vasculari, vi cujus communicatio inter varios polypos intercedit. Nec protermittenda quæ occurrunt in ovariis,

(1) Cadet de Gassicourt. Diction. des scienc. médic. Tom. 7. 
quæ interiora sunt polypo, atque granulos minutissimos albi coloris gerunt; e matrice deductis ovis, corporibus junguntur, et paulo post rugæ in superiori parte conspiciuntur, ex quibus, temporis progressu, prodeunt tentacula, orisque constitutio perfecta apparel; unde ex hoc momento etiam poIyparii amplificatio videtur, licet aliter circa hæc Lamarck placuerit.

Vescitur autem polypus corallii iis minutissimis animantibus, quæe infusoria dicuntur, quæque elitusa abunclantissime reperiuntur in is præsertim locis, ubi major vis astus adesse intelligitur; ex alimentorum autem facilitate deducendum est, quod plures non modo polypi, sed et molluschorum species adsint in unis quam in aliis plagis, in hac vel illa anni tempestate.

Si vero non seorsim polypum atque polyparium observare velis; habebis tenuem vestem albam, uti jampridem innuil Imperato, vel tunicam si Donati et Cavolini verbis uti malis, quæ constat ex innumeris ferme aliis membranis tenerrimis, quibus adhærent recensita corpora polypos constituentia; hæc tunica caduca, fragilis est, brevi dissolutura. Ex hac tunica profluunt vasa cylindracea aliis vasis minutioribus adnexa, guorum functiones esse putavit Donati corallio alimentis ducere, quod singulare prorsus, atque futile argumentum est, ni dicamus hes tubos polypum ipsum constituentes quorum longitudo lineam non excedit, polypario catenus inservire quateuus cidem adharent. Ea 
ixidem convexa pluries est ut polypi recipiat corpus, atque ex granulorum multitudine, quam recipit, eundem quem axis colorem exhibet.

Totius autem corallii involucrum tum ititernum tum externum vi ignis in minutissimam pulverem reducitur cinerei coloris; quemadmodum autem, pergit Donati, cinis scheletri imaginem indicat, ita et cinis corallii exhibet corpora minutissima et candidissima simul conjuncta sphæricæ figuræ; porro in primævis constitutionibus, et interior et exterior vestis optime conveniunt; quod magis magisque obstat ejusdem scriptoris opinionibus, idest plantie naturam inesse corallio, et polypum eidem non adhærere.

Abunde autem crescit in litoribus Sardinice, atque a Genuensibus, et Neapolitanis multis ab hine annis apud Indos commercii causa defertur ( I); nec in Sardinia tantum, verum etiam penes Galliam Narbonensem, penes Siciliam, atque in Adriatico, alibicque invenitur; tamen prioris regionis corallia longe uberiora, atque majoris pretii sunt, quam posteriorum locorum.

Cæterum ea quæ asserunt de corallii insulis, non de hoc genere speciatim tenenda sunt, quum nullius momenti partem insularum earumdem constituant, sed de meandrinis, astrceis, sarcinulis, aliisque generibus quæ cum corallii fragmentis

(I) Davide Bertolotti. Viaggio nella Liguria marittima. Torino I834. P. Colletta. Storia del Reame di Napoli. Capolago 1834. Tum. L, lib. 2 , pag. 184 . 
implexa conspiciuntur. Illud hinc profluit haudquaquam insulas per se hæc polyparia constituere, sed cumulos, iis tantum in locis, in quibus undæ minus profundæ videntur. Quapropter quæ non modo a viatoribus ( 1$)$, sed etiam a geologiæ cultoribus (2), de hisce insulis referuntur, fundamento carent (3).

Hucusque incegnitum genus in stratis geologiæ non modo antiquioribus, sed et recentioribus ipsemet primum ejus existentiam fateri posse vehementer læetor; diluvianæ enim ætatis mediana strata illud exhibent in Italia.

\section{CORALLIUM RUBRUM}

\section{BAUH.}

Stirpe ceiquali, continua, dichotoma, striis obsoletis obliquis. Gesner. Fig. lap. pag. 132. Corallium.

C. Bauhini. Pinax. theatral. botan. Basil. 1623, pag. 366 . Boccone. Obs. mar. 1674 .

Marsilii. Hist. marit. pag. 108 et seq.

Donati. Prod. Adriat., pag. 43 , tab. 5.

Pallas. Elenchus zooph. pag. 223.

Cavolini. Mem. pag. 32.

Scheweiger. Handbug. pag. 434 .

Lamarck. Histoir des anim. I et 2 edit., tom. 2. Ehremberg. Polip. de la mer, rouge, pag. I3o.

De corallio rubro, quod isis nobilis nomine signatum apparet apud Pallas, ut Royen sequeretur

(x) Kotzbue. Voyag. aux Ind.

(2) Rozet. Traité élém. du géologie, pag. $9^{3}$. Ami Bovè. Guide du géolog. voyag., tom. 3, pag. $12 x$.

(3) De-la-Bèche. Manuel géolog. pag. 385. 
exemplum, multo plures egerut quam recensiti; nam inter veteres Aldrovandi, Wormius, Bonnani, Tournefort, Mercati, inter recentiores Linneus, Lamoroux, Blainville, Cuvier de eodem mentionem habuerunt; unicam speciem constituit, qua corallii genus innitatur. Omnia igitur, quæ de corallio referuntur, ad hanc speciem pertinent et vicissim. Brevis si quidem ejus altitudo, rarius in occidentali, aut orientali; septemtrionis expositione aborret: itidem aliquando rotundata est forma hujus polyparii, aliquando depressa.

Nonnulla addidit quoque Delle Chiaje circa corallium rubrum, quæ cernere est apud eumdem auctorem de Mediterraneis divitiis optime meritum. Habitat in oceano Indico, in Mediterraneo.

Reperitur in colle Taurinensi.

Mus. Paris. Vienn. ect. (viv.) Mus. Taurin. Collect. Bellardi, Morelli, Michelotti (foss.) 


\section{ISIS}

\section{LINNEUS, PALLAS, LAMARCK}

Polyparium fixum, dendroideum axe articulato, crustaque corticiformi non adharente compositum.

Axis centralis caulescens, ramosus; articulis lapideis, striatis; internodiis corneis, coarctatıs.

Crusta corticalis in vivo carnosa, polypifera; in polypario ex aqua emerso non adhurens, plane vel partim decidua.

Agimus de eo genere, quod licet diu cognitum sil, tamen ad tempora Linncei cum corallio confusum fuit a plerisque. Licet autem Linnceus primus isidem, nomine, sejunxerit a corallio, cujus intuitu Pallas novum genus confrrmavit, atque auxit; non desunt tamen argumenta, quibus edoceatur ejus distinctionem a coralliis vere, proprieque dictis nomine, et re jam antea factam fuisse: nam articulatum corallium isidem vocat Aldrovandi, idemque Besler; Boccone autem genus isiclis nominat pseudocorallium,quia accedit utique, sed tantum pro parte ad corallium. Gualtieri vero Lythophyton articulatum in iside cognovit, prius ab adhæerentia, alterum a speciali indole isidis ductum vocabulum.

Pallıs, autem dum isidem memoravit, tria genera complexus est; nimirum isidem, melitcam, et corallium, quæ nostris temporibus distincta sunt: quid plura? Lamoroux, atque Eluremberg mopseam indurerunt, quae quartam partitionem inducit in divisione a Pallas excogitatam. Nostrum erit hujus 
generis momenta referre, et paulo post videre, quæ reapse nova genera servanda sint nec ne.

Sane ubi articuli isidis, melitece, mopsece continuo adhæreant, vix aliqua, quidquid alii sentiant, superesset ratio ut memorata genera sejungantur; nam deductis nodis, potior deducitur character'; aliocquin vero omnia concurrunt, quæ ad genus corallii constituendum recquiruntur. Licet enim strata concentrica, quemadmodum in iside habemus, deficiant; tamen, quoad sulcorum ordinem crassitiem, adhærentiam, per omnia exequuntur hæc genera; ast si ponamus invicem articulo disjunctos ut simul nodos tantum exhibeant invicem internodiis corneis adnexos; si corticalem crustam non adhærentem, deciduam et internodia, et nodos tegentem; si cellulas planas in ea crusta reponas; si articulos corneos itidem admittas, non amplius corallium, seil isidem habebis; quæ alioquin cum antipathe, quoad strata, quibus articuli constant, optime convenit.

De iside autem, intuitu melitece, mopsece, diffcilior est quæstio; nam tota discriminis ratio in internodiis consistit, cui aliam Ehremberg addidit, de natura calcari nodorum isidis. Melitea igitur in internodiis spongiosis, turgilis quiescit; mopscea in inversa natura materiei, quæ ipsam constituit, neque ramos gestat in ejusdem internodiis.

Certum in primis est, isides non differre a me. litceis ex eo quod alius est axis horum generum; verumtamen quia genicula alius sunt indolis, quia 
cellularum oscula non sunt prominula; quia rami ex articulis non prodeunt.

Certum pariter est, mopsceam, teste Pallas, uti isidis præbere materiam, vel etiarn, si Ehremberg audiamus, præbere materiam corneam in geniculis, in articulis vero calcarem; sed hoc modo compositum genus, quærimus, quod nam consistat discrimen inter isidem et meliteam, si huic posteriori dichotomam demamus speciem; præterea, quo nam discrimine mopscea sejungatur ab alterutra. Constat in primis apud omnes, convenire inter se hæc genera tum quoad naturam corticis, tum circa quamdam relationem polyporum, et eorumdem dispositionem. At vero, etsi ponamus isides optime per se consistere, tamen mopsce in meliteam impingit; nam peculiaris ille status corticis exterioris, uti probe notat Pallas, modo verrucas exhibet, modo iisdem caret; hic enim ab rtate, aliisque adjunctis pendet; verum insuper cellulas recipiunt; quum hæc cellularum dispositio æque contingere possit in melitea coccinea, ac in mopsca dichotoma haudquaquam hic character sufficere potest. E contrario quum æque ramosi sint articuli in melitea, ac in mopscea, quod eadem sit axis natura in utroque genere, quod denique internodia æque turgida sint in mopscea, ac in melitea, non video, cur utriusque generis distinctionem feramus. Ad illud, quod ait Milne-Edwards, mopsceas potius eum iside convenire quam cum aliis, difficile est cum eodem consentire, sive enim attendas natu- 
ram nodorum, sive geniculorum, sive ramorum qui oriuntur in melitea, contra ac in iside, omnia discrimen mopscece ab iside indicant; quod ex crusta ducitur distinctionis fundamentum, infirmum esse, nemo non videt.

In stratis diluvianis unam tantum ad hanc diem invenimus, de qua nuper.

\section{ISIS MELITENSIS}

\section{GOLDFUS}

$$
\text { NoBIS (Tab. I, fig. I ) }
$$

Articulis lapidcis, cylindraceis, striatis, geniculis incrassatis, junctura conica, axi tubuloso.

Scheuchzer. Herb. Diluv., tab. 14, fig. I. Knorr. Petref. III, pag. 194.

Scilla. De Corporibus Marin., pag. 63, tab. 21, fig. r. Goldfus. Petref. Germ. pag. 20, tab. 7, fig. 17. Blainville. Manuel d'actin., pag. 503. Milne-Edwards Auct. ad Lamarck, tom. 2, pag. 477.

Nomine geniculorum hoc loco indicat auctor internodia; nam hoc nomine proprie dicuntur, quæ articulos conjungunt, et substantiæ coriaceæ sunt; licet et indiscriminatim genicula usurpentur pro articulis, quia invicem inserviunt ad universum polyparium conjungendum.

Jamdiu cognitarn fuisse hanc speciem testatur Scheuchzer, ille idem auctor operis Homo diluvï testis; postea vero amplificavit eamdem Scilla, qui et descriptionem, et iconem præbuit; recentissime vero Goldfus eidem nomen apposuit. 
30

Dubitatur an isis reteporacea a Goldfo memorata reapse in hoc genus cadat; affirmat Blainville; incertus hæret Edwards; ipse fidenter nego; nam neque strata, neque sulcorum natura; neque pori, qui conspiciuntur in specie proposita a Germanico scriptore cum isidibus conveniunt.

Habitat.... Reperitur in colle Taurinensi (raro). Mus. Taurin. Collect. Milne-Edwards, Michelotti. 


\section{GORGONIA}

\section{PALLAS, ESPER, LAMARCK}

Polyparium fixum, dendroideum, axi centrali, crustaque corticiformi compositum.

Axis basi explanata, fixaque, caulescens, ramosus, substriatus, solidus, corneus, flexilis: centro divaricato.

Crusta corticalis, axem ramosve vestiens; in vivo mollis, carnosa, polypifera; in sicco spongiosa, porosa, friabilis:osculis cellularum ad superficiem insculptis, vel prominulis.

Tentasulis 8 ad os polyporum.

Polyparium gorgonice constat ex operibus polyporum omnimodo similium iis, qui inveniuntur in coralliis; id autem a Batavo Pallas accepimus; fuit Blainville prxsumptionibus innixum, atque firmatum a magno nominis nostræ ætatis scriptore, appositis hac de re in mari rubro investigationibus susceptis (1). Eherembergi tamen doctrinam ante cessit Esper, qui nobis pretiosiora de gorgonice natura reliquit (2): varia itaque notatu digniora hic asserenda subjicimus. Crusta, quæ gorgonias circumdat, mollis est, et quidem eidem caducitati obnoxia, ac crusta, qux reperitur in iside; ubi exsiccetur, adhæret pro parte axi, porosa evadit, atque ex porositate friabilis est; in ea polypi conspiciuntur irregulari prorsus modo, ac in corallio, in iside, in melitea.

(I) Ehremberg. Mem. sur les polyp. de la mer rouge.

(2) Esper. Planzenthiere. Suppl. 2, pay. x et seq. 
Quoad axem, discrimen ponit Lamarck inter gorgoniam, atque antipathem, quod hæc sit magis continua, vitreamque fracturam exhibeat, contra in gorgonia, quod hujus nec adeo solida materia, atque illam vitream partitionem non ostendat, sed insuper adjiciendum est, in axi centrum gorgonice haudquaquam in medio esse, quemadmolum est in antipathe, in corallio, in iside, sed vel ad unum, vel ad aliud latus vertitur Hinc strata quæ conficiunt polyparium haudquaquam rotundata, haudquaquam cy lindracea: præterea hic axis in nonnullis speciebus non continua materia repletur, sed in centro vacuus reperitur, contra ac se habeat in antipathe, in corallio. Spinæ, quæ adsunt in antipathe deficiunt in gorgonia, ramorum serie eadem non est in utroque genere.

Gorgoniæ insuper proprium est, ut polypos recipiat similes iis, qui in coralliis adsunt, polypos autem antipathis, vel ex cellularum dispositione, atque prioris tegumenti axe alio modo se se habere, vel saltem dispositos esse, ipsius polyparii investigatio declarat.

Dum autem in gorgonice genere versamur, abs re non erit varias opiniones circa ejusdem divisionem perpendere, ut, iis perpensis, quæ tutior sit, facilius apparere et amplecti possimus.

Putabat Defrance ( 1 ) duas consistere posse gorgonice partitiones: prior eas complectitur, quæ

(I) D iction. des science natur., tom, $19, \mathrm{pag} .325$. 
munitæ sunt papillis, quasque Lamoroux (I) putabat ad corpora polyporum pertinere; alia distinctio gorgonias exhibet cortice vix observatu digna, simplices, pinnatas, ramosas, aut articulatas.

In priori divisione cernere est plexaurce genus a Lamoroux inductum, qui in gorgonice dispendium quinque genera componere studuit. Primum habet axem cylindraceum et cretaceam crustam exsiccationis ope tenuem, aut tuberculosam; tertium ostendit axem depressum, et partem corticalem subporosam, at ejus facies minime conjuncta est, a qua unice differt a secunda divisione, sed prominentias exhibet dispersas. Quartum genus præditum axe cylindraceo partem corticalem crassitie mediana exhibet; cellulæ prominulæ, squamosæ, elatæ, et aperturam præbent syderiformem octo radiis signatam. In quinto ordine ex laudati Lamoroux doctrina veniunt cellulæ elongatæ pyriformes, squamosæ; hisce gorgonice, eunicece, plexaurce, primnoc, muriceœ nomina addixit.

Gorgonice distinctio nuper memorata non displicuit Blainville, neque Ehremberg, nec ipsi Mil$n e-E d w a r d s$, ut non obscure indicat ad Lamarcliii notas: quin imo novum adjunctum genus reperimus ab Ehremberg vocabulo pterogorgice ex regulari polyporum dispositione deductum.

Non is ego sum, qui tot tanti nominis scri-

(I) Lamoroux. Polyp. flexibl. Paris, 18r6.

Blainville. Manuel d'actin., pag. 500.

Eleremberg. Polyp. mar. rubri, pas. 130. 
ptores provocare audeam; tamen notare fas sit omnia genera memorata nihil aliud esse, quam partitiones qure gorgonias quidem afficiunt, sed in eas incidunt indiscriminatim: sane si mihi demonstraretur polypum alium esse, silerem procul dubio, et in fossilibus polypariis investigando temere agerem ea conjungendo, quæ natura ipsa sejunxit; sed cum ex memoratis scriptoribus eruerim eumdem polypum omnibus communern esse inductis generibus, fundamentum, cui tot partitiones excogitatæe innitantur, deficere contendo.

Neque hic illud contingit quod in antipathe, et in corallio; nam axis peculiaris dispositio, polyporum diversa indoles, saltem ex eorundem alimentorum, atcue digestionis ratione, versari discrimina in gorgonice genus evidenter ostendunt. Neque ex isis, vel melitece divisione quidpiam conjici posse ad rem nostram, crusta, polypi, vel axis ratio patitur.

Neque etiam opponantur superficies continuæ, prominentiæ effusæ, elatæ, vel squamosæ et apertura præditæ, vel pyriformes, vel dispositio polyporum, vel papillarum, quemadmodum innititur Ehremberg; nam considerando statum peculiarem cujusve gorgonice, ætatem, et locum in quo reperiuntur facile dignoscemus, vel in hisce speciebus, que constituunt memorata genera pluries indictos characteres deesse, vel in plurimis illis speciebus, quas adhuc inter gorgonias retinuerunt, adesse, quæe in aliquibus memoratis generibus compre- 
henduntur. Quis peculiarem hane dispositionem inficiabit in gorgonia tuberculata, quam ceteroquin memorati viri ad gorgonias reapse adhuc pertinere declararunt? Quis gorgoniam pinnatam adhuc in hoc genere recensebit? Et si gorgoniam petechi. zantem ad pterogorgias non accedimus, quum alioquin in polypariis lamelliferis id libenter agamus, silicet singularis ordinis admittamus sectionem, uti cernere est inter oculinas et alia genera, mirum non est; nam superioris crustæ temperamentum non mutat axis indolem, neque peculiariter afficit axis, et crustæ naturam, uti afficit symmetricum ordinem, vel regularem dispositionem quoad polyparia lame!lifera.

Denique quxro utrurn agatur de pluribus speciebus, an satis eisdem consultum sit? confusio ne omnino extranea sit propositis rebus? Haudquaquam: age de gorgonia lepadifera, de gorgonia muricata, in hisce habebis genus eunicea, habebis muriceas; quid quod, si prominentias cellularum agnoscimus in uno et in altero casu, nunquam oblivisci earumdem debemus: modo vero hoc inductum est, ut, si elatæ hæ prominentiæ sint, attendantur, nequaquam si oblongæ. Sileam de charactere qui ex axe compresso deducitur, qui in spiculis ponitur, qui de retractatione polyporum in plexauris fertur: hoc tantummodo quæram, qua nam de causa, si hi characteres sufficere videntur in gorgoniis, non sufficiant in aliis; quæro an spongia muricata auctorum, an spongia cancellata Lin- 
nwi, an aculeata ejusdern parem non meruerint divisionem.

Neque vero cujusve novi generis ex is receptis insufficentia intelligi potest, nisi singula videamus. Quod attinet ad plexauram, Lamoroux hujus et aliorum generum auctor ita definit, ut sit poJyparium dendroideum, ramosum, asperum; crustam solidam, vix acidis effervescentem gestans, pluresque cellulas planas effusas, magnas: at id quidem auciorifacile fuit probare in gorgonia friabili, in gorgonia flexuosa, impossibile tamen fuisset plerumque in gorgoniis proprie dictis, etiam gorgonia granulata, gorgonia flabellum, quæ cellulas planas inæquales habent; plures gorgonice itidem crustam habent plus minusve solidam, cum hoe ex adjunctis fortuitis potius quam ex alio capite pendeat. De acidorum effectibus in crusta, neque mirum, neque novum, sed plerisque crustis non modo plexauri, sed gorgonice, sed corallii, sed melitece proprium est, ut animantis quidpiam in se crusta recipiat etiam in eodem axe, uti demonstravimus de corallio disserentes.

Non est cur muricere, vel cunicea genus servare contendam, nam quoad cellulas corticales, eæ præditic sunt osculo xque in muricea, ac in eunicea. Primnoas itidem haudquaquam recipere possumus cum potior ejusdem favore non vigeat ratio.

Non neggo sectiones ex cellularun dispositione duclas plurimi conferre art optimam subdivisionem 
totius gorgoniarum generis, sed in hisce adjunctis tota contineri debet quæstio de cellularum natura alia, atque alia prout de eunicea, vel mutricea agitur; alioquin tot genera inducere deberemus quot ferme sunt astracarum, atque sarcinularum species. Adeo porro verum est gorgoniam cum corallio non convenire, ut Ehremberg, qui earn in mari rubro investigavit, novum genus ex ipsa constituerit, quod dixit pterogorgiam, uti supra notavimus. Primitus Goldfics gorgonice fragmenta in stratis geologicis reperiri docuit, quum antea altum hac de re silentium fuerit servatum; accuratus siquidem investigator gorgoniam in dolomic thuringice semel iterumque cognovit.

Qua ætate, et quot species agnoscendæe sint in dolomia non bene inter auctores convenit; et Brogniart (r) eam ad calcem gallice carbonatce, quæ ad strata primæva pertinet, provocat (2), et album, vel cineraceum colorem exhibet. Una mica in causa fuit cur lamellis sit composita; idem ferme sentiebat geomera Haïr (3).

Aliud placuit De-la-Beche, atque Rozet, qui recentiorem ætatem eidem tribuere (4), quin tamen igneam dolomiae originem negaverint.

(1) Diction. des scienc. natur., tom. х3, pag. 4 ro. Traité élém. de minćralogie, tom. I, pag. $23 x$.

(3) Diction. cit., tom. 8, pag. 31 , et tom. 34, pag. $25 \mathrm{~F}$.

(3) Traité de minéral. I et 2 edit., tom. I, pag. 420.

('t) Manuel géolog. par Henry De-la-Bèche, pag. 405.

Traité de géolog. par Rozat, pag. 3og. 
Distinctionibus est resolvenda quæstio, nam vel agis de ea dolomia, qux cristallisatione eminenter pollet et albissima est, vel de aliis dolomice speciebus; prior ad strata non fossilifera pertinere procul dubio debet; quod si agatur de aliis dolomiis uti indicant strata, quæ eisdem subsunt, videntur ooliticam ætatem præseferre quum originem igneam retineant. Cæterum hæc est communis opinio quæ alioquin refragatur, quod in Spedia Guidoni notavil. Unde sequeretur si eum, atque De-la-Beche audiamus æque priorem, ac posteriorem dolomice naturam ad ooliticam ætatem indiscriminatim pertinere; sed hoc nihil vetat quominus variis temporibus dolomia prodierit, atque strata plus minusve vetustiora occupaverit.

Nolim tamen ut putes summi momenti characterem esse, qui deducitur ex dolomia: peculiaris enim est, atque inter strata geologica vere proprieque dicta locum obtinere non potest: provido autem consilio Virlet, atque Bovè monent cavendum esse ne dolomiam cum calcari magnesiaco confundamus, cum quo sæpe dolomia adnexa fuit. In calcari magnesiaco licet habeamus ælatem geologicam coevam dolomice, tamen abunde testacea, polyparia, botanices documenta miramur, ex quo consequitur neptunianæ originis esse calcarem magnesiacum, dolomia non item.

Dum itaque dolomiam dicimus, strata, quæ eidem adnexa sunt, præ oculis habemus, quibusve pluries confusa reperitur. 


\section{GORGONIA SEPULTA}

\section{NOBIS}

Ramosa, subdicotoma, axi crasso, albo; centro distincto.

Esper. Planzenthiere. Suppl. 2, pag. 9o, tab. 26.

Difficile admodum est definire quæ nam gorgonice species hæc sit de qua agimus; nam hoc unum eruimus plura adesse strata in axe, qui centrum proprie non indicat, rami autem sunt grassiores, atque breves; ima parte adhærent.

Habitat..... Reperitur in colle Taurinensi et in Sicilia. 
40

\section{A NTIPATHES}

\section{PALLAS, ESPER, LAMARCK}

Polyparium fixum, subdendroideum, axi centrali, crusiaque corticiformis, evanida et decidua compositum.

Axis basi explanatus et fixus, caulescens, subramosus, vitreus solidus, flexilis, spinis exiguis sœpe munitus.

Crusta gelatinosa, polypifera, florescens, in vivo axem ramosque vestiens, in speciminibus ex aqua emersis evanida.

Polypi ignoti, calyces cornea stirpi insidentes subturbinati.

Sertulariarum familiam hoc genere complere, quoad geologicam xtatem nostram attinet, credimus, iis enucleatis, quæ ad antipathem cognoscendam requiruntur. Atque ad illud quod sit fixa, subdendroidea, quod crusta corticiformis evanida, polypifera, nihil singulare affertur; agimus enim de is characteribus, qui æque corallio, ac antipathi prosunt; de aliis non item. Vitrea siquidem fractura, continua materia per strata disposita, eaque minutissima indicia linearum ferentia, unde ejusdem amplificatio facillime detegitur, spinæ præterea adeo fiequentes in antipathe, quæ ex axe procedunt modo irregulariter, modo in ordinem dispositæ, flexibilitas ramorum in primæris temporibus, ostendunt tum discrimina, qux inter alia genera, et antipatıem existunt, tum antipathis genuinam indolem. Quoties igitur de antipathe sermo erit, attendamus naturæ materiei, fructibus, ramis, 
spinis, et si in vivis crustæ, atque qua nam ratione insideat aliis corporibus, hæe omnia non inconsulto ita se se habent. Obscurius est quod Lamarck ait, dum de subfragili axe loquitur, tenuior ne, hic, axis est, ac cæeteris in partibus? Haudquaquam: an alterius naturæ? minime; quominus utramque sententiam admittamus, obstat generis definitio, et antipathis investigatio. Non levi itidem menda laborat quod doctissimus auctor ait, dum monet ne loco gorgonice, antipathem habeamus, quasi absentia minutarum spinarum in gorgonice axe sufficiat ad duo gener'a distinguenda, sed hoc monitum plerumque inutile est; neque enim semper spinas reperimus in antipathe, uti in antipathe ligulata videmus, et in antipathe clathrata, aliisque; ergo patet reapse casum evenire posse quo destitutio spinarum veram confusionem ex hac causa inducere possit.

Antipathis cognitionem, vel apud antiquissimos scriptores habemus; nam corallii nigri nomen, vel apud Dioscoridem invenimus; Rrmphizıs pariter de eo mentionem habuit; Boerhave, Tournefort, aliique inter litophyta antipathem posuerunt; nihil tamen clarius, quam ea quæ habemus apud Pallas, Esper, de gorgonia antipathe; lignum definientes rigide corneum, solidum, aterrimum, extus flexuose striatum, basim extra cineream; truncum brevem in ramos subdivisum, aliaque similia.

Si quas invenimus difficultates dum judicamus de antipathe in statu viventi, qnot majores adsint 
in investigatione antipathum fossilium, nemo non videt: quis $\therefore$ g. antipathem myriophyllam, vel pennaceam cognoscere potest; tota igitur distinctio quoad posteriores in lamellis, in spinis, si adsint, in natura linearum, ramorumque dispositione quiescit.

Antipathes licet rariores quam plurima alia polyparia, effusæ tamen reperiuntur; nam inveniuntur in mari Mediterraneo, in mari Norvegiæ, si audiamus Brunnichen littoribus Martinichæ et Carolinæ, alibique.

Nescio an in statu fossili reperta jam sit, nam De-la-Beche, Milne-Edward, altum hac de re silentium servarunt, certum tamen est in Italia in stratis supracretaceis medianis adesse.

\section{ANTIPATHES CORTICATA}

\section{LAMOROUX}

мовіs (Tab. I, fig. 5)

Antipathes parce ramosa, asci solidissimo spinis numerosis, sparsis echinato; cortice poris nullis.

Lamoroux. Polyp. Fles. pag. 374 .

Lamarck. Anim. Invert. I et 2 edit. tom. 2. pag. 480.

Habitat in Oceano Indico. Reperitur in Sicilia, prope Dertonam, et in colle Taurinensi. Mus. Paris. Britt. Vienn. ect. ( viv.) Collectio Mus. Taurin. Michelotti ( foss.) 


\section{ANTIPATHES SERIALIS}

$$
\text { мовіs (Tab. 1, fig. 2) }
$$

Antipathes ramosa, axi spinis plurimis longis,

in lineis longitudinalibus signat.

\section{Habitat . . Reperitur cit. loc.}

Mus, Taurin. Collectio Rochetta, Mareskal, Michelotti.

\section{ANTIPATHES VETUSTA}

\section{NOBIS}

Antipathes simplicissima, rotundata, lavigata, parce ramosa; axe cylindris plurimis, perspicuis, adnexis composito.

Hæc species non ut prior spinas gerit in ordinem dispositas, neque continua adeo materia præstat, ut cerni ejus axis compositio nequeat; sed omnia strata quæ hanc speciem constituunt visibilia sunt, et proterea ne unam quidem habet spinam. Non dubito quin aliqua species reperiri possit quæ huic referri queat, sed cum hic externi omnes characteres deficiant, nihil amplius quæri potest quam de ejus axe, ut et in prioribus.

Habitat.... Reperitur in Italia, et præcipue in colle Taurinensi.

Mus. Taurin. Collect. Michelotti.

\section{ANTIPATHES HIRTA \\ мовіs (Tab. I , fig. 3 )}

A. vilrea, loevigata, parce ramosa, ramis rectis incurvis, spinis acutis, sparsis alternis munita, solidissima.

Habitat... Reperitur in collibus Dertonæe et alibi. 


\section{ANTIPATHES SIGNATA}

$$
\text { мовіs ( Tab. 1, fig. 4.) }
$$

A solida sostis longitudinalibus granulo sis exarata suleis medianis.

Habitat.... Reperitur in colle Taurinensi. Animadverto confundendam non esse neque antipathem subpinnatam, quæ pinnulas transverse exeuntes habet, neque mimosellam, quæ habet ramulos decomposito-pinatos, pinnulas setaceas, neque alias species cum antipathe hirta; multoque minus antipathes feniculum,larix, scoparia, cæteræque cum antipathe signata convenire possunt. 
LAMARCK, LAMOROUX, BLAINVILLE.

Poliparium lapideum, simplose, turbinatum vel cuneiforme, extus longiludinaliter striatum vel costatum, basi acuta. Stella unica, varia, axillato-terminalis lamelloso stellata, marginibus crenatis, centro exerto.

De eo genere modo nobis agendum est, quod fuit relatum ab ejus auctore inter polyparia lamellifera, inter madrephyllcea a Blainville, et anthopylliis a Goldfo sape adjunctum.

Plures oriuntur procul dubio gravis momenti questiones circa turbinolias, quarum summa hæc est. 1. Constat ne ex uno, vel pluribus polypis? $2{ }^{\circ}$ Unam ne, an plures cellulas fatemur? $3 .^{\circ}$ Ejus libertas fortuita ne est, an eidem generi propria? Ubi hæc omnia clara in luce ponantur, non erit cur diu ancipites hæreamus; firmum habebimus genus ad hanc diem traditionis ergo tantummodo servatum, maximi in geologiæ momenti, vel antiquissimarn spectes hujus scientiæ historiam ad eam diluvii, imo ad hanc nostram perveniendo.

Ad primam quæstionem quod attinet, duæe sunt opiniones; putabat Lamarck, cum eoque numero plures, unum animal, videlicet unum polypum sufficere ad turbinoliam extruendam; ideoque ita sensit, quia una stella reperiatur, licet 


\section{6}

plures laminx radiales in ea adsint. Quod ex consideratione omnium polypariorum, quæ cellulas plures ad hunc modum exhibent et tamen unum tantum polypum continent, profluit. Hæc sane non nova cxteroquin sentiendi ratio omnes ferme Zoophythologice cultores habuit sectatores. Nuper tamen diverse sensit germanicus Steininger (I), qui posuit unum animal in primæva turbinolia ætate, ea tamen loge affectum, ut paulo post ex ipso met polypo proles nasceretur, quie matri conjuncta opus cum ea compleret, turbinoliam conficerent, eidemque eam formam præberent quam quotidie ab eadem assecutam novimus.

Quin citius quam par est, hanc opinionem rejiciamus, juvabit ejus gratia provocare investigationem ad madreporam myriophthalmam, quæ ita est implicata, et obvoluta ut perdifficile sit in ea quid concurrat secernere. Nobis autem cum liceat sectam turbinoliam observare, cum caryophrlliis colligere, duobus argumentis hanc opinionem infirmare contendimus. In primis hæc præsumptio efficeret ut polypi turbinolice tentaculis carerent; et tentaculos reapse in turbinoliis reperiri relatio cum caryophylliis, astrceis, aliisque generibus abunde probat, quemadmodum nostræ ætatis insignes nautæ tulerunt (2). Hæc relatio tota quanta est ex turbinolice naturali di-

(1) Méin. de la sociét. géolog. de France. tom. 2 pağ. 2 ,

(2) Voyag. de l'Astrolab. tom. 8 act. Quoy et Gaimard. 
spositione, internæque formæ structura profluit: deinde sectum ipsius turbinolice corpus, en ${ }^{\top}$ quod tibi exhibet: cellulam inferiori loco positam prope basim in qua polypi saccus continebatur; ex hac cellula inferiori, aliæ prodeunt, eæque vel rotundatæ, unde in definitione turbinolice diximus polyparium turbinatum, vel cuneiforme quoties posteriori hoc casu cellulæ in angulis dispositx sunt; hæ itidem cellulæ sejunctæ sunt, atque polyparium circumdant; in medio pariter minutissimos loculos conspicimus eidem polypo inservientes.

Si itaque una præcipua extat cellula, si superiores tentaculis inservire compertum est, si denique ordo utrimque adest, et in generali forma turbinolice, et in omnibus cellulis invicem comparatis, non est, cur plures hic polypos admittamus. Nam hoc in casu habes centrum in quo recipitur polypi corpus, habes tentaculos reapse conneros, quia in unum idemque punctum concurrunt, habes denique naturalem unius polypi in polypario turbinolice dispositionem, atque probationem.

Ad alteram nunc veniamus opinionem. Unam ne inveniamus cellulam vel plures in turbinolia? priori sententixe favebat Defrance (1) cujus definitionem turbinolice amplexam quoque cernimus a Blainville (2) in eodem magni nominis opere,

(1) Dictionnaire des sciences natur. tom. 36 pas. $9^{1}$ in definit.

(3) Cit. diction. tom. 60 pag. 30\%. 


\section{8}

et fortasse quoque in nuperrimo suo actinologice et zoophytologice documento.

Sed non est cur diu laboremus investigando an et quomodo apta dici possit hæc opinio ad inducendam veram hujus polyparii cognitionem; vidimus in turbinoliis unam cellulam in basi ex qua alixe profluunt; si itaque hoc verum est, uti ipsa turbinolice investigatio declarat, concipi non potest utrum una sit cellula an plures; corpus in plures partes divide lamellis plus minusve confertis, habebis quidem idem corpus, minime unam cellulam, sed et plures, quæ in unam concurrunt, quod et ipsi memorati viri in monticularia aliisque generibus cognoverunt.

Multo difficilius est Goldfi, Lamoroux, opiniones circa libertatem turbinolice refellere, et eam Lamarchii sustinere, idque potissimum quod cum turbinoliam viventem cognoscamus quidem, non autem de ejus polypi mentionem occurrat, hinc priesumptione ferme ducimus magis, quam vera et genuina investigatione adeo in zoophytologia exoptanda. Non ita tamen semper est; nam et analythica methodo plura assequi licet.

Sane si cum Lamarck putarem libertatem turbinolice eam a quovis alio recepto genere secernere, nisi probaretur ex ætate eandem libertatem pendere, nihil amplius foret cur hoc genus infirmare valeamus, et ipse primum affirmarem in turbinolia caryophyllias non venire, et vicissim. Ad inducendam horum generun communionem et 
quidem sub hoc unico respectu obstat difficilis probatio fortuitie libertatis turbinolice, quia foramen sive loculum communicationis inter corpus ipsius polypi et externa corpora probat tentaculum, vel quid simile in polypo turbinolice; tentaculi autem præsentia vel defectio aliud animal indicare videtur; præterea quin de irregulari indole caryophyllia loquamur quod non contingit in turbinolia, animadverto hoc cognoscere posse aliqua ratione, quis enim v. g. in turbinoliam crispa, vel turbinolia sulcata, aut pediculos agnoscet, aut varietates exhibere potest quot in caryophylliis inveniunfur; et sane ridiculum esset affirmare turbilonias in stratis geologicis, omnes vel adultas vel juvenes fuisse; at hæc distinctio in geologiæ documentis clarissime nitet, vel libera, vel pediculum habent hujusmodi corpora; si primum turbinolias agnoscimus, sin alterum caryophyllicm vel aliud quid prout zonplyytorum docet historia.

Quidquid sit aliqui putant quæstionem adhuc sub judice manere, ancipitemque formam, quam fossilia exhibent tanti non esse faciendam, ut caryoplyylliarum, quarum perspecta est polyporum indoles attendatur.

Hisce positis, hoc temperamentum adhibendum esse crederem, ut potius, quam libertatis, simplicitatis ratio habeatur, ita ut, soluta de hac simplicitate quæstione, nihil amplius definiendum supersit, eritque corpus, quod tibi proponunt vel turbinolia vel caryophyllia prout vel simplex, vel compositum sit polypa- 
rium dummodo cæeteri characteres concurrant, qui ad unum vel alterum genus constituendum requiruntur. Non ignoro denique, lihertatem locomotionis vim dimetiri, atque hujusmodi facultas in polypis attendenda est; sed ipse, cum locomolionis momentum non auferam, atque ea concipi æque possit si soluta sit, nec non; potius in tentaculis, quam in universo complexu polyparii ei polypi, quorum est firmas habere generatim sedies, ni ventus et undæ alioquin disponant, eam reperiri contendens, non video, cur ex hac facultate, quam integram eidem relinquere oportet, quidquam contrarii procedere videatur ad propositam seclionem vitandam.

Jam autem in grauswacke habemus turbinolias, atque frequentes sunt in Irlanda: in stratis carboniferis Gotlandice, uubinoliam turbinatam, echinatam, pyramidalem, mitraiam, furcatam laudamus; in stratis quoque zechstein indieia hujus generis reperiuntur. Si Phillips andiamus in stratis ooliticis et turbinolia dispar adsit oportet. Eadem autem mitrata turbinolia cum turbinolia kenigi sui copiam in stratis cretaceis exhibet. Cietera ad posteriorem etatem, videbimus.

Denique figuræ turbinolice tum trochiformis, tum sulcatce, quas nobis tribnit insignis zoophythologice cultor Lamororsx, haudquaquam turbinoliis conveniunt, de quibus cgit; nam celluam medianam, et singularem illam lamellarum dispositionem, quan laudatus auctor cxhibuit in iconibus suis, omnino desideramus. 


\section{TURBINOLI A ITALICA}

$$
\text { NoBis (Tab. I, fig. 8) }
$$

Turbinolia compressa costato-angulata, sulcis intermediis; costis rotundaits, frequentioribus; crenatis; stella maxima, rotundata: centro papilloso.

Peculiarem turbinoliam exhibeo quæ capuli imaginem exhibet, vel calyptrece, atque non ambiguis characteribus est signata. Deorsum costis longitudinalibus angulatim ad basem adnexis; grenulata est; inter has costas alias potiores itidem rotundatas conspicimus, quæ numero duodecim sunt, ipsius stellæ radios potiores efficiunt, atque binubo dispositæ, sex angulos præbent. Stella maxima, axillaris, plana, papillis medianis munita, circumcirciter multipliciter septa.

Habitat . . Reperitur in Italia.

Mus. Taurin. ect. Colleci. Barelli, Rochetta, Maresckiall, Bellardi, Michelotti etc.

\section{TURBINOLIA PATELLATA}

\section{LAMARCK}

Turbinolia depressa turbinato-truncata, lamellis radiantibus tenuissimis; basi obuusa; stella ovata, maxima, margine conferto.

Borguet. Trait. des petrif. tab. I. fig. 5. Scilla. Corp. marin. tab. I4.

Lamarck. Hist. des anim. I. et 2.edit. tom. 2. pag. $360 \mathrm{n}$. I. Defrance. Diction. des scienc. natur. tom. 56. pag. $9^{1}$. Blainville. Manuel. d'actin. pag. 342 .

Memorata species a priori distinguitur ratione lamellarum, marginis, stellæ atque basis. 
Habitat. . Reperitur in Gallia prope Mans, in montibus Calabria, et prope Veronam. Mus. Paris. Taur. Coll. Michelotti.

\section{T URBINOLIA AR M A A}

$$
\text { мовіs (Tab. I, fig. 9) }
$$

Turbinolia cylindracen, ad basim quinque spinis exertis, solidis munita, costre alternatim dispositce; stella rotundata, centro papilloso.

Agimus de ea specie, quam nisi exhiberet nobis natura vir excogitare possemus; hec tamen spinarum dispositio non nova est in testaceis; nam in cartais sepe occurrit; peculiaris tamen omnino est ea quam in producto longispino nobis offert Sowerly in accuratissimo sno, de testaceis fossilibus Brittaniæ, opere.

Spinæ, quæ in hac turbinolia adsunt ad calcem ferme planulatæ, basi sunt adnexæ, ita ut una ex centro prodeat; quincrue alie circumcirciter eandem basim se extendunt; cæetera hujus polyparii pars cylindracea est, et lamellas habet inæcuales, potiores: tamen directionem spinarum sequuntur ut numero quoque quinque extent; inter has, alis prodeunt multo minutiores, prope marginem leviter crenatæ: stella rotundata, planulata, centro papilloso.

Si ex iis essem, quibus tot notatu digniora, quot genera, procul dubio haec turbinolia haudquaquam cum turbinoliis quiesceret, sed cum multo satius conjungere, guam disjungere studeam, 
quum hoc posterius studium iis potius pertineat, quibus concessum est methodos generatim amplecti, et validiores inducere, inter turbinolias hanc speciem addixi, utut quælibet aliorum sit futura opinio.

Habitat . . Reperitur in colle Taurinensi.

Mus. Taurinens. Collect. Sotteri, Bellardi, Mareshill, Barelli, Rochetta, Michelotti.

T URBINOLIA OB ES A мовіs (Tab. 2, fig. 5)

Turbinolia depressa, patelliformi, brevi, costis 14 potioribus undato crispis; interstitiis lamellis minoribus tribus, marginem versus, leviter laciniatis: stella concava rotundata, centro papilloso.

De alia nec minus singulari turbinolia quastio est, utpotequæ habet formam trochiformem, quo quidem sensu a turbinolia armata distinguitur, magisve cum turbinolia patellata convenit; coste autem omnes laciniatæ sunt circa marginem, unde crispæ atque crenatie conspiciuntur. Stella rotundata, atcue concara est, papillis in centro præditis; basi acuta.

Habitat . . Reperitur in Italia in montibus Dertonæ, atque in colle Taurinensi.

Mus. Taurin. Coll.Barelli, Rochetta, Michelotti. TURBINOLIA PYRAMIDATA

$$
\text { повіs (Tab. 2, fig. 4) }
$$

Depressa, costis longitudinalibus, crassis, raris 6 angulatim ad basim dispositis, interstitiis leviter, et obsolete sulcalo-crenatis; stella maxima, rotundata, plana.

Prioris affinis hæc altera est species; sed non 
adeo cyathiformis, et costæ potiores sunt pyramidatim dispositæ, ita ut, quod indicat, exhibeat hujus speciei imago: stella latissima est, atque rotundata, itemque plana. Præterea costæ interstitiales rotundatæ sunt, atque minuta grana, quæ eidem aisunt omnino in superiore specie desideramus.

Adsunt hujus speciei varietates, quæ basim depressiorem exhibent.

Habitat..... Reperitur in Italia prope Dertonam. Mus. Taurin. Collect. Michelotii.

\section{T URBINOLIA TROCH IFORMIS}

pallas, мовis (Tab. г, fig. 7 )

Turbinolia cuneata, extus sulcis longitudinalibus, costis undato punctatis, exarata; stella oblonga. Cancellis latere aspersis.

Pallas. Elenchus zooph., pag. 3оว̃ (Madrepora).

Lamarck. System. des anim. invert., I et 2 edit., tom. 2, pag. 36r (Turbinolia crispa).

Borson. Catal. Coll. Miner. de Turin, pag. 68 r , n. 57.

Cuvier et Brogniart. Oss. foss., tom. 4, pag. 67.

Lamoroux. Exposit. meth. des polyp., pag. 51, tab. 74 . Goldfus. Petref. Germaniæ, pag. 53, tab. 15, fig. 7.

Jamdudum cognita fuit hæc species, atque nostra rtate duplex tulit nomen; unde ad integram et primævam nuncupationem modo eam provocamus; etenim, sin prima fronte, saltem ex definitionis expositione, aperte discimus a Pallas, quid sibi vellet dum definiebat madreporam trochiforsnem, quam paulo post Lamarck, et omnes qui 
eum secuti sunt unanimiter turbinoliam crispam dixerunt.

Ait Pallas, in Gallia frequenter prope Courtagnon, atque Grignon, reperiri madreporæ obverse conicæ integerrima, et elegantia specimina. Prebentia sæpe compressas species extus teneriter striatas, supra cavas, lamellis integerrimis, stellatas. Quapropter, demptis aliis speciebus, quas ad hujus varietatem provocat auctor, liquido patet de turbinolia crispa sensisse: multo prestantiora sunt ea, quæ, lente inspecta hæc species, prebet; nam, non ut in cæteris bene mullis, sulcis costre respondunt rectæ, sed in hac costa illse undate symmetricce sunt; marginem versus directreperagunt; insuper lamellas rectas exhibet hrec turbinolia, quemadmodum cætera species; minuta grana, omnem revolutarum costarum mulitudinem tegunt. Reperitur prope Courtagnon.

\section{TURBINOLIA NANA}

\section{LEA}

Turbinolia subcuneata, longitudinaliter costata, sulcis sim, licibus, costis 24. Sexdecin ad basim protensis, duobus convolutis, stella elliptica absque stylo.

Isaac Lea. Contribution. to geology. Pliiladelphia $183 \mathrm{r}$, pag. $19^{5}$, tab. 6, fig. 209 .

Velim ut notes in hac specie singularem lamellarum ordinem; qua ratione crenatæe sint; cujus sit indolis basis, atque margo stellie turbinolice nance, ut ejus characteres assequaris.

Habitat . . Reperitur in stratis supracretaceis Americes in regione Alabama. 
56

Mus. Philadelphiæ. Instit. New-Jorck. Collectio Lea.

\section{TURBINOLIA GOLDIUSII}

LEA

Turbinolia cuneata 24 fulcis, longitudinalibies munita duobus, ex lateribus decem, coteris duo leviter plicatis atque adbasim deductis; basi coartala stella elliptica, lamella rugosa.

Isaac Lea. Contribution. cik pag. 193. tab. 6. fig. 208.

Differt hæc species ab omnibus recensitis quoad basim, quæ veluti truncata videtur, quoad lamellarum similitudinem, quoad sulcos, qui adsunt ad latera hujus turbinolice, nec non, quia hæc species stellam ellipticam, et ferme planulatam habet.

Dubitare videtur Lea, an turbinolia crispa quid commune habeat cum hac nostra; præterea, an conjungi possit; ipse, cum memorato auctore nego id contingere posse: sedulo enim perpensa turbinolia crispa, vel turbinolia trochiformis basim ferme acutam habet; et sulcis duobus ad latera turbinolice Goldfusii posita, caret.

Habitat... Reperitur in regione Alabama.

\section{TURBINOLIA STOKESII}

\section{LEA}

Turbinolia, granulata, cuneata, 24 fulcis longitudinalibus ex utraque facie signata; ex hisce duo ad basim curvatim proferuntur; duobus ad latera adnexis, ad basim itidem protensis: basi emarginata; stella elliptica; lamella rugose. Isaac Lea. Contribut. cit. pag. 194. tab. 6. fig. 207.

Certe si unice spectemus lamellas rugosas in 
hac specie vehementius ancipites hærere deberemus an ipsa turbinolice trochiformis nomine, venire posset; sed, si auctorem nostrum audiamus dum de sulcis, et de lateribus, nec non de margine sermonem habet, turbinoliam Stokesii veram speciem fatemur.

Habitat ... Reperitur in regione Alabama.

\section{TURBINOLIA MACLURII}

\section{LEA}

Turbinolia cuneata, minute crenellata, fulcis, costisve destituta; tunida; duobus tuberculis utrimque prcedita, basi rotundata; stella sub-elliptica superius, poris irregularibus, sparsis insculpta.

Lea. Contribution. cit. pag. 193. tab. 6. fg. 206.

Turbinolia Maclurii simplicem superficiem præbet, atque dispositio lamellarum undata, peritus in hac specie incognita est, licet cæteroquin totidem adsint lamellæ in interna structura, unde stella repetit originem. Ambigua ex auctoritate Lea marginum hujus speciei indoles est; probabili ratione defendere possumus rotundatam esse.

Cæterum quoquot retulimus species ex confundi cum recensita auctoris Americani ${ }_{\text {a }}$ ulla ratione nequeunt.

Habitat... Reperitur, uti memoratæ, in regione Alabama.

Mus. Philad. Instit. Nerw-Jorck. Collectio Lea etc. 
T. cuneato compressa, costis raris, obsoletis, rotundatis, ad latera foliaceis, extensis alarum instar; sulcis medianis, profundis; stella convexo-oblonga, papillis medianis.

Borson. Oryct. pedem. pag. 35. ( madr. n. 6.)

Variet. basi elata, stella latissima.

Dum hanc speciem memoro, dubitari posset an quid commune habeat cum madrepora areolata, de qua egit Pallas; verum animadverto madreporam seu, ut hodiernis utar vocibus, turbinoliam arcolatam, cuneatam formam non exhibere; sed ovalem; quod tum ex definitionis oratione; tum ex citationibus ab eodem Pallas relatis aperte liquet; nam ipse ait, subcaliciformem formam habere, calycem esse in laciniis crispatum, extus parce crenalo-muricatis: deinde indita Sloanii, atque Petiveri auctoritate, satis superque ostendit, quid senserit, dum madreporam areolatam describebat. Dubitandi antem ratio, quam nuper afferebam, in eo erat, quod ubi inspiciamus tantummodo definitionem, apparebit nihil ibi tradi, quod æeque non conveniat et turbinolice areolate et turbinoliee avicule; hinc, quum ipse ait, turbinoliam areolatam simplicem, stellaque præditam esse crispatolaciniosa, et lamellas crenulatas habere, hæc omnia et turbinolice aviculce aptari possunt, quæ possidetlamellas crenulatas, generatim in loquendo, stellamque crispam habet. Quid de subpedicillo? 
sane hic locus parram ingerit difficultatem; nam ex auctoribus recensitis ab eodem Pallas discimus modo adesse, modo deesse hunc pedicillum; igitur de omnibus speciebus, quæ in hanc speciem cadunt sensisse videtur Pallas, sive hoc pedicillo polleant, sive non.

De eo potius quærerem, cur nam corallium dixerit turbinoliam areolatam, licet ceteroquin corallii genus a madreporis ipse distinxerit; una superest ratio, nimirum, ut suum scribendi modum vetustioribus scriptoribus accommodaret, quod et hodie a plerisque perbene usitatum est. Meminit denique in hac madrepora concurrere ommia ut in madrepora meandrina, in qua omnino alia est natura; ad id conciliandum superest ut dicamus plures species comprehendisse in madrepora areolata; ab aliis atque aliis corporibus, unius speciei definitionem cooptavit, quod tametsi cuipiam parum honestum et congruum æquitati videatur, quum privatæe investigationis limites excedat, tamen aliquando utillimum esse cognovimus; hinc optime Gray in zoologia effemeride quod prodiit Londino dum de cyprexis loquitur, animadvertit, circa hoc genus distinctiones ineptas ductas fuisse, quia eadem species variis obnoxia mutationibus, pro vario statu, etateque varia nomina meruerat: hinc etiam Sowerby atque Desayes passim in suis operibus ajunt, incerta corpora, et vix perspicua, tamquam species usque nunc habitas fuisse: horum posterior, forsan primus 
difficillimam specierum componendarum, certis sub basibus, viam ingreditur. Dummodo de iis non agatur, quæ ipsum laudant auctorem.

Turbinolia avicula compressa est, costas habet frequentiores, obsoletas, duabus basim versus elongatas, lamelliformes: basim acutam, stellam linearem elongatam: interius sepimenta sunt inæqualia atque ad latera crenata.

Habitat ... Reperitur in Sicilia, prope Placentiam, in montibus Dertonæ, et in colle Taurinensi, et alibi.

Mus. Taurin. Paris. Collectio Morelli, Rochetta, Mareskall, Bellardi, Michelotti.

\section{TURBINOLIA COMPRESSA}

\section{LAMARCK}

Turbinolia turbinata, cuneato-compressa, lamellis incequalibus appropinquatis, distinctis, incequalibus rectis, septis transversis crebris, conjunctis; stella concava, oblonga: basi acuta.

Lamarck. Anim. invertebr., tom. 2, pag. $23 \mathrm{r}$, n. 4 . Lamoroux. Exposit. méthod., pag. 51, tab. 74, fig. 22, 23. Cuvier. Règn. anim., 2 edit., pag. 313 , tom. 3. Blainville. Manuel d'actin., pag. 342. Defrance. Diction. des scienc. natur., tom. 56, pag. 92.

Magni momenti qurestio circa turbinoliam compressam exagitatur, atque ex variis speciebus a Milne-Edward ad Lamarcliii auctarium adjunctis, tres saltem conjungendæe sunt.

Hanc sane opinionem eruimus ex Defrance, qui vera harum turbinoliarum investigatione potitus 
notabat, turbinoliam compressam, ellipticum, et turbinatam, quibus addo lineatam Goldfi, unam componere speciem debere; nec immerito; nam certe, cæteris paribus, in omnibus hisce tribus speciebus habes characteri, qui apprime omnibus conveniunt, ex quibus non modo speciem, sed ne dum varietates cognoscere vales. Loqui ne amas de turbinolia elliptica, et ipsius definitio, et quod addidit Defrance, sat manifeste indicant agi de turbinolia turbinato-compressa, striis longitudinalibus crispis exarata; sed et hæc concurrunt in turbinolia compressa; nec, quod lamellæ crenulatæ sint, refert; nam, quum hæc, modo crispæ, testibus Defrance, el Milne-Edward, modo crenulatæ, testibus Cuvier, et Brogniart, evidenter apparet, nihil interesse. Confugere ubi malis ad turbinoliam lineatam Goldfi eadem res se se habet; nam quid amplius ait, quam basim incurvam, subcompressam testam, superficiem striatam, stellam ellipticam, lamellas majores minoresve alternas concurrere in turbinolia lineata.

Neque hic quidpiam cerno guod non conveniat æque turbinolice compresse, quin imo plura ex characteribus tributa a Goldfo, omnibus forma, turbinoliis conveniunt; nam si ponas compressam esse turbinoliam, necessario fluit consectarium stellam oblongam exhibere; lamella in omnibus turbinoliis inæquales sunt, non item in turbinolopsi: eo quod prominule sint, hocidem turbinolice crispce, echinatce, compressee convenit. 
62

Cave tamen ne, ut in cæteris, ita in turbinolia turbinata cum Defrance pariter sentias qualem, qualem a Linnco accepimus, a Lamarck renovata fuit, nostrave ætate i'lustrarunt; nam turbinolia turbinata Linncei turbinata est, non compressa; deinde extus tantum substriata, centro discoido pollet, contra in turbinolia compressa; ergo unam speciem non constituunt.

Cæterum, quod ait Milne-Edwwards, turbinoliam delphinam in hanc speciem concurrere verissimum quoque puto, nam in turbinolia compressa adsunt quoque memoratæ laminæ transversæ, quæ longitudinales attingunt; itemque irregulares sunt. Deinde, quid clarius fateri potest, quam illud Defrance, ubi provocat propriam speciem ad turbinoliam compressam Lamoroux; et ipse Lamoroux candide fateur de turbinolia compressa a Lamarck memorata sermonem habere.

Pluries hujusmodi quæstiones occurrunt, quæ directe ad rem nostram pertinere non videntur, sed quum potissimum intersit veram specierum naturam cognoscere, præcipua saltem sunt discrimina ferenda.

Habitat.... Reperitur in Delphinatı, et alibi. Mus. Britt. Paris. Mus, Taurin. Collect. Michelin, Defrance, Michelotti. 


\section{TURBINOLIA CLAVUS}

LaMarck, мовis (Tab. 2, fig. 2)

Turbinolia turbinato-clasata, resta; basi acuta : striis longitudinalibus granulatis predita, margine simplici, stella oblonga.

Lamarck. Histoire des anim. sans vertebr. I. et 2 edit. tom. 2. pag. 362. n. 7.

Delonch. Encyclop. pag. 76 r .

Defrance. Diction. des scienc. natur. tom. 36. pag. $9^{2}$. Blainville. Ibid. cit. dict. tom. 62. pag. 3o8.

Nomine turbinolice clavus eam intelligimus, quæ elongata est, clavæ formam præbet, stellam habet oblongam ferme linearem; ad latera strias ostendit subdentatæ; eæ ferme æquales decurrunt atque totam turbinoliam complectuntur. Long. et lat. var.

Habitat . Reperitur in Gallia prope Agen; et Aquisgranum, in colle Taurinensi, et Dertonensi; prope Veronam.

\section{TURBINOLIA SULCATA}

LAMARCK, мовIS (Tab. I , fig. 6)

Turbinolia cylindraceo-turbinata; sulcis longitudinalibus elevatis, nudis, ad interstitia transverse strialis; basi acuta; stella rolundata, concava; margine crispo.

Lamarck. Op. cit. 1. et 2. edit. tom. 2. pag. 362. Lamoroux. Exposit. meth. des polyp. pag. 5 r.

Goldfus. Petref. Germanix. pag. 5 г. tab. г9. fig. 3. Defrance. Diction. des scienc. natur. tom. 36. pag. $9^{3}$.

Schevveign. Handbug. pag. 4r 7 .

Flemmig. Britt. anim. pag. 5 го.

Singularis est in hix specic tum forma cylin- 


\section{4}

drica tum lamellarum indoles, quæ minutissimæ sunt, atque aliquæ a basi ad marginem deferuntur, aliæ inter has ortum habent, pariterque marginem attingunt. Stella autem rotundata est, atque marginem quoque altingit. Transverse occurrunt quoque aliquæ striæ.

Ceterum, quod ait Lamoroux viginti quatuor lineas rectas adesse, haudquaquam stricte accipiendum est; nam multo plures adsunt; hoc unum cum eodem probamus, nimirum sulcos parallelos esse.

Habitat . . Reperitur prope Grignon.

Mus. Paris. Brittan. Berol. Vien. ect. Collect. Michelin, Defrance, Bellardi, Michelotti.

TURBINOLIA PHARETRA

\section{LEA}

Turbinolia clavata, cylindracea, longitudinaliter sulcala: poris bis seriatim dispositis; lamellis incqualibus; stella rotundata; stilo elato, radiato.

Isanc Lea. Contrib. to geolog. pag. 196. tab. 6.

Incertus hærebat Lea, an ex Goldfi figura judicium ferendo, quæ de turbinolia sulcata afferuntur, turbinolice pharetrce convenirent. Tamen peculiaribus characteribus hujus turbilonice innixus, aliud sentiit, ita suadente lamellarum dispositione insita in turbinolia pharetra, vi cujus 24 sulcos enumeramus, costis respondentes, quarum 6 circa centrum quiescunt; 6 altere breviores sunt; quæ supersunt duodecim, alternatim adhuc 
breviores sunt. Stella rotundata est, nescio utrum plana, an margo ejus simplex; spiculum elatum $\delta$ radiis præditum. Ex hac etiam turbinolia liquet concipi non posse, qua ratione adhæreat; item cum turbinolia sulcata atque compressa difficiliter admodum componi hæc dispositio potest.

Habitat ... Reperitur in regione Alabama. Mus. Phil. Instit. New-Jorck. Collectio Lea.

\section{TURBINOLIA SINENSIS}

\section{NOBIS}

Testa obconica, subdepressa, lamellis innumeris, cequalibus, obsoletis; stella ovata, planulata, basi acuta.

Si turbinoliam excogites cujus basis sit acuta, quæ subdepressa sit, infundibuliformem naturam circa stellam induat, cujus lamellie vel costæe extus obliteratæ planam quasi superficiem exhibeant stellamve planulatam, ovatam, peculiarem procul dubio speciem habebis, cui novum nomen corporis, quod exhibet similitudini comparatum, tribuendum esse putavi.

Habitat ... Reperitur in colle Taurinensi.

Mus. Taurin. Collectio Rochetta, Micheloiti。

TURBINOLIA BASOCHESII

DEFRANCE

Testa compressa, brevi; basi acula; lamellis crobris minulissime exasperata; stella lineari, murgine simzlici. Defrance. Diction. des scienc. natur. tom. 50. paso g) Edward. Auct. ad Lamarck tom. 2. paz. 364. 
Goldfus. Petref. Germ. (turbinolia complanata.)

Turbinolia Basochesii, quam alio nomine turbinoliam complanatam Goldfus vocavit, itidem a Blainville compressce turbinolice perperam conjuncta, singularem cyatiformem figuram, depressam, multis costis lamelli-formibus exaratam, easque vel simplices vel crenulatas exhibet; stella linearis est, margo simplex.

Habitat . . Reperitur prope Frejus in Gallia. Mus. Brittan. Paris. Berol. Collectio Michelin, Defrance, ect.

TURBINOLIA CUNEATA

GOLDFUS

Turbinolia obconica-compressa, lamellis lateralibus, inaequalibus, obsoletis, majoribus, rarioribus, stella oblonga, margine 12 aut 16 vicibus septo: basi non revoluta.

Goldfus. Petrefacta Germ. pag. 53. tab. 14. fig. 9. Blainville. Manuel. d'actin. pag. 342. Milne-Edward. Auct. ad Lamarck. tom. 2. pag. 363.

Disputatur an turbinolia sexdecim costata a Goldfo memorata cum hac conveniat; sed convenire procul dubio, indicant varietates, quas habemus in turbinolia cuneata.

Habitat ... Reperitur in Prrencis, in agro Vicentino, et Astensi.

Mus. Paris. et Taurin. Collectio Golldfi. 


\section{TURBINOLIA GRANULATA}

L AMARCK

Turbinolia obconica, basi incurva, lamellis lateralibus granulatis in stella orbiculari singulis alternatim brevissimis.

Lamarck. Histoire des anim. I. et 2. edit.tom. 2.pag. 363. Goldfus. Petrefact. German. pag. 108.

Habitat... Reperitur prope Cassel in calcari arenaceo.

Mus. Paris. Berolin. Collectio Lamarck, Goldfi.

\section{T URBINOLIA CORNUCOPIA}

\section{NOBIS}

Turbinolia cylindracea basi arcuatim revoluta; costis majoribus decem, in eorum interstitiis tribus totidem minoribus sulcis divisis; facie granulata, stella rotundata, centro papilloso, margine scabro.

Habitat ... Reperitur in agro Dertonensi.

Mus. Taurinens. Rochetia, Bellardi, Michelotti.

\section{TURBINOLIA PRÆLONGA}

\section{NOBIS}

Turbinolia rotundata, prolonga; apice recurvo; striis filiformibus, plurimis subundatis : stella rotundata; versus basim leviter revoluta.

Hæc species gigantea est, atque plurium pollicum magnitudinem excedit.

Habitat... Reperitur in colle Taurinensi(frequens). Mus. Taurin. Coll. Bellardi, Morelli, Rochetta, Michelotti. 
NOBIS

Turbinolia turbinato depressa, costis raris, membranaceis, remotiusculis, interstitiis planulatis, stella apiciali; margine crispo, basi leviter revoluta.

A. Varietas costis rotundato granulatis.

Pauca requiruniur, ut distinguamus turbinoïiam raricostum a cæteris turbinoliis; nam attenta basi qua parum revoluta est, plus minusve acuta, attentis lamellis que circumdant turbinolice corpus, atque inter se dissitæ, membranaceæ, aliquando granulatæ; attentis interstitis planis, abunde eruitur hijus tirbinolia indoles ac natura. Quoad stellam nihil habemus singulare.

Habitat . . Reperitur in colle Taurinensi.

Mus, Taurin. Collect. Pochetta, Michelotti.

\section{TURBINOLIA KONIGII}

MANTELT

Turbinolia cylindraceo-turbiazata; sulcis longitudinalibus 25 vel 30 elevatis; stella orbiculari, margine crenulato. Martell. Geolog. Sussex. pag. 85. tab. 19. fig. 22. 28. Flemining. Brittan, anim. pag. 5 ro.

Blainville: Manuel d'actinol. pag. 342 . Milne-Edwards. Auct. ad Lamarck. tom. 2 pag. 364.

Si probaretur in hac specic basim revolutam, et sulcos adesse crenatos, favore turbinolice granulate responderem; quum alioquin forma, sufficiat ad dignoscentum tum Coldfi specicin, tum eam crum insignis Mantell proposuit. 
Habitat ... Reperitur in Anglia, in marna. Mus. Britt. Instit. Lond. Collect. Flemming . Mantell, ect.

\section{TURBINOLIA PLICATA мовіs (tab. $2, f i g .9$.}

Turbinolia cylindrica basi revoluta, acuta, costis frequeritioribus, rotundatis granosis, sulcis levibus, distinctis; stella ovato-rotundata, margine incequali.

Pauca sunt, quæ ita figuris complecti possint, ut reapse quam malis, exhibeant speciem, quapropter descriptionibus sunt supplendi defectus. Cum itaque amica manu figuras adjunxerim, eo eram, ut pro parte cognitioni supplerem. Addendum idcirco est in hac specie concurrere hasim leviter revolutam, figuram cylindricam, costas rolundatas, parum depressas, atque pro se ferentes grauulationes, quæ marginem versus, majorem sui copian et clariorem exhibent. Sulci sunt leves, tancu distincii, atque uti costæ a basi ad marginem currunt; stellam habemus ovato- rotundatam, quæ amplius quam 40 radios emittit, si gुeneratin faciem ejusdem observare malimus; in margine irregularitatem lamellarum, quum inter potiores lamellas prominentes tres minores adsint.

Hæc differt a turbinolia Konigii quoad sulcos, eorumque numerum, nec non quoad basim a turbinolia mitrata, quia neque subcompressa est, neque lamellæ papillosie sunt aut subcorinatæ: a turbinolia granulata, quia in hac cosiæ rotundatæ 
70

sunt, atque alternalio earundem penitus incognita. Varietas hujus speciei verum prelonga, minus granulata est, atque ad turbinoliam multispinam propius accedit.

Habitat ... Reperitur prope Dertonam, et prope Sciolze.

Mus. Taurin. Collect. Rochetta, Mareskall, Sotteri, Bellardi, Michelotti.

\section{TURBINOLIA MULTISERIALIS}

$$
\text { Noвis (tab. II. fig. 7.) }
$$

Turbinolia brevi, cylindracea, basi revoluta acuta, costis longitudinalibus undato-creratis, filo medio; 4 sulcis, costisve leviter granosis, intermediis: stella rotundata, centro papilloso.

Diu dubitavi utrum hæc species proprium nomen haberet, an aliud eidem addendum; nam etsi scriptores huic posteriori sententiæ proniores sint, tamen recte propria nomina defendunt, quum cæteras species consuluerunt, saltem eas, quæ magis perspectre dicuntur. Hoc in nostro casu; nam si qua foret turbinolia, ea esset vel turbinata, vel sulcata, vel caryophrllus, vel celtica, vel granulata, vel Konigii. Quoad turbinoliam turbinatam, quum nec ejus basis revoluta, extus tanturn sit substriata, quum alium marginem exhibeat, ea certo cum turbinolia multiseriali non est confundenda. Neque turbinolice sulcate comparatio diu vigere potest cum turbinolia mulliseriali, vel basis, vel lamellarum, vel formæ ipsius turbinolice sulcalce, natura id repugnans: prior 
illa ratio in causa quoque est, cur turbinolia multiserialis differat a turbinolia caryophillus, et a turbinolia celtica.

Erit ne confundenda cum turbinolia granulata, et cum turbin lia Konigii, aut plicata? haudquaquam; nam cylindracea forma, concava stella , costæ medianæ, quæ in nostra specie adsunt, quin de ceteris loquamur impedimento sunt, quominus turbinolia multiserialis, cognitis speciebus nomine conveniat.

Habitat ... Reperitur in montibus Dertonæ.

Mus. Taurin. Collect. Sotteri, Rochetta, Michelotti.

TURBINOLIA NULTISPINA

$$
\text { мовіs (Tab. 2, fig. 6.) }
$$

Turbinolia turbinata, rotundata, basi exerta, acuta, breviler revoluta; costis ramoso-muricatis; margine inoequali; stella concava: interstitia multisulcata granulata.

Costæ hujus turbinolice muricatæ sunt, atque constans earum numerus et dispositio non est; in interstitiis minoribus granosi sulci conspiciuntur, atque numero trium vel quatuor sunt, prout costæ majores magis vel minus distant. Basis leviter revoluta est, atque acuta; stella concava, papillosa, lamellis, seu radiis inæqualibus prædita; margo itidem inæqualis.

Habitat . . Reperitur in montibus Dertonæ et Genuæ.

Mus. Taurin. Collectio Sotteri, Morelli, Bel- 
lardi, Rochetta., Minurestall, Vesin, Terver, Michelotiti.

\section{TURBNOLIA CYATHUS}

solander et ellis. nobis ( Tab. 3 , fig. 3.)

Turbinolia simplici; clavato-turbinata; stella concava, centro papilloso; costis majoribus alternis, obsoletıs; basi depressa, corporibus constanter adhorente.

Solander et Ellis. The natural history of many and uncomman zoophyt. tab. 28. fig. 7 .

Esper. Planzenthiere I. pag. I 43. tab. 24. fig. I Marsilli. Hist. phis. tab. 28. fig. 128. u. 1 1.

Scheweiger. Handbug. pag. 4r 7. (antophyllum)

Flemining. Brittan. anim. pag. 5o7.

S. Ehremberg. Mem. pag. 76. (cyathina cyatus.)

Lamarck. hist. cit. ap. pag. 346. tom.2. (caryophillia.)

$\mathrm{Ab}$ is polypariis quæe turbinolias proprie dictas constituunt, paulisper ea differunt, quorum basis adhæret, atque fixa est quibuscumque corporibus; notatu tamen digniora, quia solitaria seu simplicia, uti loqui amabant veteres, sunt: inter hæc quæ passim etiam caryophyllice nomine veniunt, primum locum tenet caryophyllia cyathus s slicet ex plerorumque opinione simplicitas non sufficiat. Varii de hac turbinolia egerunt, sed constans est consensus, brevem esse generatim, rotundatam, atque gestare sulcos mediocres, stellam orbicularem, centro papilloso. Margo non simplex est, idest non conspicitur in eo æqualitas lamellarum, uti indicavit Esper, sed inæquales hre lamellæ sunt. 
Habitat in mari mediterraneo, rubro. Repe:tlur in agro Vicentino atque Astensi.

In Museo Florentice, Pisurum, Auguste Taurinorum; Collect. Sotteri, Morelli, Bellardi, Mareskall, Michelotti.

\section{TURBINOLIA CYLINDRICA}

NOBIS

Turbinolia simplici elongato-cylindracea; basi adnexa. longitudinaliter sulcata; lamellis cequalibus; stella valde concava.

Vix cogitare possumus eam turbinolice vel $c a$ ryophyllice speciem, si communi vocabulo uti malimus, ita compositam, ut lamellæ aut granulatæ aut inæquales non sint; hisce omnino caret turbinolia cylindrica; quibus si addas et stellæe profunditatem, et simplicitatem hujus corporis, abunde hujus speciei descriptioni consultum est.

Habitat ... Reperitur in agro Veronensi.

Collect. Gazzola, Catullo, Michelotti.

\section{TURBINOLIA CALVIMONTII}

\section{L $\triangle \mathrm{IARCK}$}

Turbinolia elongato-conica, stricta; stella leviter umbilicata, 2 pollicilus lata, 60 ferme lamellis alternatim majoribus. Guettard. Miem. Delph. tom. 3.pag. 463.

Defrance. Diction. des scienc. natur. tom. 7. pag. 193. Lamarck. Encyclop. pag. 168. (caryophyllia)

Habitat ... Reperitur prope Verdun in Gallia. Mus. Paris. Collect. Lamarch, Defiance, ect. 
NOBIS

Turbinolia brevi; basi pedicillo adnexo tenuissimo, stella maxima rotundata, costoe leves rotundate, interstitiis tenuissimis sulcis signatis; punctis undique insculptis.

Hac quoque species recenseri inter caryophyllias in vim distincti pedicilli, deberet; tamen pergit turbinoliurum speciem constituere, uti supra adnotavimus; puncta autem non grana adsunt, quorum evidens discrimen, posteriora enim faciem turbinolice, seu superficiem non inforformant, uti priora. Insuper diligenter notare debes interstitia costarum non sulcata, sed lineis rectis longitudinalibus, numero tribus, sigrata esse. Non inficiar alias adesse turbinolius, qux eadem pedicilli dispositione pollent, sed quum ex majori numero judicandum sit, atque ex quantitate metienda sit hujus pedicilli dispositio, quæ in causa fuit cur Goldfus anceps fuerit in turbinoliis admittendis; propterea species, quæ eam evidenter atque constanter ostendunt, ab iis procul dubio secernendæ, quæ eidem viam vel facto, vel data opera animantis, seu polypi præcludunt. Habitat . . Reperitur in colle Taurinensi.

Mus. Taurin. n. . . Collectio Rochetta, Bellardi, Michelotti. 


\section{CARYOPHYLIA}

\section{DONATI, LAMARCK, ULAINVILLE}

Polyparium lapideum, fixum, stirpe composita, ramosum, caule ramisque turbinatis; longitudinaliter striatis.

Stella unica, lamellosa, terminalis.

Polypi, ore polygonaliS tentaculis coronato, corpore oblongo.

Age nunc et caryophylliam expende.

Hoc siquidem genus a Lamarch originem ducit; quæ enim antea polyparia hoc nomine veniebant nihil aliud ferme erant, quam corpora ad unam eandemque speciem pertinentia (I) quaque madreporce caryophyllites vocabantur, licet caryophyllice nomen jamdiu usitatum fuerit apud Borguct ac Cartier (2) non certo atcue determinato modo. Curyophy-llice genus inter recentiores firmarunt Lamoroux, potiori felicitate Blainville, Defrance, Phillips, Martin, (3) Hisinger, (4) Mantell, (5) aliique, si Goldfum excipias, qui, rejecta hac divisione, putavit plerumque caryophyllias se se referre ad oculinas;

(I) Rumphius: Mus. Amboin. vol. 6. pag. 245.

Pallas. Elenchus zoophyt. pag. 278. et 3 г 3 .

Linnaus. System. naturæ. edition. varia.

(2) Borguet. Trait. des pétrificat. Paris $17 \Varangle 2$ pag. 58.

(3) Martin. Gróolog. mem. on W'estrer. Sussex. IS $\mathrm{S}$.

(4) Esquise d'un tableau des pétrifications de la Sricle par mons. Hisinger. Stochholm. $\mathrm{xS}_{29}$.

(5) Hantel. Illustrations of the geoliggy of sussex; et illustrations of tilgate forest. ect. 


\section{6}

quæ opinio licet non contemnenda argumenta præseferat, tamen et caryophylliarum, et oculince discrimen neque difficile est detegere.

Sedulo investigantes duas habemus stellarum species in oculina, harum aliæ terminales, aliæ non terminales; at in caryophylliis non adsunt nisi terminales; præterea oculina minime est longitudinaliter extus sulcata, neque omni ex parte verum est turbiriatam esse: caryophyllias autem, et sulcatas et turbinatas esse ex definitione colligimus. Demum quod hanc opinionem refellit, situm in intima, in vera stellarum natura. Adhuc conspice sectarn faciem interiorem caryophyllice, et habebis plures internos sulcos costis respondentes attenuatis, quæ a centro ad stellarum superficiem vehuntur; idem ne dicere potes de oculina? minime sane; imo contrariam prorsus rem habebis; nimirum, costæe illæe stellarum ex centro prodire videntur circumcirciter, non ex inferiori parte originem ducentes, uti cernimus in caryophylliis.

Quapropter ex lamellarum dispositione, tum interna, tum externa, ex stellarum ordine concludere debemus Goldfi opinionem, qui caryophyllias rejicit, minus solidis inniti argumentis.

Non diffiteor, uti jam notavi, aliqua, vel ex adhærentia, vel ex ramorum dispositione, et stellarum similitudine, parata esse ad utraque polyparia conjungenda; sed nimis vagaret ille, qui hisce tantummodo suffultus presidiis oculinces in 
caryophylliis, vel quod idem est caryophyllias in oculinis cerneret; nam adhærentıa triginta non dicam speciebus, sed generibus saltem convenit; unde veteres madreporarum sectionem inter simplices et compositas vix ac ne vix quidem agnoverunt; similitudo autem stellarum nos ad sarcinulas usque duceret; deinde improbabile omnino est tanti nominis auctorem ad hæc nominatim respexisse; alioquin vero caryophyllias, quas cum oculinis convenire fatetur, in novum genus anthophyllum ab ipso inductum, disponere ausum fuisse. At de hisce satis, definitionem attendamus,

Polyparium lapideum, fixum, ait Lamarck; notum est hanc proprietatem caryophyllice in causa fuisse, cur turbinolice a caryophylliis secernentur, et, cum peculiare organum in basi caryophyllice locum habere autumaverint, turbinolice et caryophyllice discrimina augerent, atque amplificarent.

Item, quum sermonem habemus de caryophylliis earumque divisione, dubium non est, quin juxta vulgarem agendi morem, distinctio inter caryophyllias stirpe solitaria, et caryophyllias stirpe implexa præditas, optima sit; verumtamen jure durat dubitatio, ubi fasciculatas inter, et eas, quæ ramosæ tantummodo sunt, comparatio instituatur; nec ratio obscura, quia non adeo liquet, quotuplici sub respectu vere fasciculata dici possit caryophyllia; sic caryophyllia solitaria a caryophyllia arbuscula facile distinguitur, tamen ab the posterion flexuosam secernere non ita facile 
est; nam ramorum dispositio, uti cuipiam patet, ita vel tempore vel fato implicari potest, ut, fasciculata nec ne caryophyllia sit, definire non valeas.

Ergo eatenus fasciculatæ formæ ratio habenda, quatenus hæc aliis adnexa non minoris momenti adjunctis, quãque alioquin per se sufficerent, ut species constituerent. Potior itaque ratio erit, quam ex stellæ ejusdem dispositione habebimus, quum ex hac stella pendeat totius interioris polyparii structura.

Dum autem dicimus terminalem caryophylliam esse, non excludimus stellas, quae inferiori loco continentur in aliis ramis, ex quibus caryophyllice est metienda species. Stellam dicimus adesse non cellulam, uti multi loqui amant; nam si corpus exhibeas, atque in eo plures ponas partitiones, corpus quidem unum habemus, quatenus complexum recipit, cellulas autem plures, quod evidens est; cellulæe enim, inducta partitione, plures sunt; hinc errore profecto lapsi sunt, qui docuerunt unam cellulam in caryophyllïs inveniri; quæ cum plures reapse exhibeant, non ob id plures, eadem stirpe indicant stellas, sed unam tantum, quam ad lubitum modo magis, modo minus implexam excogitare potes, vel, ut nostri locui amant, habes steliam modo simplicem, modo compositam.

Ex caryophyllice speciebus alia genera composita quoque fuerunt, preter illud memoralum a Goldfo; 
inter cætera dendrophylliam et anthophylliam numeramus; horum unum Blainville, aliud Scheweiger laudat auctorem: utraque tamen genera sustineri ac recipi nequeunt; nam genus dendrophyllice per omnia ferme comparatum est ac genus caryophyllia; et sane de dendrophyllia, ait Blainville, polyparium calcare esse, fixum, in ramos deflexum, vel dendroideum, extus striatum, interius concavum, et tanquam truncalum esse. Si posterius discrimen tollas, amplificationis ergo fortasse adjectum, nihil erit cur dendrophyllias valeas a caryophyllia sejungere; idque modo probavit Milne-Edward, qui ejusdem novi generis mutatione neglecta, citationis causa species a Blainville dendrophylliis adnumeratas recensiit inter caryophyllias, quibus apprime conveniunt. Sane si alia non superveniant validiora argumenta, et genus Scherveigeri ejustem momenti est; nam nihil cerno, quod eidem proprie aptari possit; nam dum fixam anthophylliam dicit, et id concurrit in genere caryoplyyllice; si demonstret in superiori parte expansam esse, id non modo caryophylliis, fungiis, aliisque generibus convenit. Usus tamen, quem penes, ut ajunt jurisconsulti, est jus et norma loquendi, priorem Blainville divisionem rejecit, posteriorem Scherweigeri admisit.

Ad polypum quod pertinet, nemo non dubitat primum Donati ejus definitionem dedisse; ab hoc autem auctore ad nostram xtatem perveniendo pauca addita huic polypi inrestigationi conspi- 
80

ciuntur; nam tametsi Cavolini de hoc polypo meminerit, tamen tum ex ejus tabulis, tum ex descriptionibus eruimus de caryophyllia a Donati relata cognitionem ipsum non habuisse. In unaquaque cellula, ait, polypus continetur tribus partibus compositus; nimirum pedes (tentaculos), concham (cellulam), caput (orem) ostendit. Pedes originem ducunt a duobus appendicibus conicis. Ex hisce appendicibus constituitur pars rotundata, quæ aliquo sub respectu musculis ventris respondet, vi cujus pes movetur ultro citroque, atque conjungitur cylindro variæ naturæ. Numero plures sunt pedes memorati circum dispositi, laminisque adnexi. Circa os caput polypi corona veluti conspicitur, radionum summa celeritate præditorum oscillatorii motus causa. Itidem 8 radios conspicimus, quibus polypus utitur ad vescendum.

Huic veteri opinioni adhærendum putavit Blainville, qui definitionem polypi ad hune ferme modum composuit. Animal actiniforme, subcylindricum, corona simplici aut dupla ( quo referuntur pedes appendices Donali) tentaculorum brevium perforatorum; unde jam pridem cum Milne-Edward consentire videtur circa divisionem, cui pertinere hoc polypariun debet. Sed neque ex hoc capite defendere potes discrimen inter turbinolian et caryopliylliam, quia cellularmm ordo sepissime pari ratione comparatum est in turbinolia ac in caryophyllia. Potius discrinen auget inter turbinolicis, corroplirlluts, atcue fungius; ita enim haec 
genera invicem adhærent, ut, uno sublato, et aliud intercidat opus est, sufficitque vel stellarum, vel lamellarum, vel exterioris faciei inspectio, imo specierum comparatio, ad dignoscendum an et quatenus sejuncta dici queunt.

Breviter dendrophyllice, anthophyllice, cladocorce, et lobophylliae species turbinoliis, vel caryophylliis addicimus, prout simplices atque solitariæ stirpis indicium præbent, vel prout pluribus stellis, nec solitariis stirpibus carent.

Antiquissima sunt caryophyllice vestigia; nam ea in grawacke jam reperimus, prout accipimus tanquam formationem; de qua alienum non est dicere, aliquos geologiæ, nec inferioris notæ scriptores esse, qui putant pari ratione ad primævas formationes pertinere; atque ex is fragmentis testaceorum, quæ ibidem reperiuntur, aliqua superioribus stratis computanda esse; aliqua reperiri in iis stratis quæ improprie grawacke nomen merentur. Inter hos eminet Anglius Doctor Macculoch ( $\mathrm{I}$ ) qui hac in parte ab opinionibus $D c$ La-Beche, Beumont, Dufrenoy, Prevost, Bové, eminenter differt. Tanti momenti quæstionem derelictam reliquerunt alii; est tamen, et adest Sismonda opinio qui meo infirmiori judicio consentit, et putat distinctio, quæ inter grarvacle et strata inferiora fossilifera excogitata fuit a De-la. Beche, minus solidis inniti argumentis, verum

(1) Macculoch. Geological classification of rocks. London. 19:2. 
$\delta_{2}$

faletur gravvacke aù struta fossilifera inferiora pertinere, ita ut hiec strata recipiant quæ sub hac nuncupatione sedimenta veniunt atque grawacke non excludant. Ceterum caryophyllic conutus sedimentis carboniferis insidet, atque eam concomilantur juncea caryophyllia atque duplicata, stoildarisque. In colitica ætate vigere pergebat hoc genus in caryoph, llia Bebrissonii, conyexa, aliisve: crelaccis in rebus adest, uti testantur Ami Bové alque Roset, (1) quos præcesserat Alexander Brogninet (2). In stratis autem supra cretaceis, vel alio nomine dilusianis, cam invenerunt jampridem Scild in Sicilia, Borgue in Helvetia.

\section{CARYOPHYLLIA CARIOSA}

\section{GOLDFUS}

Crassa, humile deliquescens, striato-cariosa; ramis truncatis, stellarum lamellis irregularibus.

Coldfus. Petrefact. Germaniz. pag. 45 (Lilhodendron) Blainville. Manuel. d'actinologie pag. 346.

Miline-Edwards. Auclos. ad Lamarch. tom. 2. pag. 358.

Habitat ... Hepertur in Germania, atque prope Parisios.

Mus. Berolin. Parisiens. Collectio Goldfi, Munster etc.

(I) Rozet. 'Traité élément. de Ģéologie. cit. pag. 349.

(3) Borgniart. Diction. des sciene. natur. tom. $3_{9}$. 


\section{CARYOPHYLLIA GRACILIS}

\section{GOLDFUS}

Caryophyllia cespitosa, erecta, subflexuosa; ramis cylindricis gracilibus dichotomis requalibus confertim striatis. Goldfus. Petrefacta cit. pag. 44 tab. I 3 fig. 2 (lithodendum) Blainville. Manuel. d' actin. pag. 346.

Milne-Edvvards. Auct. ad Lamarch. tom. 2 pag. 357.

Non una certe est species quæ conveniat aliqua ratione cum caryophyllia gracili; nam caryophyllia sinuosa, vel alio nomine caryophyllia cristata, uti loqui amat Ehremberg, ramos flexuosos, compressos, cespitosos habet. In caryoplyyllia angulosa occurrunt rami breves, erecti, creberi. Nec infrequens est hæc dispositio in caryophy lliafle$x$ xusa, aliisque; tamen, si simplicitatem hujus speciei, si ramulos quibus prædita hæc caryophyllia fuit attendamus, facere non possumus, quin eam admittamus,, atque eidem conjungamus caryophylliam dichotomam, quæ cum ea confunditur; nam æqualitas ramorum, præterquamquod non sufficit ad unam speciem inducendam, nec deficit in caryophyllia dichotoma.

Habitat ... Reperitur in Helvetia et prope Quedlimbourg.

CARYOPHYLLIA CESPITOSA

\section{LINN.}

Caryophyllia fasciculata; ramis cylindricis, distinctis, leviter striatis, flexuosis, hinc coalescentilus; stcllis concavis; lamellis æequalibus.

Pallas. Elenclus Zooph. pag. 3 I 3 n. 184 . 
Linn. Gmelin. system. natur. pag. 3770 .

Esper. Plasfenthiere. I. tab. 29 pag. 157

Blainville. Manuel d' actin. pag. 345.

Schevveiger. Handbug. pag. 417 .

Milne-Edvvards. Auct. ad Laniarck tom. 2 pag. 353.

Duæ sunt species, quæ non minimam relationem habent, ab Esper inversa ratione ac Linnceus, definitæ: qua in re cum Pallas convenit, ita tamen ut madreporam caryophy-llitem dixerit; ex quo fluit hanc speciem plura nomina habere: vel enim dicitur cespitosa ex Linnæi auctoritate, vel caryophyllites ex Pallas doctrina, vel fascicularis, uti Esper placet; hinc quod memorat Linnoeus, madreporam flexuosam, Pallas cum sua ccespitosa confundi, minus verum esse demonstravit Esper: stupescit propterea animus, cur Lamoroux hanc renovaverit sentiendi rationem.

Nota igitur in hoc polypario complexum plurium ramorum, qui conferti, subtus conjuncti, cylindrici; ferme aquales sunt; sulcos externe gerentes, irregulares, stellanque superius profundam: nota insuper ramulos, rui ad latera oriuntur angulatim et recte, nunquam disposili, sed flexuosi. Monet insuper semel iterumque laudatus Pallas sufficere mobiles lapillos, male exsurgunt hujusmodi polyparia; vulgaremque cylindrorum longitudinem esse dimidii plus minusve pollicis; crassitiem vero ex ala pavonis.

Habitat in Oceano indice et mediterraneo. 
Reperitur in collibus Dertonæ, in stratis supracretaceis Belgii atque Daniæ.

Mus. Britt. Paris. Berolin. Vienn. etc. (viv.)

Mus. Hafniæ, collect. Michelotti (fossilis)

CARYOPHYLLIA REPTANS

NOBIS

Cary. tabulis, elongatis, cylindricis undato-gibbosis, costis longitudinalibus, cqualibus granulosis constituta.

Si inspiciamus in hac caryophy.llia tubulos æquales, qui cylindricam formam et flexuosam habent; si attendamus ad costas longitudinales quæe ejusdem dimensionis atque granulosæ sunt, atque passim stirpes, unde novi ramuli ex tubulis proficiscuntur, cognoscere possumus characteres hujus caryophyllioe. Goldfus memoravit hanc speciem Lithodendron granulosum.

Habitat.... Reperitur in agro Pisano in stratis supracretaceis (frequens).

Mus. Taurin. coll. Michelotti.

\section{CARYOPHYLLIA AMICA}

$$
\text { NOBIS (tab. 3. fig. 5.) }
$$

Caryophyllia depressa; fasciculis cylindraceis, turbinatis, adnexis, longitudinaliter sulcatis; stellis rotundatis.

Non ignoro quasdam caryophylliarum species maximam habere, pro parte, relationem cum hac caryophyllia; sic caryophyllia dianthus, Godlfi, caryophyllia fasciculata, Flemmingii, alireque permultæ cespitosæ sunt; nec nova est hæc stirpium caryophyllia figura; nam in ramea, in co- 


\section{6}

rymbosa madrepora Foskalii rotundatos ramos habemus, nec in cariosa hunc ordinem desideramus. De stella pariter, communia quxdam huic aliisque speciebus occurrunt; nam in caryophyl. lia dichotoma, angulosa, et in quibusdam aliis caryophylliis stella itidem rotundata est, at ea quæ hanc speciem constituere valeant perperam quæris: hinc in trunculari, quæ valde huic speciei affinis est, rami sunt divergentes, et crusta lamellosa connexi; præterea fastigiati atque obconici, indeque toto cælo differt a caryophyllia amica, quæ insuper extus reticulata non est.

Non desunt, qui putent, tunc speciem esse, quum vere proprieque singula cujusque speciei characteres demonstrantur, sed nullius ponderis hæc objectio; nam ubi per hæc ire lubeat, vix speciem in omnibus scriptoribus invenies, quam sustinere valeas; nam generatim species nihil aliud sunt quam varietates peculiares, varietates ex diversitate eorum, quae genera constituunt, proficiscuntur.

Habitat . . . Reperitur in colle Taurinensi. Mus. Taurinens . . . collect. Michelotti.

\section{CARYOPHYLLIA TRUNCATA}

\section{LAMOROUX}

Stirpe composita, superne plana, ferme truncata; longitudinaliter forte striata, precipue in parte superna, stellis rotundatis; margine simplici.

Lamoroux. Exposit. méthod. des polyp. pag. 85 tab. ${ }_{7} \mathrm{~S}$ fig. 5 encyclop. pag. 169 . 
Blainville. Manuel d' actinolog. pag. 346.

Milne-Edvvards. Auct. ad Lamarh. tom. 2 pag. 35 r.

Non ita facile hujus speciei exarantur proprietates, nisi ad cyathophyllum Goldfi mentem revolvamus, idque potissimum, quia annuli circumdant ramos hujus caryophyllice, æque ac iidem inveniantur circa crathophyllum germanici scriptoris; neque hoc ignoravil anctor hujus speciei, qua de agimus; qui tamen fracturas putavit, quæ ex annulis descendunt, atque licet hac de re altum silentium, tum in sua historia methodica polyporum, tum in cncyclopedic: verumtamen aliæ notæ non deficiunt, ad eludendam cyathophylli similitudinem.

In cyathopyllo cylindros habemus cellulis divergentibus compositos, quæve originem superne altera ex altera ducunt, quin referat vel ex centro vel ex latere id ortum habeat; præterea quod potissimum est, animadvertit Wilne-Eldwards dum ait in singulis polyparii cyathophyllorun cellulis habitare polypum: non ita cum eodem de cyathophyllii, astrece, alio generum conjunctione sentio : secus enim contradictionem, quam posuit in hisce duabus opinionibus, sustinere oportcret. Habitat . . Reperitur prope $C_{a e n}$ in Gallia, et in colle Taurin.

Mus. Paris., Mus. Taurin,, colleet Soiteri, Michelotti. 


\section{F U N G I A}

IMPERATO， STUTCHBURY，LAMARCK.

Polyparium lapideum, simplex, orbiculatum vel oblongum, superne convexum et lamellosum, lacuna centralioblonga. Inferne concavum, et scabrum, vel lineis circularibus exaratum.

Slella unica, lamellosa subprolifera, supernam superficiem occupans; lamellis dentatis aut latere asperis.

Gradum quendam propinquitatis cernimus inter fungiam et turbinoliam ac caryophylliam; et siquidem quoad lamellas, quoad superioris faciei similitudinem, nec non quoad totius corporis horum generum relationem nonnulli characteres æque turbinoliam ac fungiam afficere videntur; monitum tamen velim, ut probe teneas, quæ alterutri generi conveniunt; fungiam cum memoratis non confundas. Lacuna, quæ in fungia reperitur ea deest in turbinoliis, caryophylliis; deinde ea minutissima pororum indicia in caryophyllia, meliusque in turbinolia patentia, in fungia desiderantur.

Quod si quid ponderis forma est, eam in fungiis distinctioni locum præbere non est ambigendum: superna æque ac inferior facies suadent propterea de genere singulari prorsus agi: neque difficultatem facessit quidam insignis scriptor (I) dum regerit spatium centrale lamellas neutiquam afficere, in errore enim lapsum fuisse et hoc probat quod judicium tulerit ex fossilibus, in quibus

(1) Diction. des scienc. natur. tom. 60 pag. 304. 
haudquaquam lamellarum adhærentia dilucido cerni potest; nam si reapse consideremus, quo nam nitantur lamellæ cum centro, et caryophyllice, et fungice rationern habemus; fungias, inquam, inferne conjunctas esse quemadmodum et polyparii, et polypi naturalis dispositio postulat.

Aliud discrimen profluit ex ipsa natura polypi; fertur enim membranaceum, simplicem, ore lato munitum esse ad tentaculorum similitudinem; habitare polyparium calcare, quo de quæstio: difficilius autem est huic definitioni aptare illam, quam tradidit Rumphius (r); renovavit Pallas (2): obductas scilicet " fungites esse visco æmulo amyli " cujus plicæ elevatiores oras gerunt instar den" ticulati limbi operis acicularii, et obtectas esse " innumeris oblongis vesiculis ex eadem gelatina "formatis, quæ vitam sub aquam produnt" sed bene perpensis adjunctis, nemo non videt amyli nomine venire tegumentum ipsius polypi; ubi plicas memorat elevationes, cerni indicia lamellarum, quæ in polypario concurrunt. Verissimum quoque est rupibus fungias incumbere, nec fere nisi rarissime, tumque per exilem et debilissimum pediculum affixas inveniri.

Veterum scriptorum opinionem Stutchbury assensum meruisse constat (3), qui tradidit fortuitam esse libertatis conditionem in fungia; quæ

(1) Rumphius. Mus. amboin. vol. 6. pag. 246. et seq.

(2) Pallas. Elenchus Zooph pag. 283 n. I65.

(3) Stutchbury. Transactions, of the Limn. societ. vol. 6. 


\section{$9^{0}$}

ratio non parum proderit ad propositum nostrum dirimendum ubi agentes de turbinolice et caryophyllice discrimine, non hanc unice, uti plerique sentiunt, attendendam esse rationem jam pridem monuimus.

Fungice characteres prosequentes, abs re non erit providam Goldfi sententiam firmare (licet eadem Fischer displicuerit( (I)) qui primus cyclolitem fungice per omnia ferme accedi, posuit (2): quod an et quatenus verum sit in primis videamus, et optimam quidem esse rationem ex utriusque generis comparatione ductam meno non autumat.

Polyparium lapideum, liberum, orbiculatum, vel ellipticum, incipit Lamurck, cyclolitem definiens; sed hæc omnia fungice æque ac cycloliti conveniunt, nisi quod simplicitatis notam ex gallico scriptore effugere videtur cyclolites; sed si perpendamus revera lamellarum dispositionem, nihil supererit, cur comparatio inter fungiam, et cyclolitem corruat. Superne cyclalites polyparium est convexum et lamellosum; centro sublacunoso; at præterquamquod et sublacunosi centri nomen conveniat quoque fungiis, vix hæc nota attendi debet; omnes sciunt stellarum centra polypariis lamelliferis lacunam præbere. Quoad stellam unicam, lamellosam, supernam superficiem occupantem, lamellis tenuissimis, integris praditam, eandem habemus etiam in fungia.

\footnotetext{
(I) Fischer. Bibliogr. paleontol, anim. pug. 330.

(3) Goldfies. P'etrefacta Germanix. articul. fungice
} 
Illud itague remanet, ut de inferiore superficie sermonem habeamus, atque, liac difficultate resoluta, nihil amplius definiendum supererit; quum aliquid peculiare necessario adsit oportet in $c y$ clolite, unde ab aliis generibus cognoscatur.

Vix eatenus repetenda mihi videretur apta distinctio inter cyclolitem et fungiam, quatenus auctor veram docuisset inferioris superficiei naturam in cyclolite. Quid reapse tradidit circa hanc superficiem inferiorem? hoc unum; eam esse scabram in cyclolite, et lineas circulares concentricas. Quis tamen neget harum linearum dispositionem in omnibus fungiis deficere? Prequamquod scabram hanc partem quoque esse in fungïs testantur ferme omnes species. Non erit cur ad fungiam agariciformem, ad fungiam cyclolitem provocemus, ad hæc probanda.

Præterea certum est internam cellularum, et centri, marginisque naturam eandem esse tum in cyclolite, ac in fungia, iisdem in locis reperiri, varietatesque easdem exhibere utrumque genus.

Verumtamen licet et amplectamur libenter Gol$d f i$ opinionem, cui quidem deflectere etiam videtur ipse Blainville, tamen negari non potest, et hic reviviscere difficultatem inter turbinolias, et $c a$ ryophyllias, ita ut, sepositis prioribus, et hæe posteriora genera sejungantur ; conjunctis, hæc conjungantur, quæ nisi a fortuita libertate turbinolice penderet, nec adhuc resoluta foret. 
$9^{2}$

Ceterum, ubi inspicias fungiam, semper tibi necessaria erit positio illius crusæ, quæ evanuit, iisque minutissimis insterstitiis, quæ adsunt reapse in hujuscemodi polypariis; ita ut inepte ex hoc solo polypario de genere feras judicium; et sic vicissim, si ex illa crusta quid deducere putaveris.

Demum per omnia laudamus divisionem Blainville, qui sejungit fungias habentes unam tantum stellam ab iis, quibus sunt plures; id et peculiaris polyparii indoles et polyporum relatio exposcit.

Antiquissime viguit fungia, nam in stratis carboniferis Gottlandice, in calcari jurassico, in oolite, non infrequens est; cretacea quoque sedimenta eam servarunt, atque a diluviano cataclysmo ad nos usque pervenit. Discriminis autem ratio intercedit inter unam et alteram speciem: sic discoideam cyclolitem in oolite perperam inquires; nummismalem cum elliptica non reperies; itidem lavem fungiam cum complanata ne confundas; tertiarii geologici ordinis posterior est, non item prior. Plenior tamen erit cognitio apud Goldfum, Schroter, atque De-la-Beche quoad vetustiores species, quæ ad rem nostram non pertinent.

\section{FUNGIA JAPHETI. \\ nовіs (Tab. 3 , fig. 6 ).}

Orbicularis, lacuna centrali oblonga, stella planulata; margine rotundato; basi attenuata; costis minorilus potiores alternantibus.

Diu dubitavi, an hæc species se referret ad 
aliquam ex is jam ab auctoribus indicatis; sed non potest convenire cum fungia semilunata, quæ latera compressa habet, quæque in limbo ostendit sulcum longitudinalem; neque cum fungia compressa concordat, quæ vel ob id unum, quod inferne papillosa est, in statu fossili cognosci non potest; præterea cuneata est, stellamque angustam gestat. Eadem forma, quæ impedimento fuit cur fungiam japheti aliis accederem, se se obstat huic unioni, sive de fungia cyclolite, sive de fungia scutaria, limacina, aliisque agatur; præterquamquod centrum hujus polyparii differt ab eo quod conspicimus in fungia patellari, in fungia agariciformi, ubi etiam de lateribus muricatis in prima, de lamellis denticulatis in altera silere malimus.

In hac itaque specie concurrunt lamellæ alternatim majores, ita tamen ut plures aliæ minores adsint inter easdem: margo hujus polyparii rotundatus est, atque ex eo ad basim, costæ lamellis respondentes, rotundatæ, leviter granulatæ decurrunt; nota tamen, quod hæ costæ ferme æquales sint: quum e converso lamellæe in supernam faciem valde inter se non crassitie, sed magnitudine differant: stella ipsa planulata est, quod rarurn evenit in fungiis; basis attenuatior conspicitur, ferme rotundatam formam habens.

Habitat .... Reperitur in colle Taurinensi.

Mus. Taurinensi. Collect. Rochetta, Michelotti. 
94

\section{FUNGIA CORONULA}

\section{GOLDFUS}

Stella orbiculari, depressa, stella planulata; basi truncata, lacuna centrali infundibuliformi; lamellis remotis, majoribus, minoribusque aliernis, memüranis transversalibus adnexis.

Goldfus. Petrefacta German. pag. 5o. tab. 14. fig. 16. Blainville. Manuel d'actin. pag. 338.

Milne-Edvards. Auct. ad Lam. tom. 2. pag. 375 .

Fluctuat hæc species inter fungian cyclolitem, patellarem, et aguriciformem; nullibi tamen cum memoratis speciebus convenire videtur; nam prior subelliptica est, stellam habet convexam; quod pertinet ad fungian patellarem, subtus muticam eam appellant (I); laterales muricatas lamellas ponunt; nec basim planam, uti in nostra cernimus specie.

An cum fungia agariciforme conveniet? Haudquaquam, nam hanc subtus scabram esse docent (2) ; stellam convexam; lamellas esse denticulatas, majoresque in longitudine radiorum.

Adest igitur in fungia ccronula vera species, quæ insuper cum complanata, vel titiculata fungia confundi nequit.

Quia hanc speciem habemus in formatione carbonifera, ideo difficultas oritur, num, quam

(1) Lamoroux. Exposit. mét. des polyp. pağ. 52.

Solander et Ellis, pag. 58. tab. 28. fig. 1. 4.

(2) Lamoroux. Cit. loc. et opus. pag. 52.

Scheweiger. Handbug. pag. $4 \times 4$.

Stutchbury. Transact. of the Linn. vol. 16. 
ipse propono de stratis supracretaceis eidem re. apse consentiat : tradunt siquidem, ex recepta praxi, absurdum videri, quæ propriæ sunt retustissimæ ætatis, et ibidem propria documenta jacent, eadem reviviscere coepisse in tertiario cathaclysmo, qua de re valde miratur Des-Hayes, de trigonïs verba faciens; dum innuit eas in supracretaceis formationibus deficere (1): ex hac quxstione potior orta est, nimirum relatio testaceorum inter fossilia atque viventia.

Sed hæc altera, postquam diu disputata fuit, nostris ferme temporibus doclissimi viri demonstrarunt, cujusve ætatis propria testacea, quorum similia perperam inquiris, adesse (2): hoc veteres cognoverunt, unde Ovidius " nec species sua cuique manet: rerumque novatrix ex aliis alias reparat natura figuras. " Priorem quod attinet propositionem, notare juvabit, hanc reapse rerum seriem nos assecuti nondum esse, ita ut temeritatis notam non effugeret, qui testaceorum, vel zoophytorum historiam in variis ætatibus componere, atque perficere putaret; hinc illud, non

(1) Parrot. Oblectam. phys. 1822.

Idem. Memor. accad. San. Petersbourg. I831.

Adolp. Brogniart. Considér. génér. ssr la nat. de la végétation aux divers. périod. Paris 1828 .

(2) Cuvier. Recherches sur les ossem. foss. passim.

Idem. Discours sur les révolut. du globe. Paris i 825 .

Ch. Zieten. Pétrifications du Wurtemberg. Stuttgard.

Nilson. Petrificata svecana. Stoccklom. I\$27.

De-la-Beche. Manuel du géolog. I. et 2. edit. passim.

D'Archiac. MIémor. géolog. passim. 
96

inveni, igitur non extat, plerumque fundamento caret; non extarent revera si id probabili ratione firmari posset, at ubi deficit ratio, frustra affirmabitur quod negari potest.

Non inficiar longam investigationem atque accuratum studium sufficere ad cognoscendos characteres præcipuos cujusve formationis; quo tendunt plerorumque conatus, verum cetera non excludunt frequentiora documenta, si horum respectu concordis vigeat exoptatus scriptorum consensus.

Hic etiam refellere non vacat quorundam opinionem qui ammonites, turrilites, scaphites adhuc nostris temporibus vigere autumant invisis regiogionibus, atque in viscera marium; iis enim, qui obliti nuper memorato geologiæ præcepto formationum, tempestates, fluctus, insulas e mari prodeuntes, princeps aqux filum, corporum eorundem specificum pondus ubi testacea soluta ab animantibus sint, perperam opponas.

\section{FUNGIA HEMIPHÆRICA}

\section{LAMARCK ( cyclolites)}

Fungia orbiculata, superne convexa: lacuna centrali oblonga; stella tenuissime lamellosa.

Lamarck. Hist. des anim. invert. tom. 2. pag. 367.

Scheuchzer. Herbarium diluvian. tom. 13. fig. I.

Goldfus. Petrefacta Germanix. pag. 48. tab. 14. fig. 6. Fischer. Bibliogr. palæont. pag. 339.

Linn. Esper. Petrif. tab. I. fig. I - 3 (madrep. porpita).

Cuperem ut in hac specie inferiores circuli con- 
centrici, vi quorum auctores eam retulerunt inter cyclolites, attendantur; lamellarnm minutarum numerus præ oculis habeatur, quæ ad latera granulosæ sunt. Varia magnitudo ejusdem est.

Habitat . . Reperitur in Delphinatu, colle Taurinensi, et in Germania.

Mus. Brittan. Paris. Berolin. Taurin. Collect. Michelin, Vesin, Michelotti.

\section{FUNGIA ELLIPTICA}

\section{LAMARCK}

Fungia elliptica, superne convexa, lamellis obsoletis; lacuna centrali elongata.

Lamarck. Hist. cit. tom. 2. pag. 367. (cyclolites) Flemming. Brittan. anim. pag. 3 1 0.

Nescio qua de causa vir doct. Fischer cyclolitem ellipticam et hemisphcericam conjunxerit; forma enim, et lamellarum numerus diversæ sunt indolis in una ac in altera specie.

Habitat ... Reperitur in Delphinutu, et in Anglia. 
$9^{8}$

\section{FUNGIA RADIATA}

\section{GOLDFUS}

Testa hemispherica, undique radiata, lacuna orbiculata; basi plana, radiatim et concentrice striata; lamellis majoribus geminatim in stellam conniventibus.

Goldfus. Petrefact. Germanix. pag. 48. tab. 14. fig. I. Blainville. Manuel d'actin. pag. 336. ( cyclolites) Milne-Edvvards. Auct. ad Lamarck. tom. 2. pag. 368.

Habitat . . Reperitur prope Aquisgranum, et alioquin in Germania in stratis stepracretaceis. Mus. Brittan. Paris. Berolin. Collectio Goldfi, Defrance, ect. 
LAMARCK, CUVIER, SCHEWEIGER.

Columnaria Goldfus. Lichostrotion Parkinson.

Polyparium lapideum liberum, massam simplicem, crustam, e tubis coactis constitutam, sistens.

Tubuli plurimi, paralleli, verticales vel prysmatici, fasciculatim aggregati; septis intermediiset transverse coactis.

Usque nunc ea polyparia describere aggressi sumus, si caryophylliam excipias, quæ libertate prædita, suaque cellula contenta, non massam exhibent, sed simplex corpus indicant; nunc de iis, in quibus hic ordo cellularum conspicitur adeo frecuens, ut stellæ adnexæ videantur peculiari dimensione, et figura donatæ, unde generum divisio deducitur.

Qua quidem in re monitum velim, ne hoc unum sufficere, ut proinde vel omnia, quæ similem stellarum seriem exhibent in unum genus componamus, vel innumeræ divisiones oriantur, quæ involutam magis Zoophytorum classem comparationemque reddunt; ita si priorem sententiam sequemur, nihil reliqui, exempli gratia, quam inter cætera alveolitem, et favositem, imo et tubiporam conjungere, eodemque nomine am- plecti; e converso si plures, et nimize sectiones amabis, nullum dubium, quin astrece, ipsæque sarcinule et pavonice tot nomina generum recipere deberent, quot species adesse scriptores 
I 00

fatentur. Itaque, quid reapse unicuique generi conveniat penitus investigandum; sique alio modo recte partitioni consuli nequeat, quænam propria sint cuilibet divisioni, ex ipsa definitione metiendum erit. Præstat igitur sarcinulas definire.

Nomen polyparii lapidei, quod convenit sarcinillce eo potissimum inductum fuit, ut Lamarck cohæreret propositioni ab initio latæ de partitione nempe polypariorum, prout simplicem membranam, vel corneam, vel lapideam exhibent; nec difficilius intelligitur, quonam sensu sarcinulam liberam esse dixerit; nam ea polyparia libera nuncupanus, quæ non adhærent aliis corporibus, licet et plures cellulas, et plures polypos ostendant; quum ceteroquin non desint, qui putaverint, et adhærere ipsa polyparia sarcinularum. Massa, quam exhibet sarcinula, non unius est indolis; nam a speciebus pendet ejusdem sarcinulce temperamentum, quemadmodum evenit in omnibus aliis polypariis, quæ lamellifera sunt: illud tantummodo certum est hanc massam constare ex tubulis connexis, qui si deficiant, vel confundantur sive eorum exordio, sive superius, non sarcinulam, sed astrceam habebis; qua quidem in re animadverto errore lapsos fuisse quotquot docuere, reapse tubulosas astracas inveniri: nam si hoc admittamus necessarium prorsus est, ut vel unum vel alind genus anferamus; quum ciuædam occurrere debeant, unde generum ducatur origo. Practerea, hoc posito, evanescit di- 
scrimen, quod in stellarum natura posuerunt; nam stellæ æque in astrceis ac in sarcinulis ejusdem sunt indolis, eisdemque varietatibus subsunt, quot ferme excogitari possunt, ut demonstrarunt, qui astrcearum species enumerare aggressi sunt.

Exacta quæstione ad species, quarum dubia indoles, nemo non videt astrceam v. g. agaricitem non esse veram astrceam: nam ex is quæ habemus in ejus definitione nihil afferri potest, cur potius in astrceis, quam in sarcinulis eam recipiamus: adde hoc pertinere ad astrceas, ut sint incrustantes, quemadmodum major earum pars est, juxta descriptiones, quas tulerunt ii, qui astrceas tubulosas a sarcinulis sejungere contenderunt: adeo verum est hanc distinctionem natura generum astrcearum et sarcinularum convenire, ut et veteres et recentiores scriptores id probaverint.

Et sane quoad veteres, habemus apud Borgzzet, Rider tubularice nomen præbuisse sarcinulis, astroitem autem Cartier veram sarcinulam nuncupasse : eamdemque tubulosam esse affirmaverit; ne scilicet cum iis, quæ madreporce vocabantur , confunderetur; id probat semel atque iterum Pallas, qui reapse plurimi interesse notat, agatur ne de madrepora tabulis composita, an de is , quæ hoc tubulorum ordine carent? quando e converso sermo est de vera astrcea cujusmodi (astrea ananas) de eadem altum silentium quoad tubulos servat. 
Mea denique opinio sponte fluit ex iis, quæ de astrceis afferuntur; nam astrcea Borgueti et astrcea stellata, quas non inepte quis conjungeret, veræ sunt sarcinulce; nec unus Defrance, qui astrceam astroitem reram sarcinulam esse fatetur; sed et in hoc censu ponunt astrceam aleuticon.

Non is tamen sum, qui putem reapse inter memorata genera, distinctiones eximias, et plures adesse, ita ut astrceam a sarcinula toto cælo absit: novimus enim, plurima eisdem convenire, quoad stellarum dispositionem, ordinem, centra, quoad supernam faciem; sed quum neque per ea ire liceat, nisi alioquin omnia polyparia lamellifera confundamus, ita ut nec meandrina, nec monticularia, nec montilvatia, generum firmitatem adipiscerentur, concludendum est, licet firmiora deficiant: saltem ea omnia adesse in sarcinula, quorum vi cætera genera polypariorum lamellis præditorum subsistant.

Tubuli autem sunt verticales in sarcinulis, idest e basi prodeunt, non communem, sed cujusvis tubuli propriam, rectamque ferme lineam servant; præterea tubuli aggregati sunt. In tubulis alia consideranda occurrunt, nimirum numerus fasciculorum, quos componunt, et eorum invicem tubulorum connexio: atque in primis certum est plurimos adesse tubulos sarcirulce sive minuti, sive crassi sint; itidem certum est fasciculatim aggregatos reperiri, quæ duo tubulariis et favositibus communia sunt, item stylince maxime sub hoc 
respectu cum sarcinulis conveniunt, nec aliud de columnariis legimus. Attamen quamvis hæc verissima sint, certum pariter est sepimenta transversa et intermedia non eodem modo se se exhibere in sarcinulis ac in memoratis generibus; non ea cerno in stylinis non in tubiporis; in favositibus autem hæc quidem sepimenta interna, quæ stellam componunt, adsunt, sed in hisce habemus tot minuta foramina, quæ in sarcinulis, columnariis aliisque deficiunt.

Superest adhuc distinguere columnariam a sarcinulis juxta Goldfi, et Milne-Edwards sententias. Discriminis rationem ponunt memorati scriptores in crassitie, in axe solido stellarum, et in ejus concavitate; sed nemo inficiabit reperiri sarcinulas quavis tubulorum magnitudine præditas; vixque attendam, quæ communia sarcinulis, columnariis et lithostrotiis. Nec majorem ingerit difficultatem centrum stellarum, ejus convexitas; nam, uti videbimus, quædam sunt sarcinularım species, quæ hanc dispositionem indicant; modo eadem carent. Circa tubulorum prysmaticorum naturam, non inficiar alicujus momenti esse hanc tubulorum dispositionem; sed quum hæc non sufficiat, alioquin vero cætera omnia communia sint sarcinulis, nec cum Flemmingo vel Parkinson lithostrotion, nec cum Goldfo et Edwards columnariam sustinere possumus.

Tamen, ut tria memorata nuper genera conjungamus, oportet ita latius sarcinulas accipere, 


\section{4}

ut ex varietatibus ad columnarias perveniamus; quod idem est ac si ex columnariis proficiscantur sarcinulce.

In muschelkalk, atque zechstein primus columnarias invenit Goldfus, quarum memoriam jam antea susceperat in grauıvacke, quæ invenitur prope Senekasee, atque New-Yorck, dum alveolatam columnariam meminit. In oolitica quoque cetate viguisse, strata, quæ adsunt prope $M O$ jenvic, Meurthe alibique testantur.

Quæ subsecutæ sunt vicissitudines, prima sarcinularum fragmenta protulerunt, atque ex hac tempestate ad diluvianam cetatem perveniendo sensim numero majores extiterunt, ita ut tunc temporis quamplurimæ extiterintspecies, quas hodie desideramus; dum quatuor tantummodo habemus, quæ in Indiis vivunt.

Sarcinulam in stratis subfossilibus, quæ nomine gallico, terrain clysmien appellat Brogniart, nunquam memorarunt, quum Krıot tantum fossilia, quæ prope Nicaam et nonnulla quæ in Svetia reperta sunt pro basi hujus sedimenti posuerit. Hoc tamen posito, nemo quædam testacea ibidem signata prope Nicæam seperire potest, quum mente tantum ab auctore, quem memorat gallicus geologiæ cultor, fuerint concepta. Ita bolma rugosa, otavia purpurea, teba pisana, rumina decollata, fidela theresa, cyclope neritoidea, nomina sunt, qux risurn tantum movere valent: hoc commendo is, qui 
Montfortium sequi cupiunt, ut saltem pari potiantur doctrina, neque me invidia destitutum, solius scientiæ non scriptorum vindicem, malo animo prosequantur.

De generis origine disputationi locus non est, at silentio præterire nequimus in tubularïs veterum specierum, quæ sarcinularum nomine veniunt indicationem habere.

Attenta igitur sola cylindrorum dispositione, vel apud veteres probata erat distinctio sarcinularum a cæteris astrceis, quibus cum convenire non unus affirmat, ex iis, qui de geologia nuperrime, non infelici partu, scripserunt. Ea siquidem est natura discriminis, quod ad stellas et tubulos sarcinulce ac astrece, ut saltem saltem potior sit, quam ea, quæ extat inter spirif $r$ ac terebratulam, inter venerem, et cythercam intes. escharam et flustram.

\section{SARCINULA PERFORATA}

\section{LAMARCK}

S. tubis in massam aggregatis, erectis; utrimque perforatis; interna pariete lamelloso stellata, margine incequali. Lamarck. Hist. des anim. I et 2 edit. pag. 34r.

Delonch. Encyclop. zooph. pag. 673 .

Lamoroux. Exposit. méthod. pag. 64. Blainville. Diction. des scienc. natur. tom. 47. pag. 345 .

Hæc species constituit massam depressam, solidam, tubulis compositam distinctis, stellatim interne dispositis, interstitia plana.

Habitat in Oceano Australi. 
I 06

Reperilur prope Badajoz et in Delphinatu.

Mus. Paris. Instit. Lond. ect. Collectio Lamarck, Michelotti.

\section{SARCINULA COSTATA}

\section{GOLDF US}

Tubis rectis, divergentibus, longitudinaliter granulato costatis, lamellis connectentibus convexo-planis.

Goldfus. Petrefacta German. pag. 23. tab. 24.

Blainville. Manuel d'actin. pag. 349.

Milne-Edv'ards. Auct. ad Lamarck. tom. 2. pag. 34r. n. 3.

\section{Habitat . . .}

Reperitur in Germania in stratis supracretaceis.

Mus. Vindobonce, Berolini, ect. Collect. Goldfi, Munster, ect.

\section{SARCINULA ACROPORA}

Linn. Nobis ( Tab. 4, fig. 4.)

Tubis crassis, elongatis, rolundatis; margine annulari; stella concava; interstitiis porcatis.

Linnacus. System. natur. pag. 1276. n. 20. Borguet. Trait. des pétrif. tab. 4. fig. 26.

Hxc species aliquam relationem habet cum astreca Borguetii a Defrance inducta; at ubi inspicianus in astrcea Borgututii tubulos non esse connexos; interstitia esse latissima; licet aliud indicet Borguct cujus auctoritatem provocat $D c$ france; præterea si respiciamus intervalla, poros non exhibere, in sarcinula de qua agimus, atque costarum nexum apparere, omne dubium sublatum videtur. 
Neque sarcinula acropora confundi potest cum sarcinula perforata, aut cum sarcinula costata; tubuli enim margo, superficies stellaris nostræ sarcinulce huic conjunctioni repugnant.

Habitat in mari Americano.

Reperitur in colle Taurinensi.

Museum Taurin. N. .... Collectio Bellardi, Rochetta, Michelotti.

\section{SARCINULA PLANA \\ повіs ( $T a b . I V \cdot f i g .5)$}

Tubis rotundalis, elongatis, adnexis, superficie plana, margine integro; stellis latis oqualibus; interstitia marginibus levibus conjuncta.

Vel id unum, quod margines se se non extendant, tubulique non adeo constanter cylindraceam induant formam, quod ambulacra sint leviter striata, sufficit, ut hanc speciem distinguamus a priore, cum qua ceteroquin convenit.

Dum tamen de sarcinula plana dicere coepi, dubitavi, num madrepora acropora Esperi a Lamarck adjecta rotulosie astrea, quamque faviam dixit Ehremberg, quædam præseferret indicia, quæ sufficerent ad dignoscendum, an hæ duæ species inter se reapse convenirent.

Definitionem Linncei, prioris definitionis partem auferre nemo inficiabit, dum tradidit, stellas confertas, annulares, prominulas adesse in astrcea acropora; annulos parvos, confertos, elevatos eandem præbere, fundo profundiori. Itaque duo definienda supersunt; primo, num astreea rotu- 
108

losa eadem sit, ac madrepora acropora; prior nomen duxit a Solander et Ellis; altera vero a Linnceo, illudque renovavit Esper: secundo, an astrcea acropora cum priori sarcinula conveniat; et Esper putat reapse madreporam rotulosam esse madreporam acroporam; dubitat tamen $L a$ marck, cum eoque Milne-Edwards. Causa dubitandi probabiliter in eo erat, quod stellæ cylindraceæ, pauci-radiatce dicantur in astrcea rotulosa; in astrcea autem acropora numero plures conspiciantur: deinde additamentum illud, de lamellis circum marginem erectis, acutis directe repugnat astrece rotulosce, et figuræ quas habemus madreporce acroporce hoc indicium non ostendunt: adde, quod dicitur de basi spinula erecta prædita, in rotulosa non cerni.

Me fallit an madrepora latebrosa Sloanii conveniat cum madrepora rotulosa, et an eadem species conveniat cum madrepora acropora; affirmat Lamoroux: tamen dum de madrepora acropora Esperi mentionem agit, dubitationis signum præsefert; concluditque probabiliter confusionem tulisse Lamarck in hisce speciebus, quod neque ex omni parte verum est, nam statim ac tres species induxit, confusionem non induxit, sique dubitare ausus est, hoc, tum ex definitione nimis brevi ipsius Linnei, Mulleri, Houtteyn, aliorumque repetendum, tum ex eo quod vel ipse Esper, qui eum præcesserat, notavit, conjungendam cum madrepora acropra, madreporam rotulosam. 
Definitionibus autem attentis, quas accepimus, concludere possumus, madreporam acroporam Linncei, perperam Esper, et omnes qui hunc auctorem secuti sunt cum madrepora rotulosa, de qua meminit Solander, junxisse; nam, dum Linnceus memorat stellas confertas, annulares, prominulas, crenatas, excludit eam speciem, cujus est stellas habere pauci-radiatas, lamellas acutas, erectas, radios acutos spinula erecta.

Semel admissa divisione madreporarum non defuerunt, qui hanc sarcinulam acroporam cum astrceis conjungere ausi sunt; quin imo, vel ipse Lamarck, Blainville, Lamoroux, dum de astrceis mentionem egerunt, tam rotulosam, quam acroporam astrceam recenserunt; qua ratione nescio, nam licet sepimenta illa in hisce speciebus deficiant, quxe concurrunt in madrepora organum, tamen tubuli æque coadunati sunt, fasciculatim aggregati, nec cætera, quæ habemus in aliis sarcinulis hic deficiunt.

\section{Habitat . . .}

Reperitur in colle Taurinensi.

Mus. Taurin. n...Collectio Bellardi, Michelotti. SARCINULA PUNCTATA

\section{Linn.}

$$
\text { NoBis (Tab. 4, fig. 6.) }
$$

Globosa, punctis stellaribus suborbiculatis, incequalibus, confertis, cavis, exiguis; interstitiis levibus, poroso-punctatis.

Linnœus. System. naturæ, pag. 1277. n. 22. 
Esper. Suppl. 1. pag. 86, tab. 70.

Borguet. Traité des pétr. tab. 9, fig. 42.

Lamarck. Hist. des anim. sans vert. I et 2 edit. pag. 407, n. 8 (astræa punctifera).

Blainville. Manuel d'actinolog. pag. 383 (idem).

Non pauca in hac specie concurrunt, unde dignoscatur a ceteris speciebus; summatim vero characteres sarcinula punctratce Linncei cernere est in exiguitate stellarum; in earum cavitate; atque in interstitiis ejusdem, quæ sunt poroso-punctata. At jampridem invaluerat disputatio, num madrepora arenosa cum ea conveniret, de qua meminit Esper; at in arenosa cernimus stellas ; ut ait Linnceus, majusculas; præterea in eadem specie stellæ contiguæ sunt: contra in sarcinula punctata.

Ex recentioribus autem nonnulli hac astrcea obliti, novam invenisse putarunt in punctifera; at utrumque perperam; nam astrea punctifera vera est sarcinula, atque omnino convenit cum madrepora punctata, de qua sermonem habuit Linnceus in systema naturce: in astrcea autem punctifera veram nos habere sarcinulam vel ob id unum constat, quod relata fuerit inter astrceas tubiporas, quxe in sarcinularum censu venire procul dubio debent, uti, dum de sarcinulce definitione agebam, demonstrasse puto.

Habitat in Indiis.

Reperitur in colle Taurinensi.

Mus. Taurin. Collect. Michelotti. 
SARCINULA FAVEOLATA

\section{SOLANDER et ELLIS.}

Tubis aggregatis; stellis subangulatis, multi-radiatis; parietibus hinc inde subduplicatis.

Solander et Ellis. Corall. zooph. pag. ı66, n. 57 .

Gmelin. System. natur. pag. $3769, n$. 64 .

Lamoroux. Exposit. méthod. des polyp. pag. 58.

Habitat... Reperitur in Corsica.

SARCINULA CONCORDIS

мовіs (Tab. 3 , fig. 8)

Tubis confertis, adnexis; stellis vqualibus, rotundatis, parvis, superficiem exœquantibus; lamellis innumeris, disseminatis transversis raris; massa rotundala.

Borguet. Traité des pétrif. tab. 9 , fig. 49 (mala).

Hæc species videtur quamdam similitudinem habere cum astrcea sphcerica Defrancii; sed alia hic est tubulorum ratio.

Habitat ....

Reperitur in colle Taurinensi et Dertonensi. SARCINULA MIRIFICA мовіs (Tab. 4, fig. r.)

Tubis aggregatis; stellis rotundatis; candida fascia circumcirciter munitis; massa hemispharica.

Ubi attente inspiciamus interstitia tubulorum in hac specie, quæ non de plano sunt, sed exhibent fascias albas, stellas circumdantes, evidenter hujus speciei discrimen apparebit: quod fortasse mirum cuipiam videri potest. Ceterum innumeræ quoque sunt lamellæ, sique excipias ipsius acroporce annulos, cum eadem sarcinula acropora convenit.

Habitat ... Reperitur in colle Taurinensi. 


\section{NOBIS}

Tubulis aggregatis, distinctis, rotundatis; superficie plana; stellis concavis mulli-radiatis; interstitiis celluliformibus.

Posteriora definitionis verba indicare videntur punctiferam astrcam cum hac, aliisve speciebus convenire; sed cellulæ in astrcea textili majores sunt, conjunctique, atque interstitia non adeo late patent; poroso punctata utique est astrcea punctifera, sed hi pori non adeo et semper liquent, ut in sarcinula contexta cujus interstitia, ex lamellarum, quæ stellas, seu loculos conjungunt dispositione, sunt tamquam cellulæ oblangæ, profundæ. Eadem $\sin$ fortior ratio adest in astrcea my riophthalma; sed lamellæ internie hujus astrece vix perspicuæ sunt; stellæque prominulæ, atque echinatæ sunt.

Nescio tamen, qua nam causa ductus Lamarck scripserit, agnovisse in madrepora muricata, quam habemus in 54." tabula, sub titulo $B$ apud Esper, figuram hujus myriophthalmce astrece; nam tam ex definitione ipsius Esper, quam ex ejusdem auctoris figura, apparet, non aliud dum de hac specie scribit, sibi proposuisse, quam singulas atque potiores varietates quæ pertinent ad madreporam muricatam, complecti desiderasse: non adeo facile est confusionem gignere inter genera cujusmodi sunt astrce atque madrepora, licet exacta sit qurstio ad hodiernam disciplinam naturalis historiæ partiendam. 
Interstitiorum autem naturam, qux summi est momenti, ad species sarcinularum definiendas, negari non potest ferme in omnibus porosam esse, at videndum, utrum sulci, an lineæ, et ipsi margines uniuscujusque stellæ, quæ invicem conjunguntur (ut in nostro casu) hos poros afficiant, an reapse hæc dispositio ad memorata non respiciat, tunc enim tantum interstitia vere porosa dixeris.

Habitat ... Reperitur in agro Dertonensi.

\section{SARCINULA GEOMETRICA}

$$
\text { мовіs ( } Г a b .4 \text {, fig. 2.) }
$$

Tubis connexis, aggregatim dispositis, stellis concavis, omnibus quinquies angulato-stalutis, inferiori facie plana. A. Variet. Stellis majoribus.

Constans harum stellarum ordo in angulos sistens, ipsæque stellæ potiores, et massa, quam constituit, quæ non rotundata est, impediunt quominus hanc speciem prioribus addicamus.

Cave tamen ne hanc speciem cum astrcea gala$x e a$, vel cum astrcea ananas confundas; nam hoc generatim pertinet ad astrceas, eisdem inhæret, ut tubuli non ita distincti conspiciantur, uti in sarcinulis, ut e basi difficile sit assequi, stellarum naturam, quod tamen contingit in sarcinulis; ut sepimenta transversa modo magis, modo minus sarcinulis faveant, stella denique non tubuli in sarcinullis adsint.

Habitat ... Reperitur in colle Taurinensi. 
Mus. Taurin. num. ... (uti superiores species) Collectio Morelli, Rochetta, Bellardi, Michelotti.

\section{SARCINULA ORGANUM \\ Linnaus \\ мовіs ( Tab. 3 , fig. 7.)}

Tubis levibus, cylindricis, erectis, separatis; in massam crassam aggregatis; septis externis, transversis, tubos connectentibus.

Linnceus. Amænit. academ. 1. tom. 4. fig. 6.

Scheweiger. Beobacht. tab. 7. fig. 66.

Delonch. Encyclop. pag. 673 .

Blainville. Manuel d'actin. pag. 348.

Goldfus. Petref. Germanix. pag. 73. tab. 2/1. fig. 10. Lamarck. Anim. 1. et 2. edit. vol. 2. pag. 34r.

Sarcinulam organum, quam primum memoratam novimus a Carolo Linnceo, in peregregio suo opere de amcenitatibus academicis, veram speciem reapse constituere patet; notatu tamen digniora retulit Lamarck, dum hanc speciem illustrabat: habet, inquit, tubos verticales in organi similitudinem dispositos, proptereaque distinctos, atque inter se conjunctos per quandam, ut ita dicam, membranam; preterea lamellæ longitudinales cavitatem replent, unde et in basi, et in facie superiore stellas lamellosas conspicies. In hisce cernere est gallici scriptoris documentum, quo, in sarcinulis, astrceas tubulosas aguoscere fatetur; in astrceis autem tubulosis concurrere, quæ sufficiunt ad surcinulce genus dignoscendum; nihil itaque impedimento erit, quominus astreas tubulo- 
sas habeas tanquam sarcinulas, quum id, et stellarum et tubulorum natura, tam in una, quam in altera facie, vel saltem ex centro ad superficiem, eminenter exposcat.

Habitat in mari rubro.

Reperitur fossilis prope mare balticum, et in colle Taurinensi.

Mus. Taurin. n . . et collect. cit.

\section{SARCINULA MUSICALIS}

\section{Linnceus}

\section{Noвis ( Tab. 4 , fig. 3. )}

Cylindris truncatis, distinctis, supra crustam prominulis, et infra per membranas transversas, confertissimas, et crustaceas contextis.

Linnœeus. System. naturæ 2. 27. (madrep.)

Ellis. Actus. Angl. vol. 53. pag. 432.

Pallas. Elenchus zooph. pag. 185.

Esper. Plaflent. pag. 1. tab. 3o. fig. 2.

Lamarck. System. des anim. cit. loc. (caryophyllia) Blainville. Manuel d'actin. pag. 348. ( sarcinula)

Non dubito madreporam musicalem veterum scriptorum, quam numero plures inter caryophyllias ponunt, inter alias sarcinularum species cum Blainville disponere; adeo enim momenti intercedunt discrimina inter hanc speciem, et cæteras caryophillias, ut quin obliviscamur veri generis caryophilliarum indolem, ejusque subrertemus definitionem, id agere non possimus : et sane licet fasciculatim et caryophy llice sint, quemadmodum sar'cinula musicarisis est; licet et stellæ 
1 16

in ciryophilliis esse possint prominulæ, atque in facie superiori se prodeant, quod non deest in madrepora musicali; nemo tamen non videt membranas transversas, uti loquitur Lamarcl, vel diaphragnas, uti nuncupat Linnceus, in caryophylliis non reperiri; atque in hisce diaphragnis, Lamarcli posuisse præcipuum generis sarcinula discrimen.

Sed, hisce neglectis, quid est quod dubium inducere valeat? an tubuli? haudquaquam; hi tubuli proprii quoque sunt generis de quo agimus, eidemque conveniunt. An stellæ? at stellæ eanlem habent formam, iisdem sunt vicibus obnoxiæe quibus sarcinula subsunt. Contra, ubi probare possim omria, quæ constituunt veram sarcinulan in madrepora milusicali concurrere evanescit fundamentum, quo innituntur contrariæ sententiæ patroni. Rursus igitur recense, quæ, dum de sarcinula definitione agebamus, retulimus. Polyparium lapideum, liberum : massam simplicem, crassam, e tubis coadunatis constitutam, sistens tubuli plurimi, cylindrici, paralleli, verticales fasciculatim aggregati: seplis intermediis, et transversis coactis. Lamellæe stellatim radiantes inter tubos. Ilorum quid desideramus in madrepora musicali? quid definiendum præeterea superest? quid, ipse affirmare audeo, si qua vera est sarcinula præter sarcinulam organum; ea musicalis madrepora est: proinde, si relinere velimus sarcinule genus procul dubio makireporam musi- 
calem enumerare oportet, exclusis inconsultæ citationis ambagibus: quod in vim comparationis docuit Linnceus, confirmavit Pallas. Non omnes tamen, quos habemus icones, reapse huic speciei figuræ respondent, et laudati germanici scriptoris (Esper) opus id sat clare demonstrat; ea enim tubulorum dispositio, quam hic cernimus, omnino indoli madreporce musicali repugnat, tanto magis basis horum tubulorum, quam ita se habere excogitavit: melior autem est figura, quam inter cæteros tradidit Seba.

Habitat in Oceano Indico. Reperitur fossilis in Hibernia, atque in colle Taurinensi.

Mus. Brittanic. Paris. Berol. etc. (viv.) Collectio Michelotti, Rochettı (fossil.). 


\section{A S T R EA}

BROWN. LAMARCK. BLAINVILLE.

Polyparium lapideum, fixum, conglomeratum, strata incrustans, vel in massam subglobosam, liberam raro lobatam, aggregatum.

Superna superficie stellis orbiculatis excequatis, vel subangulatis, lamellosis, sexilibus obtecta, inferna complanata.

A sarcinulis ad astrceas gradum facere debere jampridem docuit Blainville, utpote qui lamellartm dispositioni innixus, veram utriusque generis relationem cognovit, eo saltem sensu, quo polyparia astrece et sarcinula inter se conveniunt: at non unica sarcinula intuitu dispositionis stellie cum astrcea convenit, sed et aliæ; habes in astrceis quamplurimas lamellas inæquales, ut in caryophylliis, ut in echinophoris, et turbinoliis; earum dispositio cum eisdem consentit; centrum sæpe papillosum. Præterea adhærentia cum aliis corporibus neque unice ad astraam pertinet; quin imo licet sarcinulas probabili ratione fixas creclere debeamus, tamen facto non constat.

Ad rem nostram interest etiam nosse Lamarck, astraam quoque in divisionem retulisse polypariorum, quæ lamellifera vocavit: quod, ut rectius intelligatur, res altius repetenda. Putabant nimirum veteres omnes madreporas, et madrephyllias ad vegetale regnum pertinere, quia plura ex illis, ut jam, de sertularia potissimum agentes, 
demonstravimus, morem plantarum gerere ; ideoque minime anatomiæ comparatæ principiis freti qua docemur in foliis, cellularum dispositionem adesse; causa mortis et ortus tam in animantibus, quam in plantis similitudinem præseferre, uti perbene notavit Dehaan in suo opere de monographia ammoniteorum. Adde similitudinem externam quorundam generum, uti corallina, quæ ad corallia accedere videtur sed ad eandem non dicam seriem sed ne quidem classem pertinere potest, effecitque, ut plantæ loco tegumentæ polyporum haberentur.

Hæc sententia quæ plurimum græco philosopho placuit (I) ad nostram ferme ætatem perduravit (2).

Intuitu plurimorum polypariorum postea pauci scriptores coeperunt peculiarem eorum historiam quærere, et elementorum causa in classes partiri. Nam Imperato madreporam simplicem observans, eam ad tegumentum animantium pertinere, nec absque fundamento, uti posterior experientia demonstravit, crediderat (3): hæc opinio placuit quoque Gualtieri, licet hic scriptor nihil ferme contulerit peculiari observatione dignum. Donati et Pallas pro parte eam amplexi sunt; romanus Scilla eam defendere primus coe-

(1) Aristotiles. Historia anim. Varice edit.

(2) Borguet. Traité des pétrific. cit.

Shaw. Voyag. dans la Barberie. Haye 1743.

Donati. Histor. natur. Adriat. cit.

(3) Historia naturalis, Neapol. 1599. 
pit (1). Jamvero inter madreporas a Linnceo recensitas, fuit astrcea, idque ut pareret Pallas, quem in hac parte Svevus scriptor per omnia ferme secutus est: tamen, tunc temporis usitatas novimus voces madreporce astroites, madreporce favosa: ita Boccone in suo musæo hoc nomen astrcece favosce recenset, cujus opus, licet vetustate laboret, peregrinum quid, atque notatu dignum passim occurrit.

Omnem tamen controversiam sustulit anglicus Brown (2), feliciorique partu astroam, meandrinam, pavoniam, agariciam, aliaque genera constituit in dispendium Linnceance madreporce.

Nostrum tamen non est in hisce diu immorari, cum satis superque de historia astrace sermonem habuimus; juvat itaque expendere definitionem, ut, quid astrcece nomine veniat, cognoscamus. Lapideam dicimus astrceam eodem sensu, quo pavoniam lapideam dicimus, ut innuamus, non membranam, non corneam materiam, sed lapideam in ea concurrere.

Astraca plerumque fixa est, idque exposcit polyparii natura, quo de agimus; sed aliquando evenit, ut vel casu, vel vi auferatur e domicilii loco, quo in casu etiam polypos vivere posse exploratum est: item, quoad astraeas non unus est

(1) Scilla. De corporibus mar. Iapid. Roma $\times 752$.

(3) Brown. The civil. and, natur. history of jamaica. London. ז 756 . 
modus, quo adhærent, aliquando enim tenuem pedem exhibent, aliquando vero universa facies inferior adnexa est scopulis, vel cuilibet substantiæ: ad hæc respiciens Blainville ajebat, astræas plurima genera exhibere. Loculorum sedes invicem adnexæ, unde ille idem ordo adest quoad cellulas, ac quoad caryophyllias, sarcinulas, meandrinas; verum vel ipsi polypi in polypario astrcece conjuncti sunt, vel non, posteriori casu apparet caryophylliarum discrimen; in priori, quemadmodum et ipse autumo, vel ob id unum, quod lamellæ stellarum invicem se se opponant, et loculorum communio pateat, concludendum est vasculare systema aliud esse in astrais ac in sarcinulis, atque aliis generibus. Licet autem materia lapidea obtegat hoc genus, tamen, et propriæ destructionis functionem recipere certum est; nam experientia constat, et primum a Donati atque Cavolini accepimus concham, saxicavam astrceam perforare, in eadem propriam sedem constituere, ipsos polypos miserrime deficere; quod, et in iis astrceis, quæ in stratis diluvianis collegi, semel iterumque cognovi.

Quoad stellas nihil peculiare se se offerre videtur, intuitu plurium aliorum generum; nisi quod raro sint subangulatæ; hæc tamen dispositio pendet a lamellarum natura, neque mutat astrace genus. Dixi raro, nam quum agimus de astrceis, quæ faciem subangulatam in osculis exhibent, cautos esse oportet, ne videlicet primo intuitu ad 
astrceas provocemus sarcinulas, vel favosites; quum favosites alveolata sit.

Summi autem momenti est, in astrceis oscula tantum in facie superiori secernere, id contra contingit in surcinulis; id mehercle exposcit hujus polyparii dispositio, ut polypi inferiori parte certo modo inter se conjungantur, quod in sarcinulis affirmare non audeo. Ratio præterea brevitatis, qua donatæ sunt astrece in eorum tubulis, huic argumento majorem vim, et pondus addere videtur; ni enim hi tubuli essent breves, adnexi, ex uno tantum latere perspicui, unum fundamentum deficeret proposito generi. Itaque quod ait Lamarck, ad astrcece genus servandum, integre, casteque custodiendum esse putamus, eatenus quatenus id exposcit indoles polyparii, quod sub astrcece nomine venit.

Animal autem hydriforme est, breve, ad cylindri similitudinem compositum; ore rotundato, in disci centro reposito.

Tentaculi breves; pauci, simplices, disjuncti. Licet ex Quoy et Gaymard observationibus, hæc accepimus de polipo astrcece; nemo tamen non videt multa superesse, unde dignoscamus veros characteres polyporum, qui incolæe sunt astrcearum, ad zoanthaira pertinentes, quamvis hoc singulare in astrcece polypo reperiam, quod paucis sit tentaculis instructus, contra ac alii polypi, qui iisdem ferme polypariis insident, ad hanc classem relatis. Quidquid sit, potiora desideramus. 
Non una tamen fuit ratio, qua innixi scriptores, astrceas separarunt; nam alia divisio placuit generis auctori, alia Blainville, alia aliis.

Quod pertinet ad Lamarck, ipse ponit ex uno latere astrceas stellis disjunctis munitas, ex altero eas, quæ habent stellas contiguas; quæ sane distinctio aliqua menda laborare videtur; nam plurimi interest, agatur ne de astrcea conglomerata, vel de astrcea explanata, interest videre cujusvis generis stellas; an eædem simplices, an compositæ sint. Vix opus est manere, quod addidit de stellis separatis ab eadem basi, vix attendendum: nam distinctionem cellularum in astrceis, unice in superna facie cernere possumus. Jamvero in astrcea ananas et myriophtalma, inter cætera, demonstrari hæc junctio nequit, unde hoc pauci conferre evidenter liquet. Hac itaque divisione, articuli zoophytologize auctor, in pluries laudato naturalis historiæ dictionario, minime contentus, aliam excogitavit, atque induxit; unde in undecim classes astrceas divisit, quasi non de genere, sed de vera familia ageretur.

Circa priores astrceas, quas asteroides appellat, duobus auctor nititur documentis; quod stellæ adsint, sæpeque disjunctæ; nam quoad aliam, quam affert rationem, ea petitione princicipii laborat; idem enim est disjunctum, quod contiguum non est. In astrceis autem mendriformibus, veras cerno meandrinas, quæ profecto omnino hisce astrceis congruunt; nam, quid 
tradidit Lamarck dum meandritem definivit, quam polyparium esse lapideum, fixum, in massam simplicem hemisphæricam, vel sphæroideam, glomeratum, quam convexam habere meandrinam superficiem, ambulacris subexcavatis, repandis, sinuosis; utroque latere obtectam esse: lamellas transversas et parallelas, cristis collinaribus adnexas habere. Patet igitur has astrceas nominatim veras esse meandrinas; nam cum omnes characteres habeamus in speciebus a Blainville enumeratis, quas comparat meandrinis, quum ne unum quidem adsit discrimen, non dubito asserere, hanc divisionem evanescere debere.

Tertiam etiam divisionem rejicimus, cum æque tubastrceas cognoscere inficiamus; nam tubastrcece quoque ad astrceas non pertinent; atque modicus lamellarum numerus non sufficit ad partitionem inducendam.

Gemmastrcece autem vel tubulosæ sunt, vel non: in priori casu nihil differunt a tubastrais; in posteriori, nescio, an sola stellarum elatio sufficiat, ut has speciales astrceas, non asteroides, sed gemmastrceas relinquamus. Quum siredrastrceas, et dipsastrceas cum solidis nitantur, meo quidem judicio, fundarnentis, nimirum conjunctioni stellarum, marginis naturæ, et polygonorum faciem exhibeant, non est ambigendum quin idoneas componant sectiones.

Nolim tamen, ut putes, me eo consilio esse, ut adnumerare velim quadrigenium cyathophyllium. 
a Goldfo memoratum, inter sarcinulas; nam hæc species vera est astrcea. Idem dicito de astrcea haxagoria, adamantinam prorsus referens imaginem.

Ex recepta autem praxi, favastrceam pro favosite habeto, ubi tamen demonstraretur cum favositibus convenire: si hæc conventio inter duo genera deficiat, favastrceam servabo: at ubi favastrceas servemus, multo potiori ratione dicendum est, strombastrceas, et cellastrceits distinguendas esse, utpotequod in iis nihil desideramus accuratius ad veram astrcearum indolem constituendam.

Non levem tamen laudem meruit Blainville in vindicatione astrcearum inter cyathophyllia a Goldfo inducta, quæ veræ sunt astrcece.

Quum totius hujus operis fundamentum ad geologiæ documenta, quibus adnumerantur zoophytorum vestigia, se se referat, abs re non erit, singularem atque ferme neglectam astrcearum historiam prosequi.

Constans in primis geologiæ cultorum opinio est, astrceas ad primævas ætates referendas esse, in quibus testacea reperiuntur : hujus rei testes habemus De-laBeche, Bovè , Rozet, aliosque (1).

(I) Manuel du géolog. par De-la Beche pag. 5 го.

Dictionn. des scienc. natur. tom. 39 pag. 279.

Guide de géolog. voyag. pas. Ami Bové.

Traité élément. de géolog. par Rozet.

Organ. remains. Auct. Parkinson. 
Adeo porro verum est astrcearum originem antiquissimam esse, ut astrcea pediculata in calcari gryphceas recipiente, quem cum Lias plerique confundunt, reperiatur: nec defuerunt qui geologiæ documenta in zoophytis considerantes, tuto affirmarunt, vel in zechstein, astrcearum indicia reperiri; eadem certe non defutura in calcari carbonifero, in antrachite ( 1 ); in schisto tamen astrcearum fragmenta amplius non cernimus, quam tamen formationem cum carbonifera conjungi, non pauci autumant.

Cautiores tamen esse debemus in judicio ferendo de astracarum speciebus, quibusque characteribus aliæ ab aliis separentur; sic astrcea grenulata, argus, ad tertii cataclysmi documenta pertinent; concinnam, reticularem astrceam ad eandem ælatem referunt; arachnoides, velamentosa, textilis in cretacea formatione vivebant; pentagonalem, confluentem, jurrasica sibi vindicat ætas; porosa astrcea denique cum carboniferis monumentis jamdiu quiescit: ad supra cretaceas species animum convertamus.

(1) Des caractéres des terr. de craié des Pyren. par M. Dufiénoy. ann. des mines. 3 serie tom. I. 
Linneus. nobis. ( $T a b .5$ fig. 3 )

Astrca subrotunda, gibba, solida: stellis poriformibus, parvis, teretibus, immersis ; fundo radiato ; superficie inter stellas, poris vix conspicuis, excavatis adspersa.

Linnceus. Syst. naturæ. $n$. 18. (madrepora). Esper. Suppl., I pag. 1o tab. 34 .

Non unam, aut aliam speciem cernimus, quæ indicia propria etiam huic speciei exhibeat; at nullam confundi posse cum eadem liquido apparebit. Et sane si qua esset, ea vel punctifera, vel mycrophtalma, vel stellulata, vel striata astrcea foret, sed in interstincta astraa, punctiferam non cernimus, quia stellæ inæquales sunt in posteriori, et forma globulosa est, quod, ut obiter moneam, sufficere non pauci putant ad speciem inducendam, ita ajunt radialam astrceam marginis causa ab astrcea argo sejungi posse, ananas a galaxcea, et sic deinceps. Nobis autem magis arridet eorum opinio, qui ulique marginis natura freti, specierum divisionem excogitaverunt, non vero eorum, qui ab inæequalitate tantummodo stellarum, specierum originem duxerunt; nam quum polypi, qui concurrunt in uno eodemque polypario diversæ ætatis necessario sint, pronum est concludere, inæqualitatem necessario in stellis concurrere debere. Sive itaque punctiferam serves astrceam, sive non, firma species maneat svevi scriptoris; nam in primo casu 
stellarum indoles aliud indicat, in altero casu punctifera astrcea, interstinctce cedere debet.

Item non cerno in hac specie microphtalmain astrceam; nam stellæ in posteriori sunt prominulæ, extus striatæ, margo dentatus, et interstitia granulata.

Vehementius dubium urget, si loquamur de stellulata; at ubi etiam notemus marginem elevatum habere, interstitia arenoso-scabra, neque sub astrece interstinctce nomine venire potest; ibi pertinet dubitandi nota apposita a Lamarck, dum speciem Esper signabat; quod confirmavit Milne-Edwards, dum Lamoroux tabulam signabat.

Superest, ut videamus, an astrcea striatı cum interstincta conveniat nec ne; sane, vel quoad formam, vel quoad stellas remotas, orbiculares, superficiales, non est cur discrimen agnoscamus; sed talis est interstitiorum, quæ radiato-striatie sunt, talis centri, quod tuberculatum traditur, natura, ut perperam polyparium fossile Hallstadt cum linnceana specie confundere contendas.

Esto igitur in astrcea complanata, alio nomine interstincta, superficies plana, stellis æqualibus, orbiculatis, minutis, concavis lamellæ minutie, confertæ osculorum distinctorum imaginem exhibentes.

Quod pertinet ad corpus ipsum astrece, ceu ad ejus complexum, notatu digna incrustatio ejus sub aliis corporibus, v. g. eam adhærentem mytilo margaritifero habuit Esper; quam ipse habco 
ea chamce, cujus perdifficile cognoscere est speciem, adhæret.

Habitat ... Reperitur in colle Taurinensi.

Mus., Brittan., Paris., est. (viv.) Coll. Michelotti (fossilis).

\section{ASTRÆA ARACHNOIDES}

\section{SCHROTER.}

Astrcea incrustans; stellis orbiculatis, segregatis, margine prominulis; lamellis in centro reticulatis; interstitiis subtilissime radiatis, radiis hinc rectis parallelis, illinc flexuosis.

Schroter. Einl. 3 pag. 459 tab. 9 fig. 3.

Faujas. Montag. S. Petr. pag. 77 tab. 23 fig. 9.

Milne-Edwards. Auc. cit. tom. 2 pag. 420

Goldfus. Petr. pag. 7o.

Hæc, quam a Schroter accepimus species, toto cælo a memoratis, aliisque speciebus distincta est; nam in hac perpendimus margines prominulos, lamellas ejusque formam circa stellarum radios, et corpus ipsius astrece.

Parkinsonio et Defrance placuit eodem nomine, uti apte notat $E d w a r d s$, aliam innuere speciem, quæ ex angulari stellarum dispositione, ex centri natura, ex interstitiis, alios characteres ac eos, qui sunt in arachnoide astrcea Schroterii, exhibet.

Habitat . . Reperitur in cretacea formatione prope Maestricht, in Delphinatu, alibique.

Collectio Lamarch, Goldfi, Michelotti (ex dono equitis $V$ esin). 
I 30

\section{ASTREA RETICULARIS}

LAMARCK

Astrea subglobosa; stellis augulatis, incequalibus, difformibus, profindis, centro radiatis, parietibus striatis lamellosis; margine levi.

Linnous. Amænit. acad. I tab. $4 \mathrm{fig} .16$.

Lamarck. Hist. cit. I et 2 edit. tom. 2 pag. 414.

Lamoroux. Encyclop. pag. I28.

- Parietes stellarum subnudos esse putat Lamarck, ita ut ad varietatem provocet eas astrceas in quibus parietes striato-lamellosi sunt; at perperam; nam obliteratie astrece potius indicium probent subnudi parietis; alioquin vero eminenter hisce lamellis hoc genus indiget.

Peculiari autem venustate non caret hæc species, tum ob geometricam stellarum indolem, tum ex natura marginum, qui se extollentes magis denotant lamellas, quæ in hac specie minutæ, granulatæ sunt. Nihil amplius addere possum, quum fragmentum tantummodo servem.

Habitat . . Reperitur in colle Taurinensi.

Mus., Brittan., Paris., (viv) collect. Michelotti (fossilis).

ASTR EA INTERSEPTA

$$
\text { esper, Nobis ( } T a b .5, f i g . \text { r.) }
$$

Astrœa incrustans; superficie retiululata, stellis subangu-

latis, contiguis; margine mutico; axe centrali.

Esper. Pflanzent. supple. I pag. 99 tab. 79.

Lamoroux. Encyclop. pag. I27.

Scheweiger. Handbug. pag. 4ig.

Lamarck. Hist, anim. cit, loc. pag. 4i . 
Peculiarem reticulationem, nec non marginem ipsarum stellarum inspicimus potissimum in hac specie; ea exigua est atque raro invenitur tam in statu viventi, quam fossili.

Habitat in mari Australi.

Reperitur in colle Taurinensi.

Museum Brittan., Paris., (viv) collect. Michelotti (fossilis).

\section{ASTREA ARACHNOIDES}

DEFRANCE

Incrustans, siellis pentagonis, latis, stellee maximœ, centro conspicuo, concavo; interstitiis lamellis minutissimis exaratis.

Defrance. Diction. des scienc. natur. tom. 42 pag. 383.

Guettard. Mém. du Dauph., pl. 52 fig. 2.

Parkinson. Organ. rem. tom. 2 tab. 5 fig. I.

Milne-Edwards. Auct. ad Lam. cit. loc. pag. 420.

Hæc species, quæ Defrance laudat auctorem toto cælo distat ab ea, quam ita nuncupavit Schroter, ergo alio nomine donanda.

Habitat ... Reperitur prope Verdun in Gallia. Museum Paris., collect. Defrance.

\section{ASTREA ARGUS}

\section{LAMOROUX}

Stellis magnis, orbiculatis, multiradiatis ; margine elevato obtuso; exlus lamellis denticulatis radiato.

Seba. Thesaur. tab. 112 fig. 15 .

Lamarck. Hist. des anim. cit. tom. 2 pag. 405.

Lamoroux. Encyclop. pag. I32.

Blainville. Manuel d' actinolog. pag. 368.

$\mathrm{Ab}$ is astrcis, quæ massam incrustantem ex- 
II 32

hibent, ad eas descendimus, quæ hac proprietate destitutæ, vel in totum, vel pro parte habent faciem inferiorem exaratam juxta similitudinem faciei superioris.

Dubitat Milne-Edwards, an species astrece a Pallas relatæ, nomine madreporce astroites, specimen reapse exhibeat astrece argus; dubitandi ratio posita est in nimis ambigua definitione a Pallas tradita. At licet alicujus momenti dubia in definitionis exaratione inveniantur; tamen nomen astrea astroites servare debemus.

Adeo verum est nomen Batavi scriptoris servandum fore, ut nullam ejusdem definitio ingerat difficultatem; cylindros dum memorat, more majorum, eam indicat texturam, quæ eruitur ex superiori facie; nam inferius hanc formam desideramus.

Notat insuper, lamellas esse ad centrum unitas, ad interstitia minores, crassiusculas, scabras, denticulatas, ultra limbum productas; interstitia devexa invicem lamellis se se subnectere.

Habitat in Oceano Indico, in mari rubro et prope Americas.

Reperitur frequens in colle Taurinensi.

Mus. Brittan., Paris., Lugduni Batav. Berol. Vienn., etc. (viv) collect. Mus. Taurinens., collect. Barelli, Sotteri, Bellareli, Morelli, Michelotti (fossilis). 
ASTREA FAVOSA

ESPER

Astraea subglobosa, stellis majusculis incequalibus, angulatis, margine subacuto; parietibus multilamellosis; lamellis dentatis.

Esper. Supplem. I pag. 34 tab. 45 tis. I (madrepora). Schweiger. Handbug. pag. 4!9.

Blainville. Manuel d' actinol. pag. 375 .

Non ignoro madreporam favosam fuisse nuncupatam a Linnæo; verumtamen magis crederem reticularem astrceam sub hoc nomine Linnæano comprehensam fuisse; nam brevissima est definitio, obscura admodum exaratio ejusdem; atque ex citationibus, quas refert, evidenter liquet de alia astrcea, quam de favosa ita sensisse.

Clara est figura ipsius apud Seba; atque Gualtieri tabula non latet. Præterea in hac specie Linnceus notat madreporam favitem Pallas, quam Lamarck ad reticularem provocat in ipsius definitionibus.

Neque refert Esper memorasse favosam Linncei, aut Lamarck aliam pro alia speciem citasse; hæc enim omnia lucem Linnæi speciei minime addere possunt.

Habitat in mari Rubro, in Oceano Indico. Reperitur in Gallia prope Givet, in Sardinia, in Corsica.

ASTREA DEFORMIS

LAMOROUX

Astrcea stellis majusculis, oblongis, incequalibus, mullil.-- 
$134^{\circ}$

mellosis, supre marginem elevalis; sulco interstitiali nullo.

Lamoroux. Encyclop. pag. I29.

Savigny. Descrip. Egyp. tab. 9 fig. 3.

Blainville. Man. d'Actin. pag. 373 .

Ehremberg. Opus cit. pag. 69.

Lamarch. Hist. an. inv. tom. 2. cit.

In hac specie, quam accepi ab humanitate equitis Vesin, Delphinatu adducta, quædam similia astrece pectinatce Ehrembergi inspicio, nisi cum tripollicaris sit; lamellæ recte descendentes, basis dentata ; superius disjuncta interstitio subtilissimo aliud de pectinata, quam de deformi sentiendum est.

Madrepora denticulata quam Solander et Ellis simul nominarunt, quandam similitudinem quoque exhibet relate ad hanc speciem; sed si attendamus posteriora verba astrcece deformis, difficultas evanescit. Idem dicito de astrcea versipora comparata cum astriea deformi.

\section{ASTRÆA ANANAS}

\section{LINN压US}

Astraa slellis subangulatis, incequalibus; multiradiatis ; marginibus convexis, lamellosis; lamellis denticulatocrenatis; interstitiis planulatis.

Linnous. Amænitat. academ. I pag. 92 n. 3.

Idem. System. naturæ. spec. го.

Pallas. Elench. Zooph. pag 32r. n. 189

Esper. Zooph. I tab. I9 pag, 128.

Lamoroux. Polyp. pag. 59 tab. 47 fig. 6.

Lamarck. Hist. cit. tom. 2 pag. 406. 
Dum hanc speciem expendit Pallas, innuit duplicis generis stellas esse; scilicet vel remotiusculas, vel confertas, sulco discretas, inæquales convexo-prominulas: priores procul dubio ad aliam speciem pertinent; posteriores veram astrceam ananas constituunt.

In dispendium hujus speciei novam inducere studuit Esper, dum madreporam uvam constituit, quam uti notavit Lamoroux, in ea iterum com. plecti debemus.

De cetero, multi refert in hac specie consentire circa marginis stellarum naturam; nam licet et madreporam uvam servare non possimus; tamen si margines convexos esse ponamus, atque hæc dispositio exceptionem non patiatur, quernadmodum pati non debet, procul dubio tabula, quam habemns penes Lamoroux, rejicienda est, atque confugiendum ad icones Esperi.

Ad Sebam denique, quæstione exacta, cernere est scriptores agnovisse madreporam ananas ali= quando cum madrepora uva, aliquando cum astrcea galaxea convenire; unde quid sibi voluerint, difficillimum cognitu est.

In Svetia reperiri in statu fossili jam pridem a Linnceo accepimus.

Habitat in Oceano Americano ... Reperitur in Suetia, Dania, in Sardinia.

Mus., Brittan., Paris., Vienn., Berolin., (viv). Mus. Holmice, Haphnice, (fossilis). 


\section{SOLANDER ET ELLIS \\ повіs ( Tab. 5 fig. 2 ).}

Astrea incrustans, subglobosa; stellis confertis, adnexis impressis, multilamellosis; lamellis serratis.

Solander, et Ellis. Zooph. pag. 168. tab. 47 fig. 7.

Lesueur. Mém. du Muséum tom. 6 pag. 285.

Seba. Thesaur. tab. 112. fig. 22.

Lamoroux. Exposit. polyp. pag. 6o tab. 47 fig. 7.

Lamarck. Hist. anim. cit. tom. 2. pag. 418.

Pauca ex definitione deprompta sufficient ad hanc speciem cognoscendam; nimirum quod stellæ sint confertæ, impressæ vel leviter excavatæ, atque multilamellosæ, quod larnellæ serratæ sint.

Habitat in Oceano Indico.. Reperitur in colle Taurinensi, et in Sardinia.

\section{ASTREA CAVERNOSA}

\section{SCHLOTHEIM}

Astrcea stellis confertis, immersis, contiguis, hypocrateriformibus; margine truncato siriato, discis cavis cylindricis. Guettard. Mem. 2 pag. 5 о I tab. 46 fig. 2.

Schlotheim. Petref. pag. 358.

Goldfus. Petrefacta Germaniæ pag. 65.

Blainville. Manuel d' actin. pag. $37 \mathrm{r}$.

Milne-Edward. Auctar. ad Lamarck. cit. tom. 2 pag. 42 r.

Cavernosam astrceamb Linnceus quoque cognovisse videtur atcjue probabiliter non alia species est ac ea, de qua agimus, quod eruitur potissimum, dum Linnceus memorat hyprocrateriformes stellas, easque immersas, interstitiis elevata sutura; at quum putet convenire cum astrcea astroites $\mathrm{Pat}$ - 
las, nimis incerta hæc definitio est; unde nos dum cavernosam astrcam nuncupamus, eam prout Schlotheim definivit, exæquamus.

Habitat . . Reperitur in montibus Wurtemberg. 


\section{MONTICULARTA}

\section{L $\triangle$ MARCK , FISCHER, MILNE-EDWARDS.}

Polyparium lapideum, fixum, strata incrustans, vel in massam subglobosam, aut lobatam conglomeratum, vel in lobos suufoliaceos explanatum : superna superficie iamellis elevatis pyramidatis, aut collinaribus echinata. Stello profunda, conica: axe solido, centrali, simplici, vel dilalato, lamellis hinc adnatis circumvallato.

Singularis prorsus generis examen suscipimus, quod monticulariam dixit Lamarck, hydnophoram moscovita Fischer nuncupavit; cujusvis plura propria sunt, unde secernatur tum ab astrea, tum a meandrina, tum ab aliis partitionibus polypariorum apud scriptores receptis.

Observanti monticulariam, ut in cæteris contingit, duæ notæ occurrunt, unde genus cognoscatur; harum alia posita in superiori facie, alia in interua constructione: prior decidua, incerta, varia, raro constans est; altera firminr, potioribus innixa fundamentis, divisionibus optime inservit.

Licet hæc verissima sint, tamen minime ex hoc profluit, ea quæ deducimus ex stellarum natura, cui polypi corpus respondere necessario debet, ex generali forma polypariorum nunquam, aut leviter attendenda. Sic maximi momenti sunt, quæ eruimus ex interna polyparii structura, ex eorum habitu, atque dispositione; nam eo ipso 
quod probatum est antozoa assimilata per omnia ferme fuisse polypariis lamelliferis, nihil aliud definiendum superest, quam tentaculorum dispositionem ore tenus ipsius polypi. At cum hæc dispositio tentaculorum iis sit adminiculis freta, quibus polyparium ipsum moderatur, et regitur, planum est concludere, vel ex integro polypario, et pluries ex ejus parte, cognosci posse, agatur ne de meandrina vel de monticularia: neque ex eo quod ita divisiones ducimus, sequitur, minoris habere, quæ ex posteriori investigatione consequuntur; nam hæc apprime ad conciliationem inserviunt, polypariorum classem instruunt atque perficiunt; interea dum ipsius polyparii non negligimus opus. Sic ubi sertulariam a gorgonia, a corallio secernimus; isidem a fungia, a turbinolia partimur; favositem, explanariam a pennatula; pennatulam a madrepora differre affirmamus, rationem ponimus in intima horum polypariorum natura, quæ variat, prout ad unam vel ad aliam classem se se refert.

Polyparium lapideum monticularia est, scilicet texturam confertam exhibet; fixum dici potest eodem ferme modo, quo fixam astream dicimus; ita tamen, ut crustas illas non exhibeat, quas exhibent nonnullæ astrece: lobi subfoliacei cernuntur aliquando in monticularia, atque tunc explanata superficies est.

Superna facies ostendit non stellas profundas, uti cernimus in meandrina in catenipora; sed 
stellas elevatas, pyramidatas, aut collinares, unde ex earum complexu habemus montium collectionem, a qua similitudine nomen accepisse verosimile est: hinc valles, hinc varietates, hinc elegantissimum polyparium repetendum.

Quod pertinet ad axem ipsius stellæ, nemo dubitat, quin ex scriptorum, de quibus egimus, sententia ponendus sit in superiori parte ipsius coni; sed quurn Lamarck axem centralem solidum appellet, quum axis in medio stellarum sit constitutus, et ad stellas pertineat, dicendum in inferiori superficie ponendum esse, nihilque, officere, quod simplex et dilatatus sit; quum hæc conveniant æque in uno ac in altero casu. Peculiaris hæc constitutionis species mira plerisque visa est, unde nonnulli dubitarunt an reapse novum genus esset, an moduli forent hæ astrece (1). Priori sententiæ adhærendum existimo; nam pro certo habemus polypos in iis habitantes os habuere latissimum, et membranam in hac superiori parte extensam, et informem fuisse polypum; quod ex ipsius monticularia observatione patet. Jamvero, quemadmodum, ut ait Deshayes (2) passimque confirmat Owen, receptum apud zoologiæ cultores eandem organorum formam, eandem speciem indicare, ita et

(I) Defrance. Diction. des scienc, natur. tom, 32.

Milne-Edwards. Auct. ad Lamarck. 2. edit, cit. tom. 2. pag. 29?.

(2) Deshayes. Nota ad auct. Lamarck. 2. ed.tom. 7. pag. 17. 
animantia, quæ alia sunt forma anatomica prædita sejunctum genus constituere debent; perperamque idcirco ad hoc astreas genus provocant Defrance et Milne-Edwards. In formatione jurrassica collectas monticularias fuisse, testem habemus Borguet, Luid aliosque: diluvianas breviter eas recensemus.

\section{MONTICULARIA CUVIERII}

\section{FISCHER}

Monticularia stellis elatissimis; lamellis numerosis, tenuibus, subserratis, parum incurvis.

Fischer. Recher. n. ${ }^{0}$ 4. tom. 1. fig. 2. (hydnophora)

Idem. Orytogr. de Moscou. tab. 34. fig. 2.

Guettard. Mem. 3. tab. 40. fig. 1. 2.

Defrance. Dictionn. des scienc. natur. tom. 32. pag. 500. Blainville. Manuel d'actinol. pag. 37o. ( astræa)

Lamarck. Hist. anim. 1 et 2. ed. cit. vol. 2. pag. 394 .

Licet dubitatum legimus, an reapse astream vel monticulariam habeamus in hac specie; tamen, quin animum ad tabulas, citationis ergo insculptas, revolvamus, candide fatemur non esse $a$ stream; alia est enim superficies monticularice, ac sit astrece; id marginis, et loculorum favor exposcit; hoc confirmabimus in recensendis aliis speciebus.

Monticularia folium ob id ipsum, quod explanato-foliacea sit, et habeat conulos ad peripheriam dilatato-compressos, in disco autem minores, vim et proprium nomen ex hac descriptione sortiri placuit. 
Monticularia lobata, conglomerata quidem est, sed conuli dilatato-compressi, lamellis laxis muniti, peculiarem locum, ut insignis zoophytologice cultor (Lamoroux) declaravit, eidem meruerunt.

Monticularia pol, gonata, quæ non mollo quoad lamellas serrulatas differt a monticularia lobata, sed ratione quoque conulorum, et ratione formæ a monticularia folium, propriam exhibet sui generis nuncupationem.

Hærebat Goldfus utrum monticulariam microconos numerare deberet inter astreas, an eam inter monticularias relinquere: quoad hunc scriptorem prior prævaluit opinio; ideo quia incrustans, quia conuli breves surı; quia obsolete sunt compressi; quia lamellas serrulatas cernimus, ergo ait scriptor, quid impedimento est quominus hanc monticulariam pro astrea habeamus? Verumtamen animadvertimus, licet obliteratæ costæ sint in turbinella, in fasciolaria, in voluta, in mitra, non ideo generis naturam mutari: deinde ut monticularice microconos astrece nomen addere possimus oporteret ut obliviscamur definitionis astrea, vel ut hæc duo genera, silicet monticulariam et $a$ stream simul conjungamus; quod res ipsa non patitur. Exploratum antem est hæc genera agnita fuisse a Goldfo, imo novas species in utroque genere incluxisse. His etiam neglectis, notamus, ut speciem a genere ad genus transferamus oportet, ut integra ea sit; si obsoletis characieribus prædita est, quemadmodum ad pro- 
prium genus vix pertinere potest, multo minus in aliis transferri; hoc adeo verum, ut ne unum invenias scriptorem, qui hanc doctrinam communem cum germanico scriptore habuerit: Fischer enim qui novo sub nomine monticulariam cognovit, monticulariam microconos inter hydnophoras posuit; nec insuper est cur verba faciamus de Delonch, de Blainville, Lamoroux de Ehremberg atque nuperrime de Schweiger cujus nomen in zoohhythologia semel iterumque laudamus.

Id auctarium vero Lamarckii ipse Milne-Edwards, licet totus in eo esset, ut quo meliori modo fieri posset mendis consuleretur gallicani Linncei, tamen fatetur, non ita plane rem definivisse Goldfum, dum monticulariam microconos astreis vindicavit, ob id potissimum, quod deletis potioribus characteribus, nec inde colligitur aliud exhibere genus, vel saltem, non sufficere, unde dicamus cui nam generi sit tribuendum. Ceterum, ex eo quod provocet ad madreporam exesam Pallas, aleæ periculosa est hæc citatio, vel ob id unum, quod definitio a Pallas tradita de sua madrepora, aptari ferme omnibus monticulariis possit.

Monticularia Cuvierii reperitur in Russia prope Moscou.

Habitat...Academ. Moscou, Mus. S. Petersb. 


\section{MONTICULARIA MOLLII}

FISCHER

Monticularia subglobosa, stellis parum elevatis, raris, lamellis grassis superius obtusis.

Fischer. Recreat. n. 5. tab. 1. fig. 1. ( hydnophora) Idem. Orryctogr. d. Moscou. tab. 34. fig. 4 . Defrance. Diction. des scienc. natur. tom. 32. pag. 5or. Blainville. Manuel d'actin. pag. 363.

Lamarck. Hist. anim. 1. et 2. edit. tom. 2. pag. 394 .

Habitat .. Reperitur prope Moscou.

Museum acad. Mosc. collectio Fischer.

\section{MONTICULARIA KNORII}

\section{FISCHER}

Monticularia stellis approximatis; lamellis incurvatis, brevibus.

Fischer. Recr. n. 6. (hydnophora)

Knorr. Vers. tab. 3. pag. 192. tab. suppl. 6.

Guettard. Mém. 3. tab. 27. fig. 2, 4.

Lamarck. Hist des anim. invert. tom. 2. pag. 394.

Plerique putant hanc speciem minime ad monticularias pertinere, de quo quæstionem suscipere non est animus; attamem innuam ex sola definitione, cui tantummodo innitor, aliud dici posse; statim ac enim lamellæ approximatæ sunt, incurvatæ atque conjunctæ, et quas apponunt figuras, non refragantur quominus monticulariam Knorii inter monticularias recenseamus, contrarium quid studere non licet. 
Habitat . . . Reperitur prope Moscou, et in Delphinatu.

\section{MONTICULARIA GUETTARDI}

FISCHER. nobis. (Tab. 5 , fig. 6.)

Monticularia stellis elevatis, magnis; elongatis : lamellis incurvatis formam $\mathrm{S}$ amulantibus.

Fischer. Recherch. n. 7. (Hydnophora)

Guettard. Mém. 3. tab. 64. fig. 1. 4. 5.

Lamarck. Hist. des anim. cit. ed. tom. 2. pag. 395 .

Attentis stellis, vel margine, qui elongatus est atque meandrince memoriam revocat ( $\mathrm{ni}$ adesset circumscriptio hujus marginis in stellis hujusce speciei), habemus veram monticulariæ Guettardi imaginem. Cetera clariora sunt.

Habitat . . . Reperitur prope Moscou et in abbatia dicta de Moléne in Gallia, et prope Veronam.

\section{MONTICULARIA BORGUETII}

\section{FISCHER}

Monticularia stellis elevatis, conicis, lamellis basibifurcatis.

Fischer. Recherch. n. 8. (hydnophora)

Guettard. Mem. 3. tab. 44. fig. 5, $7,8$.

Blainville. Man. d'actin. pag. 364 .

Lam. Hist. des anim. tom. 2. pag. 395.

Si excipias notam, quam addidit huic speciei Milne-Edwards, utpotequam supravacaneam prorsus ducimus; cetera firma manebunt, quoad speciem, quam Fischer dicavit viro jamdiu a plerisque Galliæ scriptoribus oblito; qui tamen summa cura at- 


\section{6}

que diligentia studium fossilium et auctorum qui eum præcesseruni, prosequutus est, uti collecta et ejusdem scripta demonstrant.

Habitat... Reperitur etiam in locis supra recensitis.

\section{MONTICULARIA TESTACEA}

\section{NOBIS}

Monticularia plana, adhoerens; conis acuminatis, rotundatis,

lamellis deciduis; margines aquales.

Singularem, quam exhibeo speciem testaceis adhxret atque tenui lamina composita videtur, coni quos exhibet, rotundati sunt, regulares, in unam protensam superficiem exarati.

Hæc species reperitur in rivo della Batteria 400 passuum ab urbe Taurinensi in is stratis, quæ non pauca alia polyparia recipiunt.

Habitat ... Collect. Michelotti. 


\section{MEANDRIN A}

BROWN. PALLAS. IAMARCK.

Polyparium lapideum, fixum, in massam simplicem .hemisphcericam vel sphoroideam glomeratum.

Convexa superficies ambulacris subexcavatis, repandis, indefinitis, sinuosis, utroque latere lamellosis obtecta, lamella transversoet parallele, cristis collinaribus adnatae.

Hujus generis historiam inquirendo, videbimus hoc nomen jampridem adhibitum fuisse; nam pectinatam meandrinam, Linnceus, Solander et Ellis, aliique dixerunt:labyrinticammeandrinam, madreporam laby rinticam vel meandritem vocare placuit Linnceo atque Pallas; prior in systema naturce; alter in elencho zoophytorum; horum $æ-$ tate potior Knorr, hanc madreporam cerebitem nuncupaverat.

Licet igitur cum nota restituta hisce speciebus auctoritas appareat, vetustissimam tamen apparet fuisse earumdem cognitionem; nihil igitur mirum si Boccone adnotabat undulatam cernere faciem in fungo maritimo de quo agebat; idem ferme sentiebat Petiverius, qui multo certius, indicis testaceorum auctorem Gualtieri, prosequutus est, dum madreporæ nomine oblitus meandrinam proprio nomine vocavit, licet et tunc temporis Brown in jamaiciensi suo opere meandrinam ut mycedium cognoverit.

Hisce relictis ambagibus, notat noster auctor 


\section{48}

meandrinas genus constituere omnino singulare atque peculiare, ipso intuitu ab omnibus distinctum, atque hoc probaturus animadvertit; adesse non stellas simplices, circumscriptas, sed sulcos longitudinales, irregulares, vacuos in superiori parte, lamellis munitos transversis et parallelis quæque ad montium summa accedunt, reperiri. Insuper ait hæc ambulacra comparari nec injuria posse vallibus tortuosis; collibus eadem forma præditis subsidentibus.

Stellam vero non desideramus, quippe in collium interstitiis peculiarem sedem habent; colles autem licet interrupti, tamen circurnscripti, definiti non sunt; unde aliud in monticulariis dicendum, quarum favore colles circumscripti sunt. Lamellæ, quæ utroque latere colles ornant, perpendiculares sunt quoad colles, et valles ex iisdem profluentes, itidem inæquales sunt. Massam, quam exhibet meandrina vel simplex vel convexa vel hemisphærica est: rotundatim aliquando dispositas et in massis magnis convolutas esse non inusitatum est.

Si vero Lesueur audiamus de polypo meandrince disserentem, docet animal actiniforme esse, aperturam, oris ergo, amplam possidere, extremitates lobatas, tentacula circa discum oralem disposita. Aliud tamen docuit Quoy et Gaymard qui, hanc tentaculorum dispositionem negarunt, atque autumarunt meandrince polypos unitos esse sinuose in ima parte vallium polyparii; neque ten- 
tacula habere, nisi ubi decidua, vitalisque horum polyporum pars invicem eos secernit; os autem, ajunt, elatum est, et locum habere in spatio quo tentacula desideramus: denique adeo invicem adhærere, ut, quo modo conjungantur cognoscere non possimus. Ehrembergi tertia hac de re viget opinio, ex qua fluit polypos meandrince tentaculis carere; unde ait Milne-Edwards probabile omnino esse, confusionem ex triplici hac doctrina emersam fuisse, quæ in polypariis eandem similitudinem præseferentibus semel atque iterum contingit.

Licet hæreamus incerti, cui nam potius ex memoratis scriptoribus credendum, tamen, cum posterior peculiare quid exhibeat, hanc quæstionem suscipere non ambigemus. Sane, si probaretur in meandrinis non adesse tentacula, jam corrueret adoptio specificationis a Milne-Edwards propositæ, qui, ut vidimus, duas divisiones admittit; in prima antozoa recenset, in altera briozoa: de hac posteriori non quæritur; sed in priori, tres classes constituit; in prima sertularias, in altera alcyonia, in tertia zoantaira enumerat, quas inter recenset polyparia lamellifera. At meandrina est polyparium lamelliferum, ut apud omnes constat; tamen desideramus tentacula sive simplicia, sive numero plura, quæ optantur unde dignoscamus memoratum polyparium ad inferiorem classem pertinere.

Difficultatem certe non tollit nota, quam adje- 
cit Edwards de meandrince polypis verba faciens; alioquin vero improbabile omnino est Ehremberg. accuratum investigatorem, in ipso limine maris rubri ignorasse de quo polypo, de quo polypario ageretur. Ego tegumenta inquirens, putarem, si in monticulariis, astreis aliisque polypariis lamelliferis adsunt tentacula, adesse procul dubio debere in meandrina, cujus, sin eadem, saltem non absimilis natura.

Quæ de monticulariis tradita, ad meandrinas extendi commode possunt circa strata in quibus reperiuntur.

\section{MEANDRINA LABYRINTHICA}

\section{PALLAS}

Meandrina hemisphcerica, anfractibus longis, tortuosis; collibus simplicibus, subacutis.

Seba. Thes. tav. 1og. fig. 9; 10. tab. 112. fig. 2, 3. Gualt. Index testac. part. 3. class. 3. tab. 51. Pallas. Elenchus zooph. pag. 297. (madrep. labyrinthica) Esper. Pflanzenthier. vol. r. tab. 3.

Lamarck. Histoir. invert. cit. tom. 2. pag. 386.

Ehremberg. Mém. polyp. pag. 99.

Varias habemus pree oculis citationes de ma* drepora labyrinthica, quas inter Militie-Edixards ponit definitionem Pallas, nomine madreporæ meandrites; quæ tamen cum nostra specie miaime convenit; nam madrepora meanárites Linncei convenit cum madrepora meandrites ipsius Pallas; e contra madrepora labyrinthica a Palias nuncupata, eadem species Linncei est, potioribus induta 
characteribus. Nihilominus, unde citationis præcaveamus errores, nec ab ea pendeamus, nec non pectinatie madreporce quæstionem evitemus, juvabit definitiones ipsius Pallas exponere, atque perpendere tum circa madreporam labyrinthicam, tum circa madreporam meandritem, cujus intuitu aliter sentire debemus.

De madrepora meandrite agens Pallas, ait agnoscere polyparium conglomeratum sessile, stellis anfractuosis, lamellis denticulatis: deinde in definitionis exaratione notat; convexam superficiem occupare stellas laciniosas, flexuosissimas, contiguas et coaptatas; centra stellarum esse longitudinalia, exilia, exesa. Idem regerit Gualtieri in terlia parte sui operis, dum hanc speciem, ait, meandritem esse costis tenuissimis munitam, magis undatis et nonnihil concatenatis, lamellosis, interstitiis angustis; quin de Brownii mycedio agamus, evidenter decet Pallas, dum de meanclrite agebat, meandrinam ce:ebriformem præ oculis habuisse; nam verba, q̧uæ subdit de stellis flexuosissimis, coaptatis, de bracteolis tenuissimis, creberrimis, quæque addit, in nota, reperiri specimina vario gradu crispata, abunde declarant dum mzandritem definiebat, meandrinamcerebriformem descripsisse.

Tantam vero, circa madreporam labyrinthicam definitionis vim desideramus penes Linnæeum, cujus erat ab ipso exordio discordiæ occasionem auferre ut incerti simus cui tribuenda definitio ejusdem: 
quin imo quum revocat alterius sui operis memoriam, confusionem gignit, quasi indicaturus conspexisse madreporam areolatam.

Videamus modo an rejecta madrepora meandrite, quid in madrepora labyrinthica a Pallas nuncupata verius inveniamus, unde pateat nostræ speciei auctor. Ait hanc madreporam conglomeratam sessilem, stellis anfractuosis, et lamellis præditam crassiusculis; deinde ait, insigniter differre a madrepora meandrite, anfractus ampliores habere, et laxiores; substantiam solidiorem, saxeam; interjectas lamellas singulas, exiguas versus centrum, centra ipsa lamellarum radiatim lamellata. Denique censet Pallas, proprium nomen Linnceum huic speciei mutasse. Quum ergo Linnceus de alia specie disseruit, de qua egit, non constal; atque hæc, definitio quum apprime nostræ speciei conveniat, eamque dilucidare inserviat, proprium auctorem eidem servare debemus.

Habitat in mari Americano et mari rubro.

Reperitur in colle Taurinensi prope Rivalta, prope Veronam et in Germania.

Musæum Taurin. Collect. Nob.

\section{MEANDRINA CRISPA}

\section{LAMARCK}

Meandrina turbinato-hemispharica; anfractibus latis, ad extrema dilatatis, lamelloso-crispis, lamellis serratospinulosis.

Seba. Musæum. 3. tab. 108. fig. 3, 5.

Lamarck. Histoir. invert. tom. 2. pag. 388. 
Delonch. Encyclop. zooph. pag. 508.

Blainville.- Manuel d'actinol. pag. 357.

Notat auctor caute versari debere in hac specie, ne scilicet eam confundamus cum meandrina areolata; quod ob duplicem causam locum habere nequit, obstante lamellarum natura, quæ in meandrina crispa sunt lamelloso-crispæ; in meandrina areolata non item; obstantibus etiam posterioris definitionis verbis, quæ habemus circa meandrinam areolatam, quibus liquet colles passim duplicatos esse. Superest igitur, ut videamus an aliæ species cum hac convenire possint; certe si quæ adesset, non foret meandrina gyrosa utpotequæ habet anfractus longos, latos, et lamellarum basim divisam; collesque truncati conspiciuntur. Eadem autem collium natura impedimento est quominus in meandrina crispa cognoscamus meandrinam phrygiam; praterquamquod aliud indicant colles singularis hujus speciei.

Vel ipsum nomen secernit quoque meandrinam filogranam a meandrina crispa.

Quid autem innuere voluerint Quoy et Gaymard de meandrina sinuosa disserentes, non apte intelligere valeo; anfractus enim lati, lamellæ inæquales, speciosæ, atque spinosæ id indicant, quod aliis pluribus speciebus convenit; idem ferme dicendum de meandrina lamellina, quæ Ehremberg laudat auctorem.

Habitat in oceano Indico. Reperitur in Delphinatu. 


\section{LAMARCK}

Meandrina subsphcerica; anfractibus tortuosis, pralongis; lamellis basi dilatatis, denticulatis; collibus truncatis, subbicarinatis, ambulacriformibus.

Pallas. Elenchus zooph. ( madrepora meandrites)

Olear. Nius. Gott. tab. 3/. fig. I et 3.

Lamarck. Histoir. des anim. cit vol. 2. pag. 387 .

Borson. Oryctogr. pedem. pag. 39.

Blainville. Manuel. d'actin. pag. 357 .

Ehremberg. Opus cit. polyp. pag. 100.

Attende differentiam inter meandrinam cerebriformem, et meandrinam areolatam, quæ non tam in tortuositate anfractuum, quam in ipsis collibus posita videtur; hinc areolatce meandrina est, colles magis longitudinales, valles latiores, et summa earundem in duas partes passim discreta; secus ac in meandrina cerebrijormi contingat.

Oplime hanc speciem notavit Pallas in tertia classe varietatum, quas exhibere credebat madrepora meandrite; dum ait, ambulacra inter anfractus vix ulla, limbos contiguos esse, sulco tantum inter prominentes bracleolas relicto; quod igitur jam antea notavi meandritem celerorum auctorum, complecti meandrinam cercbriformem, magis roboratur. Omittendum non est, dum existimamus judicium batavi scriptoris, in detritis speciminibus harum specierum varietatum aliam esse faciem, nec non gradus intermedios; quod cum non infrequens sit in testaceorum historia, uti in $c y-$ 
praarum, et pectem generibus exemplum habemus; ita non absimili modo gradum cernimus in meandrinis, quemadmodum habemus in astreis, monticulariis, aliisque polypariis: illud tantummodo monendum, figuram hujus meandrinæ, quam exhibuerunt viri clariss. Quoy et Gaymard ad aliam speciem se se referre.

Habitat mare Americ. et Indicum ubi copiosissima.

Reperitur in colle Taurinensi, etagro Veronensi. MEANDRINA D EDALEA SOLANDER. NOBIS ( Tab. 5, fig. 5.)

Meandrina hemisphcerica; utrimque anfractibus profundis, brevibus; lamellis dentatis, basi laceris; collibus perpendicularibus.

Solander et Ellis. tab. 46. fig. 1. (madrepora)

Esper. Zoph. Supp. I. tab. 57. fig. I, 3.

Lamoroux. Exposit method. des polyp. pag. 55.

Lesueur. Mém. tab. 16. fig. 10.

Blainville. Manuel. d'actin. pag. 357.

Placuit anglicis scriptoribus, nempe Solander et Ellis, nomen huic speciei tribuere, quod omnibus meandrinis generatim aptatur, utpotequæ genus indefinitæ constitutionis exhibeant. Neque iis est tamen characteribus suffulta, ut cum aliis confundatur ; nam in hac meandrina anfractus ( licet anfractuum nomen non conveniat, quia anfractum dicimus quod fractum est, non vero quod tale est irregularitate, inæqualitate) sunt inæquales, profundi, breves, certis brevibus limitibus 
circumscripti: ipsi colles perpendiculares sunt, lamellisque in utroque latere muniti, quæ tenuissimæ sunt, ita ut prima fronte deficere videantur; harum lamellarum indoles crispa apparet.

Interius inspecta hac meandrina, ut in cæeteris, cellulæ quamplurimæ, quæ pro parte systema componunt, interseptæ sunt in eorum longitudine; sed qui nam ordo adsit, impossibile in fossilibus judicatu est, atque hoc unum deducere possumus intersepimenta crassiora esse, et tam in uno quam in altero latere acuta esse; in lateribus concavitatum, in quibus reperiuntur stellæ, adesse quamplurimos sulcos, ita minutos stellis respondentes, ut punctata hujuscemodi interstitia diceres.

Ulterius investiganti apparebit, membranas, quæ cellulas transversim secernunt, modo concavas, modo convexas, modo perpendiculares esse axi ipsius meandrince; cellulas variare, neque novum, ut hæc cellularum dispositio aliquando una cum margine, astream repræsentet, et lamellas ipsas, quæ interstitia componunt, nec semper se se invicem respondere.

Meandrina dadalea duas facies ad eamdem ferme similitudinem contextas exhibet; quod mirum videri profecto debuit; eatenus enim convenire polypi in inferiori facie debent, quatenus conveniunt in facie superiori. Hæc quæstio duplici ratione solvi potest, vel admittendo meandrince polypos duas cavitates habere, easque itidem si- 
miles, atque tunc veras hydras, uti veteres fabulabantur, habemus ; vel affirmare duos polypos reapse conjunctos esse, et profecto experimenta a Donati incepta, a Cavolini prosequuta ostendunt, sejunctis partibus polyporum reproduci ad modum ipsius polypi, qui divisionem passus fuerat, nisi specialis vis aliud exigat.

Habitat in Indiis ... Reperitur in colle Taurinensi, et in agro Veronensi.

\section{MEANDRINA FILOGRANA}

\section{ESPER}

M. globosa, subgibbosa; anfractibus superficialibus angustis, tortuosis, lamellis parvis, crispis; sutura acuta, filograna.

Guallieri. Index. test. $t a b .97$.

Esper. Zoophyt. pag. I39. tab. 22 fig. I.

Lamarck. Histoir. invert. tom. 2 pag. 389.

Blainville. Manuel d' actin. pag. 358.

Colles filiformes, angusti huic speciei proprie conveniunt.

Habitat in Indiis. Reperitur in Italia.

Mus. Taurinens. Collect. Michelotti. 
LAMARCK. GOLDFUS. MILNE-EDWARD.

Polyparium lapideum, membranaceum, e tubis parallelis in laminas verticales insertis, compositum; laminis in reticulum anastomosantibus.

Alia nobis definienda superessent, antequam de catenipora agamus, de Pavonia, de Agaricia scilicet nobis antea agendum esset, quorum characteres satis abunde locis respondere eisdem in zoophythologia tributis; tamen quum Pavoniam in tertio cathaclysmo ad hanc usque diem desideremus, et agaricia jurassicam ætatem tantummodo præseferat in agaricia granulata, et lobata, quarum utraque Goldfum laudat auctorem, nihil est, cur in hisce generibus, eorumque speciebus immoremur, propterea de catenipora videamus.

Licet Pallas de veterum cognitione circa cateniporam siluerit; tamen hujus generis documentum habemus vel apud Bromel vel apud Buttner aliosque; quin Linnceum præteream, quin Esperi memoriam omittam.

A citationibus ad rem, ad definitionem revertamus; atque in primis, nec mirum valde videtur, quod ait Blainville, nilhil aliud cerni in catenipora, quam genus milleporarum; nam ad hoc probandum notamus Linnceum, hoc genus modo cateniporam dixisse in amænitatibus academicis, modo tubiporam in systema naturæ, quam po- 
steriorem opinionem cum retinuerit, adeo Lamarck placuit, ut veritus non sit, tubiporas, cateniporis adjungi, quarum tamen discrimen vel ob omnium oculos ponere non occurrit.

Ad hanc itaque rem aptissime monet laudatus Blainville, posse cateniporas ad escharas pertinere, hoc dubio motus, quia videbantur lamellæ recipere cellulas, quarum apertura opposita foret; deinde hanc opinionem reliquit, majoribus innixus fundamentis, unde caryophylliam in catenipora cernere putavit. Ulterius progreditur atque notat, cateniporam labyrinthicam convenire non posse cum cæteris speciebus, ideoque vel ad aulostomas vel ad alecto pertinere, atque proficisci debere: hinc Blainville ait, nihil aliud cernere in catenipora, quam caryophylliam tubulosam, aperturis ovalibus munitam, ad latera conjunctam, ita ut anastomosas lamellas exhibeat.

Quoad locum, qui cateniporce tributus vel tribuendus est, distinctione egemus; vel loquimur de methodo invecta a Lamarck, vel de dispositione inducta a Blainville, vel de ea, quæ eidem contingere potest. Inter polyparia foramina Lamarck cateniporam posuit, quod tamen ipsi definitioni adversatur, quam habemus sub initio de polypariis foraminibus præditis.

Nam dum definit hæc polyparia, ait, ea lapidea esse, solida, interius compacta, cellulis perforatis vel tabulosis, lamellis destitutis : præterea nulla ratione concipere possumus cateniporas cum 
milleporis, cum lunulite, convenire quarum alia prorsus est indoles: nulla itaque majori interpretatione egemus, unde rejiciamus hanc partitionem a generis auctore excogitatam, quæque non posset quin confusionem gigneret, alioquin solertissime vitanda.

Potiori ratione Blainville cateniporas comparavit stylinis; nec non syringoporis; et ne quis defendat cum meandrinis potius aptari; nam licet adsit tubulorum connexio, tamen videndum an id cæteri characteres permittant. Alia ratione resolvi hæc quæstio non potest, quam definiendo, utrum reapse invicem interius tubuli cohæreant nec ne, si tanti momenti decisio deficiat, nihil erit, cur Blainville opinionem deseramus. Hoc etiam discutiendum superest, num unaquæque cellula proprium receptaculum cujusque polypi constituat, an vero systema plurimum stellarum uni polypo conveniat.

Certum in primis est, exterius non adesse foramina, quæ quis in catenipora conspicere contendit, hinc constitutio hujus generis mirifice cum sarcinulis convenit; verumtamen stellas usque nunc desiderabamus in cateniporis, qua ratione motus Lamarck, et qui eum secuti sunt, cateniporam tubiporis adjudicavere, quibus reapse magis pertinere, quam pertineant ad sarcinulas, ex tubulorum natura ducebatur. Regerit tamen Blainville, atque suam opinionem confirmaturus ait; se eo denique pervenisse, ut lamellas ad radiorum similitudinem compositas conspererit in cateni- 
pora apud collectionem mirificam zoophytorum D. Michelin.

Ubi vera thesis, nec mea obstat opinio, qua pono flectuare inter sarcinulas et tubiporas; hoc statuto enim cateniporam accedere sarcinulis, accedit et astreis et aliis; semperque verum est, fluctuare cateniporam, nec satis demonstratum fore cui tribuenda generis affinitas: sane in jure inter duos quorum unus neget, alter affirmet, quin aliquid probent, neutro fidem adhibetur.

Notare quoque debemus sulcos, quos extus adesse putat Blainville, reapse non existere; qui enim sulci prima fronte videntur, nihil aliud sunt quam irregularis textura ipsarum lamellarum, nisi vicem sulcorum gerant, ex hujus scriptoris sententia, quæ adsunt interstitia inter polyparii cellulas; imo affirmarem aliquando sulcos adesse, qui non longitudinales, sed transversales sunt.

Non dubitamus denique asserere communicationem deficere inter polypos nisi in ima parte, quod etiam probe notandum; lamellas internas itidem adesse modo tenues, modo potiores, quæ interius ad latera sunt adnexæ: sed an hæc lamellæ simul in uno centro jungantur, nec $L a-$ marck, nec Milne-Edwards, nec ipse conspexi, nec ii ex germanicis scriptoribus, qui zoophy tologice nomen dederunt: hæc quæstio igitur sub judice adhuc est, si cateniporce a sty-linis recedunt, multoque magis nilil commune cum caryophy lliis habent. 
Manca ceteroquin definitio est quam naturalis historiæ dictionarii auctores tradiderunt de catenipora; tota enim quanta est hujus generis vis atque distinctio repetenda dubio procul a laminis in reticulum anastomosantibus, unde Lamarck, vocibus atque definitione utar.

In calcari insulæ Gothlandice, calcari carbonifero teste Hisinger respondente, habemus cateniporam escharoidem, axillarem, struem, serpulam, et fascicularem; eas in zechstein usque nunc non invenerunt: quin imo in oolite cateniporce memoria deficit. Species denique ad ætatem superiorem pertinentes, quas invenimus, eæ ad strata supracretacea referuntur.

Mirum sane videtur de genere deperdito sermonem instituere, nec alia auloporce conditio est, singularis providentice dispositio nullis circumscripta limitibus, mira semper tum in is documentis, quæ sub nostris oculis posita: tum iis, quorum præterlapsam memoriam habemus, vel nunquam assequi possumus.

\section{CATENIPORA LABYRINTHICA} GOLDFUS

Tubis tubiferis, contortis, plicato-anostomosantibus, maculis labyrinthiformibus; tubulorum ostiolis ovatis, scabris.

Knorr. Petrf. i tab. 9. fig. 4.

Esper. Zooph. foss. tab. 5 fig. 2.

Goldfus. Petref. Germ. pag. 75 tal. 25 fig. ว.

Blainville Manuel. d' actinol. pag. 352 . 
Fischer. Orytt. de Moscou. tab. 38 fig. I.

Milne-Edward. Auct. de Lamarck. tom. 2 pag. 322.

Volkmann. Siles. subt. pag. 118.

Labyrinthicam formam ad hanc speciem pertinentem impedimento est, quominus confundatur cum catenipora escharoide; præterea licet, et tubuli seriati dici queant in utraque specie, tamen paralleli dici nequeunt; de ostiolis nulla quæstio, nisi quod in catenipora labyrinthica scabri sint.

Habitat... Reperitur in Italia et prope Groningen, Caen, in insula Drummondi et alibi.

CATENIPORA PULCHELLA

мовіs ( Tab. 5 fig. 4.)

Lamellis angulosis, tubis elongatis, parvis, confectis; osculis ovalibus, extus porosis, interius lamelliferis.

Quum agimus de hac catenipora, patet nostræ definitionis vim repetendam esse, ex eo quod labyrinthi formes non sint laminæ, sed distinctas angulorum sectiones demonstrent, atque oscula minuta atque conferta sint: prius argumentum a $c a$ tenipora labyrinthica, alterum a catenipora escharoide eam secernit.

Habitat... Reperitur in locis supra citat. CATENIPORA ESCHAROIDES

\section{LAMARCH}

Catenipora tubulis longis, parallelis, seriatis, subdepressis, in laminas anastomosantes connexis; osculis ovalibus, interius crispato stellatis.

Linn. Amænit. accad. I pag. 103 tab. 4 fig. 20,

Esper. Zooph. pl. 5 fig. I. 
I 64

Lamarck. Histoir. invert. cit. tom. 2 pag. 322. Parkinson. Organic. remains. tom. 2 pag. 20.

Schlotheim. Petrif. pag. 366.

Goldfus. Petrefac. germ. pag. 79 tab. 25 fg. 4 .

IV ahlenlerg. nov. act. accad. Upsal. tom. 8 pag. 99.

Fischer. Orrytt. du Moscou. tab. 38 fig. 3.

Volkmann. Siles. subt. tab. 2o. fig. 3.

Circa cateniporam escharoidem notat Blainville in hac unica specie quiescere genus de quo agimus; tamen tam catenipora escharoides, quam supra recensitæ species vere pertinent ad genus singulare, de quo agimus.

De catenipora axillari, gravis est quæstio, eam, ut memoriæ proditum est, nomine madreporce liliacce veteres cognovere, atque Goldfus referre studuit ad novum, quod composuit genus nomine auloporce serpens. Stetisset utique hæc nova dispositio, nisi jam antea memoratum foret a Lamoroux genus alecto, cujus in dispendium vertere procul dubio aulopora debuit. Non inficiar cateniporam axillarem in genere, quo posita fuit a Lamark, consistere non posse, eam tamen ad auloporan pertinere tum ex generis, tum ex speciei definitione contendam.

Habitat . . Reperitur prode Eifet, in Norvegia, in insula Drummondi, prope Ratoska in stratis pertinentibus ad grauwachen, et prope mare Balticum in stratis diluvianis. 


\section{PORITES}

LAMARGK，BLAINVILLE, EHREMBERG.

Polyparium lapideum, fixum, ramosum vel lobatum, obtusum; externa superficie undique stellifera; axe centrali.

Stello regulares, subcontiguce, superficiales, aut excavatc; margine nullo, aut imperfecto; lamellis filamentosis acerosis, vel cuspidatis.

De porite acturi non leves quæstiones oriuntur tum de characteribus, quibus insidet memoratum genus, tum de is generibus, quæ aliquam exhibeant ipsius poritis formam, vel speciatim, vel generatim eorum inspecta natura.

Ea quæstio, quæ oriri potest circa polyparia lamellifera, si alia ab aliis generatim sejuncta conspiciantur, ut, puta, si de meandrina, atque de monticularia, de astrea agatur, ea reviviscit circa polyparia, quæ constituunt poritem, oculinam, madreporam, explanariam; imo affirmarem, vel ipsam polliciporam difficultatem ingerere. Multum tamen interest, agatur ne de pollicipora fossili, an viventi: fac eam, quin ad vetustiora provocemus, reperiri in zechstein, deinde, an valeas polliciporam cognoscere, nesciam. Attamen, neque eo nobis perventum est, ut de hac ætate loquamur, sed candide quoque fatemur evenire quandoque posse, ut ex alicujus depositi indole lateat polliciporce natura; puta si de marna, si 
166

de calcarea connexione agatur, quæ eadem ratione qua testaceorum, multo magis minutorum pororum polyparii examen impedire potest; hujus rei exempla subsunt in Gallia, in colle Taurinensi, et in agro Veronensi (1). Quod de pollicipora, ad poritem, aliasve species polypariorum, transferre commode possumus.

In porite plura concurrunt, quæ eidem abunde consulunt: ad hanc rem notandum siquidem est, externam superficiem undique stelliferam, stellæ regulares, subcontinuas, marginem imperfectum adesse; lamellas reperiri acero-filamentosas, vel cuspidatas. Non itaque agimus de oculina, cujus est rariuscula oscula habere, ubique sparsa, ut Pallas, et Esperi verbis utar; cujus lamellarum indoles differt $a b$ indole lamellarum, quæ conspiciuntur in porite; deinde licet regulares stellæ sint tum in porite, tum in oculina; tamen ejusdem dimensionis non semper sunt in oculina, quemadmodum sunt in porite hirtella, atque virginea. Adest et alind discrimen positum in eo, quod oculina sit ramosa; contra in porite, in qua placuit adesse madrepora arenacea Esperi atque Ehrembergi, in qua comprehensa fuit madrepora solida Forskalii (2).

Pro certo itaque est, oculinam licet, quoad axem, quoad stellarum figuram, et pluries quoad

(1) Mém. sur les terr. du Vicentin. Par A. Brogniart.

Saggio di Orrit. piem. Auct. Borson.

(2) Icones rerum natur. Copenhague ${ }_{7726}$ 
ramorum dispositionem conveniat cum porite; tamen aliis inniti documentis, ac innititur genus, quod investigandum suscepimus.

De pollicipora jam notavimus vel ob id, quod innumeris poris sit munita, quod stellæ neque æquales, neque seriales sint, imo quod vel ipsæ stellæ immersæ atque profundæ videantur, distare a porite. De madrepora quoque dubium sustulimus, dum de pollicipora egimus, in qua mox notabam concurrere poros, et irregulares stellas ; licet ceteroquin et hoc peculiare adsit, quod margines stellarum aliquando sint prominuli, uti exemplum habemus in madrepora abrotanoides, atque interstitia diversam præseferant indolem.

Cum seryatopora conjungi posse poritem ne quis putet; nam, cum in hoc tantummodo insideat præcipuum seryatoporce fundamentum, quod cellulæ sint seriis transversis, aut longitudinalibus ordinatæ, nec ideo similitudinis rationert adesse credimus. Mirum itaque videtur, quod asserit Lamarck dubitare, an stellas reapse exhibeat seryatopora, quemadmodum demonstrarunt auctores ipsi, quos citavit ipse Lamarck, cujusmodi est Esper, qui et tabulis, et descriptionibus ostendit, non modo externam superficiem seryatoporce stellis ornatam, verum etiam cujusvis stellæ formam (I). Hoc etiam indicavit

(I) Esper. Suppl. 1. pag. xo9. tab. x9. 
I68

jam antea Pallas (I) dum describit, madreporam seriatam preditam esse poris stellaribus, longitudinaliter seriatis, idque ad ipsius Linncei exemplum. Est tamen aliquid, quod concedere debemus huic distinctioni; et sane forma seryatoporce haudquaquam convenire potest cum porite, licet utraque species poros habeat ad eundem modum compositos; deinde tota quæstio etiam resolvitur quoad axem, non ejusdem naturæ in uno ac in altero genere. Non inconsulto itaque, non immerito Milne-Eldwards notat seryatoporis convenire tributos characteres (2).

De porite, quæ invenitur in statu fossili, si Flemming excipias, qui unam speciem memoravit, in Anglia repertam, a Parkinson allatam (3), cujus æetatem haudquaquam perspectam habeo, nemo de ea disserendum ex professo suscepit. Videamus potiores species, quæ diluvianam præseferunt rtatem.

\section{PORITES ACULEATA}

$$
\text { мовіs ( Tab. } 6 \mathrm{fig} \text {. I) }
$$

Porites, explanata, undato-gibbosa, stellis contiguis, angulosis, concavis, pistillo prominulis; margine crenato, immarginato.

Diu dubitavi, an hæc porites referretur ad jam

(I) Pallas. Elenchus zooph. pag. 336. n. rg8.

Gmelin. System. natur. pag. $3780, \mathrm{sp}, 102$.

(2) Milne-Edwards. Auct. ad Lamarck cit. tom。2, pag. $48 \mathrm{I}$.

(3) Parkinson. Organ Remains. tom. 2. tab. 5. fig. 9 . 
cognitam speciem, sed omnibus perpensis, quæ pertinent ad jam descriptas species, nec unam inveni, quæ hujus speciei nomen mereretur.

Tres enim sunt species inter porites, quæ quamdam similitudinem exhibent cum porite aculeata; nimirum porites verrucosa, porites tuberculosa, et porites arenacea. At, si verum amamus, non cerno in hac specie poritem arenaceam, quia in arenacea stellæ sunt superficiales, et perparvæ; præterea sunt rotundatæ, et prominulum centrum non habent.

Porro eadem stella impedimento est, quominus hanc speciem addicam poriti verrucosce, cujus est, ut ait Lamarck, stellas exhibere sejunctas : præterea varietas interstitiorum non leve addit discrimen.

Exiguæ stellæ arcent quoque hanc poritem a porite tuberculosa, quin insuper, vel ipsa interstitia, qux: tuberculata sunt, videlicet munita tuberculis echinatis, prominulis, columniformibus aperte indicant de alia, atque alia specie agi.

$\mathrm{Ne}$ quis demum, hanc speciem confundat cum madrepora pistillata, quam Esper memoravit ; nam porites pistillata non explanata, sed ramosa est, deinde pistillum in medio erectum stellarum superficiem excedit; contra in hac pistilla sunt utique prominula, sed relate ad stellarum marginem sunt profunda; quoad creteras porites, quarum fit mentio, secernendæ in primis sunt, quæ crespitosæ videntur, quibus deductis, nec 
aliquid erit unde oriatur confusio.

Habitat ... Reperitur in Delphinatu: collectio Michelotti (ex dono equit. Vesin).

\section{PORITES COMPLANATA}

\section{LAMARск. мовіs (Tab. 6 fig. 2)}

Porites in laminam partim liberam explanata; superna superficie subundata, stellifera, stellis exiguis, non continuis, immarginatis; interstitiis scabris.

Lamarck. Hist. anim. invert. tom 2 pag. 439.

Blainville. Manuel d' actin. pag. 396 .

Nec deficiunt, dum de complanata porite verba facimus, documenta, quibus ad alias species eam provocare possimus : adest nimirum conglomerata, adest arenacea, nec furcatce omnes proprietates desideramus.

Sed ubi quis attendat, ad priorem speciem pertinere aliam stellarum formam; adesse nimirum in porite conglomerata stellas angulatas, contiguas, aceroso-cuspidatas, atque lamellas granulatas, ut Esper verbis utar, distinctio utriusque speciei non latet: adde quod ramosa sit madrepora conglomerata; contra porites complanata non item.

De arenacea acrius disputatur, nam vel ob id, quod minutæ stellæ, eæque subconcavæ sint; atque tam porites arenacea quam porites complanata præbeant margines superficiales, deinde quod ambæ species explanatæ sint, non injuria quis satageret duas in unam speciem concurrere. 
Sed contiguæ sunt stellæ in arenacea; in porite complanata non item : porites complanata licet in massam explanatam se se extendat, tamen nec incrustans dici potest: in porite complanata stellas ex utroque latere habes, non item in arenacea; ergo conjunctio utriusque speciei cessat.

Numquid idem dicendum de porite furcata?

Circa hanc speciem notamus, eam tantummodo cæspitosam esse, nec propterea lobatam; stellas contiguas habere.

Habitat... Reperitur iu Gallia, et in colle Taurinensi, et alibi.

\section{PORITES CLAVARIA}

\section{LAMARCK}

Porites dichotoma ramulosa; ramulis crassis, subclavatis, obsolete compressis; stellis latis, sparsis, contiguis, superficialibus.

Imperato. Hist. natur. 802. fig. 814.

Moris. Hist. 3. sect. 15. tab. 10. fig. 12.

Linn. System. natur. pag. 1279. spec. $3 \mathbf{r}$.

Pallas. Elenchus zoophyt. pag. 324 (madrepora)

Esper. Zooph. vol. 1. pag. 133. tab. 2 I.

Lamarck. Histoir. anim. invert. tom, 2. pag. 435.

Blainville. Manuel d'actin. pag. 396 .

Ehremberg. Zoophy. maris rubr. pag. 117.

Jamdiu cognitam fuisse hanc speciem testantur Imperato, Pallas, Esper, aliique; optimam figuram præbuit Lamouroux, quin Lamarkii descriptioni aliquid adjiciat, vel detrahat.

Habitat in mari rubro, in Indiis, nec non 
I 72

America ... Reperitur prope Veronam, et in colle Taurinensi.

\section{PORITES ORNATA \\ Nовіs ( Tab. 6 fig. 3.)}

Porites dichotoma ramosa, ramis brevibus; stellis contitiguis, parvis, multilamellosis ; lamellis supra marginem productis; margine agelatim disposito, pistillo immerso, rotundato.

Non est cur dubites de nova hac specie, quam probabiliter pistillatce Esperi; furcatce Lamartii; subdigitatce, atque elongatce ejusdem, similis videri potest.

De porite pistillata animadvertimus, pistillum elatum, neque rotundatum esse, minutas stellas, easdemque haudquaquam angulosas. Poritem autem furcatam cum porite pistillata convenire, atque ideo toto coelo a porite ornata distare, demonstravit Ehremberg, confirmavit Schweiger. Lamellæ stellarum, earumdemque centrum, non patiuntur, elongatce poritis, cum porite ornata conjunctionem sequi. Non absimili ratione, addendo interstitia echinulata, quæ habemus in porite subdigitata, defendimus novæ speciei notas. Potior est quæstio circa vim, quam exerit novum genus inductum a Blainville sub nomine syderoporce; atque sic definitum, ut contineat porites, quarum stellæ sunt concavæ, rotundatæ, subexagonales, præbentque sex sepimenta, axem pistilliformem; unde oritur polyparium palmatum, granulatum, sed absque poris. Poste- 
rior nota necessaria videri debuit, ne scilicet cum seryatoporis confunderet novum genus; aut aliquid eidem deduceret ad illud confirmandum atque amplificandum.

Meo tamen infirmo judicio, minus apta videtur memorata distinctio, et hoc genus cum stylipora conjungere non dubito; tota enim quanta est differentia, ponit in centro stellarum, in poris atque lamellis, quarum diversissima in variis speciebus est indoles, nec propterea constans, neque sufficiens ad genera constituenda. Pistillorum varietas, probe investigando, uti et pororum, ad tantum discrimen inducendum minime apta est.

Habitat ... Reperitur in colle Taurinensi (frequens. )

Mus. Taurin. coll. Morelli, Rochetta, Bellardi, Michelotti ( uti supra recensitæ). 
LAMARCK, LAMOUROUX, EHREMBERG.

Polyparium lapideum, scepius fixum, ramosum, dendroideum; ramulis levibus, sparsis, plerisque, brevissimis. Stella aliæ terminales, aliœ laterales, non prominulœ, ramorum centris excavatis.

Quamvis Lamarck referat maximopere inter se convenire caryophyllias et oculinas; tam cum poritibus, cumque seryatoporis aliisque hujus generis magis conjunctas esse oculinas, nemo non videt; nam non hoc unum respicimus in oculina, num habeat stellam terminalem, quemadmodum in $c a-$ ryophylliis? sed insuper notamus stellas, quas conspicimus in caryophylliis totum axem, ramumque occv:pare. Præterea animadvertendum, hoc caryophylliis convenire, quod sulci longitudinales conspiciamus, totam superficiem exarantes, unumque centrum cognoscamus in eadem, quod tot ramorum seriem regerit, atque sustinet. Videamus modo, quibus notis sejungatur oculina a porite, atque ab aliis generibus. Primum distinctum argumentum habemus in eo quod oculina semper ramosa est; imo in plerisque ramosissima: deinde stellæ ipsæ raro sunt prominulæ, numquam in seriem dispositæ, quemadmodum in millepora lineata (I), in cricopora annulata (2),

(1) Esper. Zooph. Suppl. 1. tab. 19.

(2) Blainville. Manucl. d'actin. pag. 42x. 
inque spiropora tetrugona ( 1 ): deinde oculina nunquam porosa est, quemadmodum proprium poritis est, atque omnes ramuli centrum proprium habent, nec cum præcipuo confundendum. Hoc centrum videtur excavatum, contra illud quod observamus in cæteris generibus: nihil igitur supererit miri, si hoc genus servandum esse contendam.

Quoniam vero de cricopora sermonem habere instituimus, juvat Milne-Eldward opinionem referre, qui putat cum spiropora declinandam fore, notum autem est Blainville prius, Lamouroux posterius genus instituisse.

Primum autem ramorum dispositiones aliquo modo in hisce generibus conveniunt; præterea sive attendas figuras, quas retulit Lamouroux, sive rationum momenta ab eodem allata, dum suum genus composuit, fallere non potest de eodem genere utrumque sensisse.

Ait Lamouroux de spiropora, polyparium cognovisse lapideum, ramosum, poris munitum, linea spirali dispositis, raro transversalibus; cellulas itidem extus productas habere, tubulosque componere parallelos, gradatim attenuatos; in lineam spiralem exitum habere; aperturam cellularum rotundatam esse. Idem ferme ait Blainville, additque nihil aliud, quam cylindricos ramos adesse, tenues alveorum formas exhibentes. Non injuria itaque hæc componit Milne-Eldwards, ita tamen

(x) Lamoroux. Exposit. méthod. pag. 85. 
176

ut, inversa vice ac ille usus fuerit, spiroporam, quam cricoporam Blainville dixit, salutemus.

Oculince genus, quamvis effusum, tamen paucas continet species; unam enim in meditcrraneo habemus; ceteræ inveniuntur Indiis, aliisque plagis, quibus magis quam vehemens, continuus favet æstus.

Plerique putant in oculina prolifera hujus generis nec dubias notas adesse; de quo dubitare licet; nam in hac specie deficiunt, quæ præcipuam rationem generis oculince constituunt; vi cujus requiritur, ut stellæ laterales sint, atque centrum excavatum, quod desideratur in hac specie. Nec me movit, quod sulci in externa facie non adsint; nam stellæ hujus speciei differunt quoque ab iis cæterarum oculinarum quoad amplitudinem, et marginum dispositionem : preterea ramorum dispositio multo magis accedit hanc speciem ad caryophyllias, quam ad oculinas: sane, si hæc species recensetur inter oculinas, et madrepora anthophyllites, ab Esper memorata, excludi nequit.

\section{OCULINA ROSEA}

\section{pallas. nobis (Tab. 6 fig. 4)}

O. pumila, ramosissima, rosea; ramis attenuatis, stellis minutis incequaliter sparsis; aliis lateralibus sessilibus; aliis terminalibus.

Pallas. Elenchus Zooph. pag. 3 i (madrepora)

Solander et Ellis pag. 155.

Esper. Zooph. suppl. 1 tab. 36. 
Muller. Zoolog. Dav. prodr. pag. 252.

Blainville. Man. d'Actin. pag. 38r.

Lamark. Histoir. I et 2 edit. tom. 2 pag. 458.

In oculina rosea, ait Pallas, cernere est corallium pulcherrime roseum, solidum, teretiattenuatum, dichotomum, ramosissimum. Regerit præterea, habere poros prominulos, in extremis ramis crebriores, ubique sparsos, rariusculos, passim in agminula congestos. Verruculæ sunt, ex ejusdem scriptoris doctrina, passim convexæ, agminatæ, stellis intermixtæ, cavæ.

Ex his liquido patet, hanc speciem confundendam non esse cum oculina virginea, cujus est in primis, ramos tortuosos habere, deinde stellas alias esse immersas, alias prominulas, et lamellis inclusas: neque etiam confundi potest cum oculina hirtella, quæ possidet omnes stellas prominulas, echinulatas, atque lamellas exertas.

Proxima oculince hirtellce est oculina diffusa, quæ quidem, infirmo meo judicio, illius varietas tantummodo est ; nam quod sit ramosa, dichotoma, diffusa, hoc utrique speciei convenit: stellas quoque tradunt prominulas, echinulatas esse in oculina diffusa, lamellasque exertas. Superest itaque, ut videamus, quibus notis consistat $L a-$ marckii divisio. Non potest in caule consistere : erit ne in centro papilloso? haudquaquam, nam centrum papillosum est æque in oculina hirtella, ac in oculina diffusa. Tota igitur quæstio, seu distinctio fundamentum habet in lamellis serru- 
latis: at neque hæc nota sufficit; nam si diligenter perpendamus stellas, in oculina hirtella eæ serrulatæ sunt. Jamvero, quemadmodum hæc distinctio non sufficeret in oculina virginea, ac in oculina rosacea, æque corruit, quum agitur de aliis speciebus.

Multo minus nostra species convenit cum octlina axillari, qure ita nuncupata, ex eo quod stellas habeat terminales, et axillares : terminales, inquam, stellas, licet cæteroquin non deficiant axillares; nam alioguin in caryophylliam ferme impingeret.

De oculina echidnea aliud dicendum nobis est, quum peculiaris hujus oculince natura demonstret eam disjunctam esse a cæteris speciebus: certum enim est cylindros spiniformes in hac specie concurrere. Præterea quod ramuli e trunco præcipuo minuti, æquales ferme prodeant, mirum alicui videri non potest; at multum interesse, sedula investigatio docet.

Attendamus insuper, quod circa hanc speciem de qua primum sermonem habuit Korr; ( 1 ) uti postea Esper (2) stellæ plerumque terminales sint, quod in oculina prolifer a adnotavimus. Optimo itaque consilio. Ehrembeg in suo opere, peculiare nomen eidem asserere non dubitavit, unde miram hanc speciem, ab aliis, potiori nota di-

(1) Knorr. Delic. natur. tom. 1, tab. a. 11, figg. 2.

(2) Esper. Pflanzenthien. tom. 1. pay. I 5 . 
stingueret ( 1 ).

Quod attinet ad oculinam infundibuliferam notum est, eam esse ramosissimam, subflabellatam; præterea ascendere in ramulis ultimis minimis, flexuosis; marginem crenulatum habere, proindeque disjunctum ab oculina rosacea.

Circa oculinam flabelliformem varia quoque adjuncta concurrunt, unde recipi atque defendi possit; nimirum, magis stelliferi sunt posteriores ramuli, ut et minutissimi, stellæ quoque sunt minutissimæ interne striatæ, sicuti in oculina infundibulifera. Ne silentio præteream rationem posterioris speciei, duo tantummodo notabo.

Primum, hanc oculinam nomen retinere debere ab Esper eidem impositum; alterum est inepte judicasse Lamarck, Esperi speciem usitatam, atque obliteratam esse; nihil enim clarius Esper iconibus consignare poterat.

Habitat in Oceano Americano ... Reperitur in colle Taurinensi, et in Sardinia.

Mus. Brittan. Paris., Berol., Lugd-Bat. (viv). Mus.Taur.coll.Barelli,(2)Rochetta,Bellardi,Nob.

(I) Ehremberg. Polyp. maris rubri. pag. III.

(2) Collectio d. Barelli prestat ex curis quas continuo impendit in in ea aquirenda geologica documenta eidem August. Regis jussu concredita; habemus quoque ejusdem opus cui titulus "cenni di statistica min. degli Stati Sardi " ita dispositum, ut cujusvis, hujus regionis descripta appareant, geologica strata atque divitix; ita ut, hoc opere duce pedetentim vel domi, vel peregrinando, jam antea perspectas habeas quas quæris geologicas opes. Tam magni momenti scripturam, apud omnes ferme etiam cultiores gentes jamdiu desideramus. 
180

\section{OCULINA VIRGINEA}

\section{Linn. повіs (Tab. 6 fig. 5 ).}

Oculina ramosissima, subdichotoma, solida ; ramis tortuosis, coalescentibus, stellis sparsis, aliis immersis, aliis prominulis; lamellis inclusis, integris, granulatis.

Gesner. De anim. et fig. lapid. pag. 132, n. 2.

Imperato. Storia nat. pag. 623.

Petiver. Gazop. tab. 76. fig. 8.

Linn. System. natur. sp. 40 (madrepora)

Pallas. Elench. Zooph. pag 3 го. n. 180

Esper. Pflanzent, tom. I pag. I 13

Lamarck. Histoir. anim. cit. vol. 2. pag. 455.

Ehremberg. Pol. pag. 78.

Optimæ notæ scriptores Lamarck, atque MilneEdwards non dubitant asserere, ad hanc speciem pertinere madreporam oculatam Linncei atque Esper: at ha dure species toto cælo distant; hinc, ut sileam, vel apud veteres oculinam virgineam dictam fuisse corallium virgineum, quum oculinam oculatam dixerunt corcullium album officinarum, diversam, quam exhibent hæ duæ species naturam, impelimento est, quominus simul eas confundamus.

Nam in madrepora oculata stellæ sunt rariores, atque planæ, contra in madrepora virginea auctorum ex stellis aliæ sunt prominulie, aliæe planulatæ; deinde hæ regulares sunt in madrepor'a oculata. Quid? madrepora oculrata, non adeo ramosa est ac madrepora virginea. Neque ex solius Esper auctoritate id affirmarc audeo, sed et Pallas qui 
jam pridem hanc admisit distinctionem addens priorem vix palmi magnitudinem excedere, contra, posteriorem multo altius erigi.

Habitat mare Mediter. et American.

Reperitur in colle Taurinensi (fiequens).

Mus. Paris. Brittan. (viv.) Mus. Taurinensi, collectio Bellardi, Rochetia, Mi.helotti (foss).

OCULINA SOLANDERI

DEFRANCE

Polyparium ramosum, dichotomum; stellis minutis sparsis, striis longitudinalibus exaratum.

Defrance. Diction. des scienc. natur. tom. 35 pag. 355 . Milne-Eldwards. Auct. ad Lamarck. tom. 2 pag. $45 \mathrm{~s}$.

Habitat ... Reperitur prope Chaumont et Gisors in Gallia. 


\section{MADREPORA}

\section{LINNIEUS, PALLAS, ESPER.}

Polyparium lapideum, fixum, subdendroideum, ramosum; superficie cellulis prominentibus, undique muricata, interstitiis porosis.

Celluloe sparse, distinctee, cylindraceœ tubulosee, vel exarata, stellis subnullis, lamellis perangustis.

Dubium non est, quin, præter Linnceum vetustiores extiterint scriptores, qui madrepora nomine usi sunt, primam tamen ad generis traductionem Linnceus tradidit, dum in systema naturce, cavitates lamelloso-stellatas, atque poros, notabat in suo corallio; licet postea in alio suo opere, quam sibi proposuit, violaverit divisionem, dum muricatam madreporam, eam milleporam vocarit. Qua in re multo accuratior Pallas et madreporce, et milleporce limites signavit. Quum tamen intersit penitius germanici scriptoris opinionem investigare, breviter potiora attingam.

Docet itaque, primum Peysonellum mostum exemplo aucloritateque veteris Imperato defendisse madreporas, (ita dictas, ut ait Esper quasi porortum mater ) constare ex polyporum industria: pergit atque divisionem madreporarum constituit, quarum aliæe simplices, in hoc censu fungites, madreporasque trochiformes, verrucurias auctorem, reponit. Deinde recensit madreporas concatenatas, quas ita eflingit, ut in primis raras postca 
multiplices inducunt facies : inter has species numerat madreporam agaricitem.

Meandrinas autem in tería classe reponit.

Nota autem, quod refert de mycedia Brownii et Hill, rotundatam faciem ex eo procedere quod ambitus lentius dilatetur; in medio autem polyparium crassitie crescat; cernere igitur hic est explicationem methodi nuper indutæ, ope nempe vitalitatis ipsius polyparii.

Memoratus auctor rejicit Peysonelli (1) doctrinam, qui ex gregariis polypis reputans consistere astroites, affirmat, verruculas primum adesse, deinde Iateralem conspici prolem, quod cum postremum verissimum sit, priorem tamen non excludit sententiam.

Eadem nec rerum nec animantium relatio, sed agendi ratio induxit Esper, qui (2) ulteriori investigationi parcens, musicalem atque organum sarcinulam inter madreporam stellarem, atque caspitosam collocavit, atque fungiam madreporce pilece addixit.

Facto itaque eo res erat, ut insignis Galliæ scriptor madreporce nomen, quod latissime patebat uni generi tribueret; quod ipse egit, dum nomen illis speciebus servavit, quæ exhibent polyparium lapideum, fixum, subdendroideum, dum ramuli ex præcipuo trunco dimanant, cujus rei clarum exemplum præbet madrepora corymbosa.

(1) Peysoncllus. Actus. Angl. vol. 42. art. 75. pag. 467 .

(3) Esper. Zooph. tom. 1. pag. 65. 
Poros tamen, qui adsunt inter cellulas summam præbere eandemque optimam notam asserere non dubitamus ad dijudicandum hoc genus; stellas itidem inspicere oportet in ipsis cellulis, quæ non ejusdem sunt indolis, ac sint eæ, quas habemus in oculina; at ehic potius constant ex dispositione lamellarum, quæ inter se adnexæ non sunt, atque interstitiis gaudent invicem perforatis, ex quibus, internæ membranæ ipsius polypi status, atque relatio, cum ipso tegumento polyparium constituente, pendet.

Unde pocilloporce constitutio, tanquam genus corruit, quemadmodum perbene notavit Goldfus.

Madreporas in grawache reperiri ex geologiæ scriptoribus eruimus; in stratis carboniferis extitisse, hujus rei fodince in Anglia excavatæ demonstrant. Modo autem recens scriptor Sedgvich, notat in Northumberland, et alioquin detectam fuisse: pari ratione eum in Westphalia, prope Maestricht collegerunt, sed, quæ nam species propriæ sint huic, vel alteri formationi vel stratis, de hoc altum silentium servare malunt.

Non ignoro, Defrance definivisse madieporam limbatam, atque coalescentem; at præterquamquod de illis vehementer dubitat Milne-Eldwards, certe ad supra cretaceam atatem se se non referunt. Quas duas detegi in colle Taurinensi, et prope Veronam, indicabo. 


\section{MADREPORA ABROTANOIDES}

\section{tounnefort, Nobis ( Tab. $6 \mathrm{fig} .7$ )}

Madrepora ramosa, erecla; ramis compositis, pyramidatoattenuatis; ramulis lateralibus brevibus, sparsis, crebriusculis; cellulis sursum spectantibus; interstitiis verrucato-porosis.

Aldrovandi. Mus., metall. pag. 278 .

Moris. Histor. plant. tom. 3. pag. 656.

Tournefort. Institut. pag. 573 (madrep. abrotanoides).

Marsigli. Hist. mar. pag. 154 tab. 35 n. 1 jo.

Pallas. Elenchus zooph. pag. 327 .

Esper. Supp. 1 tab. 54 et 54 a

Lamarck. Histoir. anim. tom. 2. pag. 448.

Lamoroux. Exposit. method. des polyp. pag. 63.

Circa figuras exhibentes hanc speciem non bene convenit inter scriptores; nam quum ex hac specie, prout eam veteres accipiebant, alias composuerint, difficile admodum est videre, quid madreporce abrotanoides nomine servaverint; hoc adeo verum est, ut Lamarck conveniat cum Pallas dum uterque Morisonii figuras, auctoritatemque provocat; jamvero madrepora abrotanoides nihil aliud est, quam madrepora muricata Pallas, et Esper, quam novo nomine plantagineam dixit Lamarck. Sunt igitur duæ species unam reapse constituentes: ut autem plenius hoc eniteat, notamus ramos spiculiformes, margines incrassatos, rotundatos per se non sufficere ad novam divisionem inducendam, quum et in madrepora $a b$ rotanoide sæepius rotundati, incrassati margines, spiculiformes tubuli sint, hoc itaque suaderem, ut 
186

madrepora plantaginea et abrotanoides, unam speciem posteriori, vetustiorique hoc nomine constituant.

Habitat in Oceano Indico ... fossilis in colle Taurinensi (frequens) prope Veronam etc.

\section{MADREPORA EXARATA}

$$
\text { nовіs ( Tab. } 6 \text { fig. 6) }
$$

Madrepora ramosa, rotundata; ramis porosis; cellulis irregulariter sparsis, superficiem exœequantibus, lamelloso-stellatis; margine nullo.

Ubi interius madreporas inspicias, innumeras cellulas videbis, quas minuta diaphragmata circumdant; atque hic ordo adest a centro ad superficiem exteriorem ipsius polyparii. Alia verumtamen transversalia sepimenta adsunt, quæ idcirco circumscriptas reddunt cellulas ipsas : hæc respondent cellulis illis, quas videmus in externa facie ipsius polyparii, neque idcirco cum poris ipsis confundendæ.

Quod et in aliis, in specie, de qua agimus, hoc penitius inspicere potui. Quin imo stellam uti in centro oculince animadverti, in centro madreporæ conspexi; unde ni foret singularis pororum natura, quam in oculina, aliisque generibus desideramus, concluderem procul dubio, conjungenda esse hæc genera.

Habitat. . fossilis in colle Taurinensi (frequens). 


\section{U N UL I TES.}

LAMARGK, LAMOROUX, GOLDFUS.

Polyparium lapideum, liberum, orbiculare, uno latere convexum, altero concavum.

Convexa superficies radiatim striata; poris interstitialibus, minutis; concava rugis aut sulcis divergentibus radiata. Animal tentaculis in coronam infundibuliformem dispositis instructum ; mobilitate incredibili praditum ....

Ab eo singulari genere, de briozois agentes, ordimur, quod lunulites nomine venit; atque dubio procul ad flustras accedit hujus polypi natura, quemadmodum demonstravil Cavolini in suis memoriis. In flustra antem, atque eschara, Briozoa animantia agnovisse, locupletes sunt testes E/ remberg, atque Milne-Edwards ( $\mathbf{r}$ ).

Majora discrimina lunulitem inter, et alia genera ad duo summa capita refert Lamaick, quorum primum positum est in lineis concentricis, quxe adsunt in inferiori facie; alterum quia pori non adsunt nisi in uno latere. Attamen singula attendamus definitionis verba.

(1) Ubi certa demonstraretur Blainville opinio circa milleporas, tuto affirmarem cum eodem ex madrepora procedere conjunctionem atque discrimen inter antozoa atque Briozoa. Palmiporce enim quum cellulas minutas exhibeant, dissitas, profundas, atque lamellis instructas, eas ad madreporam et ilse quoque accederem. Pari ratione tentacula elongata, atque ciliata cellulis operculo præditis, dum myriaporas indicant et Eschare relationes demonstrant, optimam praberent rationem gradum faciendi ab Antozois ad Briozoa. 
Polyparium lapideum ... Nomen polyparii lapidei respondet divisioni, quam excogitaverat, multum nimirum interesse agatur ne de hoc tegumento lapideo, an corneo, et simplicem membranam constituente. Pergit et ait:... liberum, orbiculare, uno latere convexum, altero concavum ... jam avimadvertimus polyparium coalescere ex industria unius vel plurium polyporum.

Orbicularem formam, quam lunulites habet, vim maximam exhibere ad ejus characteres firmandos, dubitare non possumus. Concava superficies radiatim striata est, atque lineæ, vel sulci, qui apparent in lunulite frequentius quamplurimi sunt; aliquando tamen sunt rariores; item sæpius distincti; aliquando tamen obliterati: in eo tamen semper conveniunt, quia ex centro ad peripheriam vergant: de centro autem notare juvat, aliquando etiam oblongum esse, quemadmodum inversa facie couspicitur in cyclolite numismali, hemisphcerica, et elliptica.

Poris interstitialibus ... circa poros ii semper sunt rotundati, raro eleganter dispositi, ut in orbulite, universam superiorem faciem præumbrantes ... Convexa superficies divergentibus lineis radiata ... quod tamen, nec adeo semper verum est, ut exceptionem non patiatur; ex fossilibus enim, quos collegi, non omnes species hanc dispositionem præseferunt.

Circa polypum, putabat Lamarck, lunulitem reccnsendam esse inter polyparia foraminea, ex 
quo deducebat, deficientibus laminis, polypum, qui his receptaculis hærebat, tentaculis carere. Aliter sentiebat Blainville, qui declarare ausus est, a flustris non differre memoratum genus, atque ideo animal eadem natura donatum, commune utrique generi fuisse.

Utrique sententiæ acquiescere quis facile posset, ubi vel opus tantummodo, vel polypum inspiciat; sed quum satius sit in hoc argumento ex natura polypi judicare, recte quis cum Blainville assentire videtur; pori enim minimi, breves, recti, vel obliqui, sæpius contigui, aperturaque apicialis conveniunt æque lunuliti, ac flustræe, ergo consequens est, polypum, qui ædificavit lunulitem accedere maxime ad naturam polypi, qui flustram habital; licet alioquin solitaria lunulitis natura aliquantulum differat a polypariis, quæ flustrce, vel escharce nomine veniunt.

Potiora multo antea docuit Cavolini (1). Recenset enim vir omni laude dignissimus in suis Memoriis circa polypos maris, qui prope Neapolim vivunt, milleporam a nemine antea perspectam, ad imaginem lentis compositam invenisse, quarn milleporam cardoncello appellat. Hujus corporis, seu scheletri, uti loqui amat, basis membranam esse fatetur lapideo-calcareo compositam, rotundatam formam præseferre,

(r) Memorie de’ polipi marini di Filippo Cavolini cit. Napoli 1 ; 83 . pas. $7 \mathbf{1}$. 
diaphanam ( quod de viva lunulite facilius concipitur) lineis concentricis munitam, ita compositam, ut unum centrum habeat, unde triangula quamplurima producant. Denique poros interstitiales recenset, atque lunulites figuram præbet.

Agit idcirco de lunulite proprieque dicta: modo ad polypum accedens ait; animal hydræ affine, crusta calcarea undique obtectum, foraminibus munitum innumeris, exilissimis, unde exerunt capitula, seu ora cylindracea superne tentaculata; tentacula miræ tenuitatis, in coronam infundibuliformem disposita; sensu exquisito, mobilissimo motu retractili inter foramina.

Dum tamen Cavolini opus memoro, abs re non erit auctoritatem Allioni interponere, qui de sua madrepora Androsace ait, tribuo hoc nomen corpusculis quibusdam in colle Taurinensi obviis, quorum facies convexa est poris minimis, iisque communicantibus undique cribrata; concava vero sulcos tenuissimos, a centro ad peripheriam radiatos exhibet.

Circularis et aliquantulum dentatus est ambitus hujus fossilis, cujus diametrum linea una ad tres parisienses se extendit: crassities vix semissem linere æquat ... (vide Oritt. pedem. specimen. auct. Allioni. Parisiis. 1757 . pag. 16 et I7). Primus igitur insignis botanices cultor hoc genus fossile indicavit, quod invenit in colle Taurinensi; deinde in aliis locis repertum est, tum prope Maestricht, tum in Normandia, tum prope Kassel, 
et alioquin; cujus erit, consulat tum De-laBeche, tum Zeiten, tum Goldfum, pleniorem apud eos circa antiquiora strata hujus generis cognitionem consequetur.

\section{LUNULITES ANDROSACES}

allioni, Noвis (Tab. 7 fig. 2)

Lunulites latere concavo strïs radiata; superne convexa lineis circularibus, concentrisis, sulcisque longitudinalibus munita, poris adnexis.

Allioni. Oritt. pedem. pag. 16 (madrepora).

Lamarck. Anim. invert. tom. 2 (lunulites radiata)

Lamoroux. Exposit. méth. des polyp. pag. 44.

Goldfus. Petrefacta Germaniæ pag. 41.

Fischer. Bibliot. paleontol. pag. 344 .

Blainville. Manuel d'actin. pag. 449. tab. 75 fg. 5 .

Forma hujus speciei sæpe depressa est, lineæque minutissimæ, quæ conspiciuntur in superficie concava, pluries granulosæ videntur.

Convexa facies ea prodita est poris minutissimis interseptis a parvis sulcis, qui a centro ad peripheriam dispositi sunt.

Nomen quod primum assecuta est species, de qua agimus, eidem restituendum esse putavi.

Habitat ... Reperitur in colle Taurinensi, prope Grignon, Maestricht, Caen, et alibi.

Mus. Paris. Brittan. Berolin. Vienn. Collectio Morelli, Rochetta, Bellarïi, Michelotti. 


\section{LUNULITES PERFORATA}

MUNSTER

Lunulites cupeliformis, utrinque sulcis porosis interstitialibus radiata, cellulis orbiculuribus, inferne omnino apertis, superne orificiis centralibus pertusis.

Goldfus. Petref. Germaniæ, pag. 1 o6. tab. 37 fig. 8. Milne-Edwards. Auctarium ad Lamk. vol. 2 pag. 320.

Habitat ... Reperitur prope Kassel. Mus. Berol. Vienn.

\section{LUNULITES SULCATA} мовіs ( Tab. 7 fig. 3)

Lunulites depressa, latere altero radiatim sulcato, poris interstitialibus rotundatis; altero costis minutissimis exarato.

Gradum hæc species constituit ad oibulitem : notum est enim in orbulite concurrere poros regulariter dispositos, atque, ea dispositione sulcorum qui recensili sunt axi, carere. Illud insuper notandum orbulitem lenticulatam penes quam fundamentum habet genus de quo agimus, in quincuncem dispositionem pororum habere, quod profecto in aliis deest speciebus. Apparet igitur gradum adesse in orbulite ad lunulicm.

Inepte autem quis argumentum deduceret, ubi in concava superficie discrimen invenisse traderet; nam in orbulite eadem sulcorum dispositio est, unde etiam eruimus magis, magisque nostram probari sententiam, ex qua divisionem inter lunulitem et orbulitem, tamquam supervacaneam rejicimus. 
De hac specie tenendum est eam depressam esse, atque concavam superficiem poris invicem adnexis tectam esse, convexam autem habere sulcos longitudinales, quorum interstitia poris minutissimis exarata sunt.

Habitat ... Reperitur in colle Taurinensi.

\section{LUNULITES INTERMEDIA}

$$
\text { мовіs ( Tab. } 7 \text { fig. } 4 \text { ). }
$$

Lunulites superficie convexa, crassa, porosissima; poris adnexis, irregularibus; concava sulcis simplicibus ornata; interstitiis absque poris.

$\mathrm{Ni}$ lunulites urceolata radiatim striata in superiori latere foret, dubitare quis posset, num mea species cum eadem conveniret; at sulci quos indicant impedimento sunt, quominus hæc conjunctio locum habere queat; ceteroquin vero notamus, lentis ope vanescere eam dispositionem sulcorum, quam cernimus prima fronte in lenticulite, atque hic ordo probabiliter coalescit ex ipsa regulari conjunctione pororum, quibus pollent tam lunulites, quam orbulites.

Ubi autern usitatam loquendi rationem adhibcas, cernes, quum in hac specie desint illæe suppositæ lineæ in facie superiori, rern a lunulite propius ad orbulitem accedere. In facie autem inferiori, quod etiam notatu dignissimum, sulci secernunt radios, seu costas, quie ad peripheriam a centro transferuntur, in eaque triangulari forma terminantur. Hiec autem species dilfert a su- 
194

periori, quia pori in inferiori facie desunt, quia crassitie potiori prædita est, insuper non est depressa, atque pori in facie superiori magis regulares sunt.

Habitat... Reperitur in colle Taurinensi.

\section{LUNULITES LENTICULATA}

(orbulites) Lamx. nовіs. (Tab. 7, fig. 1).

Lunulites lentiformis, superne convexa, subtus planiuscula; poris angulosis; margine irregulari.

Lamoroux. Exposit. method. pag. 40.

Lamarck. Anim. invert. tom. 2. pag. 303.

Defrance. Diction. scienc. natur. tom. 36.

Blainville. Manuel d'actinol. pag. 4Ir.

Habitat... Reperitur prope locum dict. vulgo. la perte du Rhône, prope Asti, et alibi. (frequens )

Mus. Paris. Taurin.

Collect. Bellardi, Morelli, Michelotti. 


\section{ESCHARA.}

\section{Atheneus, Pallas, Milne-edWards.}

Polyparium sublapideum; explanationibus rigidulis, vel politis; lamelliformibus, tenuibus, fragilibus, intus porosissimis, integris, aut divisis.

Polyporum cellula quamplnrimo, contiguce, adhorentes in utraque superficie polyparii, operculato.

Superficie utrimque fenestrata.

Jamdiu memoratum genus investigandum nobis remanet; de quo tamen nec ambigua adeo, ut in superioribus disquisitio adest, attentis is quæ nostra ætate contulerunt tum Grant (1), Lister (2), tum Milne-Edivards, quo duce potiora ad escharas pertinentia, ipsumque genus ex professo investigandum suscipimus.

Docebat Pailas, escharas reperiri obvias in mari atque exhibere simplicem crustam, quæ strata vel plantas constituit: si attentius eas consideremus donare series continuas cellularum passim bifurcatas fere parallelas.

"Ubi recentes et vivas in aqua maris, sæpe renovata, escæ causa, servaveris escharas, extremam cujusvis seriei cellulam quasi trudere con-

(1) Observations of on the Struct. and natur. ol flustræ. Edhimburg. new. phil. journ. vol. 3.

(2) Some observat. on the struct. and fonct. of tubul, and cellul. philos, transact. 1834 . 
rg6

spicies, quae frequentius, aliam pariter prolem priusquam rumpatur, emiltit.

"Gemma undique clausa primum mollis est: aperitur dein, et polypum, sensim perficiendum ererit, quo adulto, durescit sensim cellula, atque escharce substantiam continuat.

« Lapidescentium eschararum margines imperfectas ubique cellulas, loculorum apertorum similes sistunt, utpote quarum anterior perficiens pars, quie mollis adhuc fuerat, maceratione periit, postica pariete, quam hic primam solidescere compertum est, et septorum parte tantum superstilibus: plerumque marginales cellulæ simplici tantum, gemmula producta seriem continuant.

" Passim vero duplicem, at non eodem tempore propullare gemmulas videas, quarum altera nunquam perfectæ cellulæ formam, aut molem adipiscitur, novam tamen cellularum seriem inchoat; unde plurimis hinc inde tali modo intercalatis seriebus, antiquæ divergere videntur , quamvis fere parallela decurrant, atque sic crusta eschare sensim in majorem expanditur latitudinem. Quum autem qua novæ prodeunt gemmulie, nunquam naturalem magnitudinem adipiscantur, fit ut nove seriei subsequentes cellulx, comparis seriei cellulis alternæe accubent: unde in escharis fere omnibus oscula cellularum in quincunces disposita naturaliter sunt (I).

(1) Pallas. Elenchus zoophit. pag. 34. el seq. 
"In osculis autem cellularum, pergit Pallas, observari solet bulla cellulæ ostio imminens, substantia escharce omogenea et continua. (De operculo procul dubiomentionem agens Briozois commune). Hoc operculum certæe ætati cellulis demum nasci inde patet, quod in cellulis medianis maxime in antiquioribus observatur, nunquam ad margikem recentiorum cellularum. ")

Hisce a Pallas relatis aliqua subjicienda sunt a Grant (1), Lister, Audouin, Schweiger (2), aliisque notatu dignissima, quæ complexus est Milne-Edwards in anctario circa opus Lamarck(3).

(1) Philosophic. journal. of. cit. loco.

(2) Handbuch der naturge schichte. vid. genus.

(3) En 1828 Moy, Audouin et moi avons constaté l'existence d'une ouverture anale située près de l'extrémité orale du corps des flustres, et nous avons signalé l'analogie qui existe entre leur structure et celle des Ascidies composées ; vers la même époque Monsicur Grant a décrit aussi la disposition générale de leur cavité intestinale, mais sans parler du point qui nous semble $\hat{e}-$ tre le plus important, savoir: la double ouverture de ce canal: enfin, l'annce dernière, M. Lister a pleinement confirmé nos premières observations, et nons avons nous-même constaté quelques faits nouveaux touchant le mode d'organisation de ces animaux. La cellule que l'on considère généralement comme une sorte de coque extérieure et inorganique, n'est autre chose qu'une portion des tégumens de l'animal, qui, dans la majeure partic de.son étendue, est encroûté de carbonate de chaux, qui se continue sans interruption avec la membrane externe de la portion molle et rétractile des polypes.

On peut comparer cette tunique externe, our manteau, à un doigt de gant dont la base tronquée serait entourée par des tentacules et pourrait rentrer dans la portion terminale, qui serait devenue inflexible par le dépôt de quelque substance 

storice in dispendium hujus et flustrae generis tres induxit dislinctiones, quarum prima flustram dixit, eique tribuit loculos completos, distinctos, planos, margine solido præclitos, recipientes membranam, in qua adest apertura subterminalis et transversa in quincunces disposita: unde polyparium membranaceum, flexibile in crustam elatum, expansiones frondescentes non exhibens, basi lineatum.

dure dans les mailles de son tissu; le point de jonction de la portion rétractile et de la portion inflexible constitue, lorsque l'animal est contracté, une ouverture appellée d'ordinaire la bouche de la cellule, et présente une sorte de lévre mobile, ou plutôt un petit repli valvulaire, de consistance cornée que l'on nomme opercule; deux faisceaux musculaires se fixent à la face interne de cette valvule, et l'abaissent lorsque l'animal rentre en entier dans la portion inférieure de son sac tégumentaire, à laquelle les muscules en question s'insèrent par leur extrémité inférieure.

Le canal digestif est suspendu dans la cavité formée par ce sac; son ouverture orale est très évasće et entourée d'un cerlain nombre de longs tentacules, garnie latéralment d' une rangée de cils-vibratiles.

Au-dessous de cette couronne tentaculaire, le canal alimentaire a la forme d' une espèce de poche cylindrique a parois ordinairement froncés, et comparable au sac branchial des Ascidies; du fond de cette cavité, que l'on peut appeller pharyngienne, descend un intestin étroit, qui bientôt se renfle pour former une anse à laquelle est comme suspendu un appendice cœeal gros et court, puis se dirige vers l'extrémité oral de l'animal, et se termine par une ouvertsre ćroite sur la côté de la gaine tentaculaire derrière le sac pharyngien.

Vicle Lamarck hist. natur. des anim, sans rerteb. a edit. fom. 2. pag. 2xí. 
De genere membraniporce, ita sentit, ut in ea agnoscat cellulas margine distinctas non proeminentes exteriori facie membrana tenuissima clausas, in qua apertura invenitur; unde oritur polyparium membranaceum non circumscriptum, in laminam protensum.

Si denique excogitemus cellulas non proeminentes, externa facie non distinctas, aperturis concavis, poriformibus, operculatis, in quincuncies dispositis, unde extat polyparium calcare, expansum, friabile, porosum, atque diversa forma contextum, tertiæ divisionis auctoris assequemur.

De hac nova sentiendi ratione dubitat, nec injuria Milne-Edwards, quia præcipuum escharce Blainvilli fundamentum in apertura rotundata consistat, vel etiam, quia deficiant signa exteriora cellularum limitum. Præterea, etiam intuitu membraniporce difficultas viget; quod enim cellulæ circa marginem distinctæ sint, neque preominentes, neque hoc polyparium videatur limitibus circumscriptum, hoc non sufficit ad idoneam divisionem inducendam; explorati enim juris est ubi agatur de cellulis, eæ in priori ætate esse rotundatas quod tam in flustra, quam in eschara contingit; imo etiam in membranipora; at ubi agatur de cellulis, quæ jam consenuerunt, oblongam vel angulosam dispositionem inducent, atque deinceps senescente polypo moxque deficiente cum aliis confunduntur neque amplius quam habuerint formam eruere possumus. Ideo 
liquet cellularum dispositionem, quam tanquam præcipuum fundamentum divisionis sibi proposuit Blainville, in plerisque fallere, nee ulla ratione defendi posse.

De membrana quoque rationem habendam esse puto; nam hujusmodi tegumenti ea vis est, ut polypos, proindeque polyparia instruere possit, prout apertura, quam in eadem cernimus unam vel alteram figuram sumit: sic in eschara cervicornis, in eschara foliacea, aliisque exploratum est margines cellularum prominere contra Blainville sententiam: sic etiam flustra foliacea in quincunces disposita apparet, ac sit eschara foliacea.

Insigne exemplum cellularum similitudinis quoad flustram atque escharam habemus in flustra fion. diculosa (I) quam bombjcinam alio modo vocavit Lamarck. Sed, ut inutilem quæstionem resolvamus, juvat de cellularum natura, potius quam de dispositione sermonem instituere. Atque ad hanc rem magnifica procul dubio sunt qua nobis reliquit Milne-Edwards, unde harum cellularum originem probaret. Ipse posuit fragnentum flustrce nuper ex unda maris deductum, in acido nitrico, quod aliis vocabulis nitri acidum, spiritum nitri nuncupamus, quod detectum fuit a Raimundo

(1) Pallas elenchus Zooph. 5̌. Non inconsulio notat Lamoroux in hac specic venire escharam frondiculosam Esperi, nam et explicalio, quam donat $E$ sper atque figuram, bombycinam indicant. Vide ad hoc Zooph. suppl. I tab. 2.

Lamoroux. Exposit. neth, des yolyp. Pas. 3. 
Lullo anno 1235 , cujusque odor penetrans atque dum in inorganicis maximam vim exerit, organica corpora labefactatur (1). Effervescente natura hujus acidi, cellulæ paulo post, flexibiles evadunt, atque penitius indolem hujus polyparii assequi potuit.

Primum enituit membrana constituens cellulas, quas conspicimus; in unaque cellula apparatus digestivus videbatur : sacci apertura soluta videbatur ex calcarea materia, atque membrana adnexa cum vagina tentaculari.

Ita ille, ut probaret cellulas, in quibus adsunt polypi escharce atque flustrce, integram partemipsius animantis constituere, atque polyparium considerandum esse tanquam peculiarem conditionem generalis tegumentariæ membranæ polyporum, ex quorum ope, atque industria constat.

An vero flustrce polypus polleat facultate respirationis in controversiam adducitur, atque certum est, si Lamarck audiamus, non reperiri hoc organum, tamen Milne.Edivards putat in eodem apparatu digestivo reperiri apparatum respirationis.

Pro certo videtur in Antozois neutiquam reperiri hujusmodi organum, vel quidpiam, quod eundem effectum agere possit; nam cum unica apertura inveniatur, et simplicissima alioquin sit horum polyporum natura, et speciale non adsit

(I) Elementi di chimica del Cav. V. Michelotti Torino ${ }^{-} 83$ 工 vol. I pag. 235 . 
organum, neque probabile est, adesse illud de quo quæritur.

De Briozois validior est sermo; cum enim non una ratione tantum natura consulere hisce functionibus valeat, quumque duplici apertura potiantur polypi, qui in hac veniunt sectione, atque in quibusdam etiam nervorum apparatus videatur, nihil impedimento est, cur organum a natura primitus insitum præsumamus adesse in Briozois, quoties potiora organa adesse ipsa nobis docuit.

Hine quemadmodum sertularice summam habent cum hydris affinitatem, ita flustra et eschara ex iis sunt generibus, quæ ad ascidias compositas accedunt.

Cæterum cellula ipsa non videtur constare ex stratis suprapositis, sed ex prysmatibus irregularibus, perpendiculatim appositis circa superficiem.

Quoad operulum quod includere inservit ipsum polypum dum in cellulam se se recipit, nihil aliud est, quam plica labialis, cujus portio marginalis soliditatem corneam adipiscitur; ubi cohæret cum generali membrana, mollis adhuc est, unde vi musculorum pariat.

Potiora ad polypum pertinentia, qui ad escharam et propinquiora genera pertinet, is relinquimus qui degunt in ipsius maris limitibus, ideoque non modo italis naturalis historia cultoribus hoc munus impendit, sed multo potiori ratione is, qui inter eas gentes consistunt, quæe cum colonias variis, ditissimisque plagis, possideant, idcirco 
innumeras relationes colunt, concredita sunt quæ de anatomia polyporum requirunt.

Quum autem mihi proposuerim observare tegumenta calcarea, quæ in tertio cataclysmo inveniuntur, licebit quidpiam adnotare de eorum opinione, qui inter escharam et flustram generis differentiam adesse contendunt.

Atque in primis, nullibi hanc differentiam nec facto quidem inductam fuisse reperio, imo et ipse Pallas, in hac re studiosissimus, flustram adjunxit escharis; ita, ut ipse collocaverit flustram foliaceam inter escharas (1) atque in truncata flustra agnoverit escharam : pari modo Linnceus dixit flustras omnia polyparia, quæ Pallas nuncupaverat escharas, unde habes apud ipsum, quæ indiscriminatim ad utrumque genus pertinere possunt (2).

Variam hac de re secutus est disciplinam Esper, qui escharas modo inter celleporas, modo inter milleporas jactavit. Quod autem pertinet ad genus escharce, ait, inepte Pallas, et Moll confundi inter se hæc duo genera, quia flustra flexibilis est, et quia cellulas habet alia forma prieditas (3).

Huic distinctioni, a Lamarck, memorice juvandæ causa confirmatæ, quamvis veris characteribus haudquam suffultæ, nilil Lamoroux adjiciendum putavit, qui definitionis a Lamarck præditæ unice

(1) Pallas, Elenchus Zooph. pag. 5 r et 56 ctc.

(2) System. naturæ auct. Linn, vide flustr.

(3) Esper, Pllanzenthier. tom. x pag. 145. 
contentus, quid cujusvis generis nomine venirel, verbo tenus custodiendum esse duxit (r).

Sane compertum est cellulas ipsas mutari, et in variam naturam converti, prout retas polyparii variat, ergo totius discriminis momentum eo reducitur, ut arbitraria omnino sit distinctio excogitata inter escharam, atque flustram.

Verumtamen Milne-Eldwards notat, duo strata in eschara adesse, in flustra non item, ergo aliud sentiendum esse (2). Nihilominus hic operis pretium est renovare præceptum, quo innixum induxit novam divisionem generalem zoophytologice, quam et nos præstantiæ ejusdem causæ secuti sumus, nimirum, non sufficere polyparia ad idoneas inducendas sectiones; et alioquin . . Quum hodie multo satius polyporum cognitionem assecuit simus, juvabit, juxta eorumdem rationes, et naturam, zoophytorum historiam enucleare. Jamvero et ipse semel iterumque fatetur, in omni causa polypos ita se habere in escharis et flustris, itidemque quoad modum incrementi cellularum, vel quoad modum, quo evanescunt nihil omnino differre. Si itaque sagax polyporum observator nolorit ex animantium natura dimetienda esse generum discrimina a pari, dicendum ubi polyparia flustra acescharce similes omnino recipiant polypos, ideo conjuugenda; ni in absurdis lincidere malumus. Adde, quod in quincunces dispositie sint cellulæ,

(i) Lamoroux, Exposition. méthod. pay. 4 et 40.

(2) Annal. des scicnc. natur. cit. loco pag. 15. 
tam in flustric, quam in escharis, utrasque porosissimas esse; præterea, sive in crustam sive in frondem expansæ cellulæ æque contiguæ in utraque facie sunt.

Quid? quod in flustris ipsis, quæ incrustantes sunt, unam tantum cernimus faciem cellulis munitam, ut in celleporis, ac reteropis? num eschara incrustans, lobata, quill exhibet, quod eas a flustris incrustantibus secernere valeat?

In geologicis stratis flustram æque ac escharam invenimus in grautwacke; nam in Anglia in Gloscestershire, Herefordshire, nec non in Germania prope Eifel hæc duo genera reperiuntur, insuper non desunt in Gothlandia in is stratis, quæ ad strata carbonifera se se referre Hisinger, atque De-la-Beche non immerito putarunt.

Animadversione dignissimum, quod hoc genus etiam in aquis dulcibus, uti vocant, vivat: tanti momenti cognitionem accepi in scriptis Pallas, dum milleporce calcarea descriptionem prosequitur.

Hanc formationem quintæ ætati tribuit Rozet, hac quidem de causa, quia ipse hac atate vetustiora documenta organici hujus mundi ponit, et præter hæc nulla, alioquin, quæ graurvactie dicit De-la-Beche, complectatur inter strata schistorum, recipientia strata gallicis vocalualis siluriens et cambris, proindeque in sua atate concurrat, quæ opinio non omni caret præsidio, peculiare enim est graurvacke sedimentum, atque ad inducendam formationem non sufficit. 


\section{ESCHARA SUBSTRIATA}

\section{MUNSTER}

L. ramosa, furcata, compressa ; cellulis quincuncialibus, orificiis orbicularibus, annulo appendiculato cinctis. Goldfus. Petrefacta germaniæ. pag. I о I. Milne-Edwards. 2 ed. Lamarck. tom. 2 pag. 27.

\section{Habitat ... fossilis in Westphalia.}

\section{ESCHARA CELLEPORACEA}

\section{MUNSTER}

L. ramosa, furcata, compressa; cellulis ovatis, sine ordine dispositis; orificiis orbicularibus, prominulis, recurvis.

Goldfus. Petrefacta germanix pag. 135.

Fischer. Bibliogr. panleont. pag. 337 .

Milne-Edward. 2 ed. Lamarck. cit. loco.

Utraque species in. Musæo M. Bonn. Munster. ESCHARA LA TA

\section{MILNE-EDWARDS}

L. cellulis magnis, angulatis, reflexis, foraminibus circumscriptis.

Milne-Edwards. Ann. des scienc. natural. 2 ser. tom. 6 pag. I I tab. I I fig. I I.

Margines cellularum, earum amplitudo, et foramina, quæ conspicimus circa easdem, satis superque sufficiunt, ut cognoscamus hanc speciem.

Habitat . Reperiluu prope Dové. 


\section{ESCHARA DESHAYSII}

MILNE-EDWARDS

L. foliacea, cellulis repandis, semilunatis, late circiter foraminibus obliquis signatis.

Milne-Edvvards. tav. 1o fig. 4 pag. I I cit. loc.

Habitat ... Reperitur prope Dové.

\section{ESCHARA AFFINIS}

\section{MILNE-ENWARDS}

L. late ramosa; cellulis oblongis, obliquatis, distinctis, margine extenso, sexangulari, circumscriptis.

Milne-Edvvards. cit. loco pag. I 2.

Habitat . . Reperitur prope Dové.

ESCHARA POROSA

MILNE-EDWARDS

L. ramosa; cellulis sparsis, indistinctis, poris minutissimis irregularibus undique insculpta.

Milne-Edvvards. cit. loco. pag. I3. tab. I . fig. 7.

Circa hanc speciem notat auctor porosissimam esse; poros minutissimos, vix distinctos.

Quid autem magis observatione dignum habemus in hac specie illud est, quod eæ laminse quæ invicem incumbunt, haudquaquam eadem vi se conjunguntur ac in cæeteris escharis, sæpiusque disjunguntur, quin detrimentum aflerant cellulis. Quid clarius innuere poterat auctor, ut meam sententiam reciperet quoad conjunctionem eschare, et flustrec? itaque non modo quoad polypos, sed 
vel in ipsis speciebus adest transitio ab uno, ad alterum genus, ab auctoribus recepta: superest nobis recensenda tam eschara bifurcata, quam eschara Brogniartii ; utraque prope Lutetiis inventa, at accuratius de omnibus escharis fossilibus, quam de iis, quæ ad unam se se referunt retatem, opus complevit citatus Milne-Edwards in opere cui titulus (ann. des scienc. nat. cit.) quod consulere operis pretium est.

Habitat...Reperitur prope Placentiam, Asti. Mus. Parisiens. Coll. Michelin, Milne-Edwards.

ESCHARA FOLIACEA

(Flustra) LıNN.

L. foliacea, lamellosa, utrimque cellulosa; lobis cuneiformibus, apice rotundatis, osculis rotundatis.

Ellis. Coral. pag. 7o. n. 2. tab. 29. a. A.

Linn. System. natur. $e d$. го. sp. $a$. (Flustra)

Pallas. Elenchus. zoop. pag. 52 .

Othon. Fabricius fauna Groenlandica pag. 436.

Grant. Edimburgh. philos. journ. v.3. pag. 107.

Flemming. Britt. anim. pag. 535.

Lamarck. Hist. anim. I. et 2. ed. tom. 2. pag. 219.

Pallas explicat primordium escharce foliacece crustulam esse, e cujus medio assurgit frons parvula, cuneiformis, supra rotundata, qua duplicatione serierum cellularum, latitudinem progressu majorem acquirit, et findi incipit. Cellulæ in duplici frondium strato confertissimæ, alternæ, arcuatæ, osculo lunato ringentes, et spinula utrinque ad osculum aurita. 
Animadvertere quoque oportet quæ tradit de polypo, nimirum, quum sit corpus vermiculare, fundo cellula adnexum, cirros, seu tentacula gerit circa caput dena, in campanæ formam repansa: notat, polyparium semper subgryseum esse in mari, temporis progressu albicans.

Notatu quoque dignissimum, quod refert circa incrementum earum specierum, quæ incrustantes sunt: novas interdum loricas, antiquis circumcrescere, ex quibus juniores denuo pullulant.

His attentis, quis discoporce genus defendere poterit? Osculorum indoles, atque opercula per omnia se habent in fuctris, ac in discoporis.

Idem discrimen, quemadmodum in sertularieis genus non mutat, eccur dum de Briozois agimus, proniores illud defendimus? Aliud utique dicendum foret, si de discopora, prout eam intelligit Milne-Edwards, ageretur; nam polyparii dispositio, cellularum numerus, et ordo, peculiare genus procul dubio indicant.

Habitat in mari Adriatico, Mediterraneo, fossilis, prope Placentiam, prope Asti, prope Albam Pompejam, in Sicilia, et alibi.

Mus. Paris. Lond. Berol. (viv.) Taurin. (fossil.) ESCHARA CRASSA

\section{(Flustra) desmaret et lesueur}

Eschara incrustans, crassa; septis prominulis, superne depressis: cellulis brevibus; ore amplo, lunato.

Desmaret, et Lesucur. Bull. des scienc. natur. 1814. pag. 53. tab. 2. fig. 1. 
Lamoroux. polyp. flexib. pag. I 2 . Blainville. Manuel d'actin. pag. 452.

Milne-Edvvards. 2. edit. Larnarck. cit. loc.

\section{Habitat ... fossilis prope Grignon.}

\section{ESCHARA CRETACEA}

\section{(Flustra) IIDEM}

Eschara incrustans, crassa; cellulis ovato-oblongis.

Desmarets et Lesueur Cit. opus pag. 53.

Lamoroux. Polyp. flexibl. pag. I 13.

Milne-Edvwards. 2 edit. Lamarck cit. vol. 2. pag. 229.

Ilac species, quæ non modo in murice trunculo, saxatili invenitur, verum etiam super pectunculis mirificam exhibet texturam in cellulis ovato-oblongis, quæ æquales, longitudinaliter dispositx sunt, atgue etiam, quia interstitia levia, radiation directa sunt.

Habitat . . Reperitur prope Placentiam.

ESCHARA TESSELATA

\section{LAMARCK. (flustra)}

Eschara incrustans, septis antice rotundatis, cellulis superne depressis; ore subrotundo exiguo.

Lamarck. Hist. des anim. invert. tom. 2. pag. 228.

Desmarets et Lesueur. Cit. opus pag. 53.

Lamoroux. Polyp. flexib. pag. $\mathbf{3} 3$.

Blainville. Manuel d'actinol. pag. $45 \mathrm{r}$.

De hac specie una cum aliis multis, dubitat Lamarcli, num reapse ad escharas, ceu, ut ipse mavult, ad flustrum pertineat, dubilandi ratio pro- 
babiliter posita est in eo quod hiec species incrustans sit, quod cellulæ superne depressæ sint; verumtamen rarum non est flustram invenire incrustantem; alioquin depressio cellularum non sufficit, ad generis discrimen inducendum: concludamus igitur veram flustram in hac specie adesse.

Habitat . . Reperitur prope Lutetias etiam in stratis diluvianis.

ESCHARA CONTEXTA

$$
\text { GOLDFus (flustra) }
$$

Eschara incrustans, cellulis ore ovali, inermi.

Goldfus. Petrefacta Germaniæ pag. 32. tab. 10 fig. 2. Milne-Ediward. 2. Edit. Lamarck. cit. loco.

Habitat. . . fossilis in Brabuntic, et in colle Taurinensi, frequens. 


\section{LINNIEUS, PALLAS, CAVOLINI.}

Polyparium lapideum, intus solidum polymorphum, ramosum.

Pori cylindrici, leviler intus sulcati, minimi, interdum non perspicui, axi polyparii perpendiculares, operculati : operculo ovali, striis transversalibus, prodito. Polypus cirris longis, ciliatis instructus.

Dum milleporam commemoramus, eam absque dubio intelligimus, qua, ex is constat speciebus, eandem animantiun, seu polyporum indolem exhibentibus; atqui, si complectimur omnes species, quas inter milleporam recensuit Lamarch, non de uno tantum genere agimus; ergo concludendum in genere milleporce venire tantummodo eas species, quae communi definitioni respondent.

Videamus itaque, quid veteres, quid recentiores auctores de millepora prodierint.

Linnceus in suo opere cui tilulus, systema naturte, nudam hanc tradidit definitionem; milleporam esse corallium poris turbinatis teretibus; quid amplius tamen Pullus, qui Linzucum pracesserat, religuit; nimirum milleporam summam affinitatem habere cum eschciris, solidiusculam, et ramosam esse, repetilque cum Imperata, habere poros cylindraceos in coralli axe dircclos. Deinde, ruod magis altentionem meretur illud est, quod aitipse, milleporas superficicitantum insculptas esse, 
quod neque in omni casu ita se habet, millepora enim truncata, millepora aspera, tubulifera, aliæque quam multe, non in superficie tantum, sed intus etiam poros insculptos exhibent.

Multo pretiosiora, licet unam tantum investigaverint speciem, quæ tamen, dubio procul, eminenter ad milleporas pertinet, scripserunt italici auctores Donati et Cavolini. Quam sibi proposuit speciem Donati eadem est, quam pseudo-corallium album, fungosum Aldrovandi nuncupaverat; notat Donati, in vim cellularum fragile polyparium esse, in quincunces dispositos poros; cinerariam urnam antiquorum unamquamque cellulam exhibere. Polypum oblongum ventri dilatatum, proboscidem, seu coronam tentaculorum gerentem, adesse; proboscidem circa latera conjunctam esse cum polypo, ope duorum musculorum.

Ubi animal se recipere velit, hac ipsa actione clauditur cellala, operoulo, superiore manente. De polypo adulto non de juniore hæc aflemari possunt.

Milleporce investigationes a Donati susceptas secutus est Cavolini; sumnam sensibilitatem, bifurcationem, non quincuncialem dispositionem admittit; quam proboscidem esse putavit Donati, coronam minutissimorum tentaculorum leviter revolutorum, esse docet; ubi prodeant polypi, tentacula cylindrum efficere.

Certum pariter, juxta Cavolini sententiam, æqualem esse dimensionem millepora truncate, tum in ramis, tum in basi, guod facillime explicarc 
possum; nam series horum polyporum, eadem semper est, sive in initio, quam in superiori facie; itaque cellula, tam in initio, quam in ramis supernis magnitudinem eandem habebit.

Suscipe modo ea perlustrare qua: nostra ætate scriptores retulerunt.

Ehremberg atque Milne-Edwards repetierunt, milleporam habere summam affinitatem cum eschara, quo nomine flustram intellexerunt: illud certe optime posuerunt, tentacula ciliata milleporam habere, cellulas sulcis longitudinalibus signatas; interruptam denique structuram in hoc polypario cerni : unde veteres et recentiores de eadem millepora consensisse apparet.

Strata cretacea milleporam recipere demonstravit Goldfus, dum milleporam racemosam invocavit, madreporaceam, compressam memoravit: illud tantummodo quæram a cultissimo scriptore, ¡quo fundamento, milleporæe appropinquaverit genera siphonice et idmonice, que num ad polyparia proprie dicta se referant, multo dubitari potest.

Cæeterum, ut libenter secuti sumus Ehrenbergi methodum, ita Blainville nobis arridet opinio, vi cujus a zoophytorum ordine spongias, et quidquid eas accedit, rejicimus, quum polypi in hisce generibus desiderentur. 
MILLEPORA TRUNCATA

pallas, Nobis (Tab. 6 fig. 8)

Millepora dichotoma, ramosa; ramis divaricalis, rotundatis, truncatis; poris quincuncialibus, crebris, minutis, operculatis.

Besler. Mus. Lochn. tab. 23.

Marsilii. Histor. maris pag. 145 .

Donali. Hist. adriat. pag. 55. tab. 7 .

Pallas. Elenchus. Zooph. pag. 249.

Cavolini. Memor. dei polipi pag. 59 .

Lamarck. Hist. natur. invert. cit. tom. 2.

Ehremberg. Hist. maris rubr. pag. 15̃4.

Delle-Chiaje. Anim. invert. di Napoli tom. 3 pag. 40 tab. 33 fig. 16. et i 7 .

In hac specie satis superque dicimus, dum eam pro precipua specie in qua genus constituitur accepimus, neque amplius quid definitioni adjiciendum superest. Restituimus tantummodo nomen auctoris, qui primus hoc vocabulo hanc speciem nominavit.

Habitat in mediterraneo, mari rubro, et in oceano ad Cornubiam et alibi. Fossilis in colle Taurinensi.

Reperitur quoque in cretaceis stratis prope Maestricht.

Mus. Paris. Berol. Vienn. (viv). Mus. Taurin.; collect. Morelli, Bellardi, Michelotti (fossilis). 


\section{TET HIA}

DONATI, LAMARCK, FLEMMING.

Corpus tuberosum, subglobosum, intus fibrosissimum; fibris subfasciculatis, ab interiore arl peripheriam divaricatis aut radiantibus, pulpa parcissima: cellulis in crusta corticali et interdum decidua immersis.

Oscula raro perspicua. Centro spinis minutis exarato.

Si quod singulare cognoscere cupimus tethiam et geodiam inquirere debemus, intricatissima corpora, nec adhuc definita cujus indolis et naturæ, statum mutantia in undis, ac in sicco loco.

De tethia hæc erunt: quid sit hoc genus; qua nam ratione cum geodia, cum spongiis conveniat, quot species; locum denique quem eidem assignare oportet.

Ad primam quxestionem quod attinet, notamus polyparium esse generatim globosum; cujus centrum rotundatuin, atque circumcirciter spinis minutissimis fusiformibus, fibris coriaceis instructum est. Ex hoc centro radii ortum habent, quæ invicem revoluta, spinis etiam munita, cylindraque sunt: radiorum summitates spinas exerunt, qua habent basem ad peripheriam conversam: vi revolutionis cylindrorum autem spinarum series, globulis divisa apparet.

Conicam autem formam spinarum uniuscujusque cylindri summilai insertam conjungit fibrosa materia, atrgue ifa rolundatum corpus habemus cel- 
lutas ostendens qux non ad aliud, quam ad inversas cyliudrorum superioresque spinas pertinent.

Hisce positis, nemo nou villet ex compressione tethice universum corpus in vim revolutionis $\mathrm{cy}$ lindrorum, contrahi; pariter se extendere hoc corpus, ubi eidem denuo restituatur libertas.

Hæc, qu:e incredibilia cogitalione viderentur, nisi experientia eadem prestitisset, eruimus ex oculati Donali investigationibus, atque probabile admocium est, potioribus conatibus, elementa ad cognoscendas spongias prebere posse. (1)

Non defuerunt, qui cogitavere tetiziam nihil aliud esse, quam spongian crustam siliciformem gerens; item conjungi quoque debere cum geodia; verumtameninterior structura tethice satis eam secernit a geodia, uti a spongia, cujus indoles adhuc nobis latet.

Satius cum Milne-Edwrards de alia re convenirem, seu de dispositione tethice, et spongice, aliarumque similium in alia classe, ac inter poIJparia; nam polypi, quos precipue desideramus in zoophytologia, omnino deficiunt in hisce generibus.

(1) Aptissime notat Doctor J. Gené in R. Univ. Taurinensi professori (cui grates alacri animo publicas ago in vim beneficiorum quibus me cumulavit) veteram opinionem inscitiam duplici generis erroribus locum præbere posse, nimirum tum quoad methodum, qux imperfectior semper est, tum quoul studiis iisdem deditos, qui recentioribus auctoribus freti infirmum de speciebus sat aptc a veteribus indicalis, tantummodo judiciun assequi valent. Vid. Anm. scient. R. Lomb. Venet. 1 334 . 
Ipse autem quum cordi maxime habuerim singularia, qui in colle Taurinensi detexi publici juris reddere; hoc genus licet ad aliam classem pertineat, complementi majoris causa, adjiciendum esse putavi.

Improvidum eorum est consilium, qui autumant antiquissima, ideo simplicissima hæc corpora esse; nam physiologia eorum ignorantia, simplicitatem probare nequit.

TETHIA ASBESTELLA

\section{LAMARCK}

Tethia ingens, turbinato capitata fibris longissimis, et fasciculatis, dense compacta; cortice deciduo; poris obsoletis.

Lamarck. Hist. natur. tom. 2.

Blainville. Man. actin. pag. 545.

Habitat in oceano Bresiliensi. . Reperitur frequens in colle Taurinensi.

\section{TETHIA CAVERNOSA}

\section{LAMARCK}

Tethia globosa, fossis angularibus, incequalibus, irregulariter dispositis; fibris e centro radiantibus; ad peripheriam fasciculatis.

Lamarck. Hist. natur. invert. tom. 2.

Blainville. Cit. loco.

Habitat in oceano Americano... Reperitur in colle Taurinensi. 


\section{TETHIA LYNCURIUM}

\section{LAMARCK}

Tethia globosa, subcorticata; fibris e sentro radiantibus; superficie verrucosa.

Marsilii. Hist. marit. tab. 14 fig. $72,7^{3}$

Donati. Adriatic. pag. 62 tab. 9 .

Esper. Suppl. 2 tab. 19 fig. 4, 5.

Lamarck. Hist. anim. invert. tom. 2 pag. 592.

Flemming. Britt. anim. pag. 520.

Habitat in Mediterraneo.. Reperitur in colle Taurinensi.

\section{TETHIA SIMPLEX}

nовis (Tab. 8 fig. 6)

Tethia globosa, stratis exiguis obtecta, pedicillo munita, foraminibus raris, obsoletis.

Habitat . . Reperitur in colle Taurinensi.

\section{TETHIA SYPHONIFERA}

\section{NOBIS}

Tethia globosa innumeris cellulis, apertis, rotundatis prodila.

Dubitavi an hæc species, quid commune habeat cum aliqua specie jam cognita; et tethia cranium nihil similitudinis cum mea specie exhibet: nam ea tuberiformis est, atque setosa. Tethiam lyncurium non cognovi in hac specie, attenta osculorum, et fibrarum indole.

Habitat ... Reperitur in colle Taurinensi. 
220

\section{TETHIA REGULARIS}

NOBIS

Tethia convoluta, stratis concentricis constituta, poris rotundatis undique insculpta.

Variet. poris minutioribus, rarioribus.

Habitat . . Reperitur in colle Taurinensi. Mus. Taurin. n. . . coll. Michelotti. 
LINNEUS, PALLAS, LAMARCK.

Polyparium liberum, ramosum, penniforme, inferne nudum, superne pinnatum, axe osseo suffultum.

Pinnce distichoe; patentes, complanatoe, plicatoe, margine superiori dentate, polypiferce.

Polypi retractiles, tentaculis radiati, intus ovipari.

Licet Milne-Edwards pennatulam inter antozoa collocaverit; verumtamen mihi videtur ad briozoa pertinere; hujus rei causæ hæc sunt, quia, canal alimentis inserviens veretillis appropinquatur; ideoque radiariis, uti docet Lamarck, propius accedunt; quia libertas motus, qua pollent, singulare systema indicat: quia desunt in pennatula internæ lamellæ, quas requirunt in antozois; deinde, si admittimus polypos polypariis adhærere, uti crustacea, oportet, ut pinnæ motu, vitaque polleant; proindeque, quid perfectius procul dubio habemus in pennatula, ac in antozois.

Superest modo, ut videamus, quid circa plures species præcipui auclores senserint, et in primis circa pennatulam phosphoream notare juvat, Lamarck in sua synonimia, et Milne-Edwards in suo auctario sensisse, Pallas ejusdem mentionem sub eodem nomine habuisse, sed perperam; nam Pallas eam locavit sub nomine 
pennatulce rubree, uti cernere est in ejusdem speciei synonimia.

Circa pennatulam argenteam, illud etiam occurrit, quod mentionem ejusdem habeamus apud Pallas, qui eidem pennatulce grandis nomen apposuerat (uti docuit Blainville) genericam illitus speciei nuncupationem a Solander et Ellis indictam ignorando.

De pennatula sagitta refert Lamarck, nomine Palias eam indicasse; verumtamen nescio an penmatula juncea, quam Pallas memoravit, ad aliam speciem pertinere queat. Hinc, qui vere hanc speciem, et ejus patriam, gallico scriptori ignotam, cognoscere cupit, ad memoratam pennatılam junceam Pallas confugiat oportet. Firgularice enim constitutio non validis documentis inniti, demonstravit Blainville.

Placuit insuper Lamarck, pennatulam cynomorium Pallas alio nomine, seu pennatula granulose vocabulo citare.

Insuper liquet pennatulam spinosam Lamarch, nihil aliud esse, quum pennatulam griseam Pallas.

Demum pennatulam griseam Lamarck cum pennatula spinosa ejusdem auctoris aptissime quis conjungere potest.

Pauca nobis cognita sunt de polypo incola pennatulce; illud tantummodo perspectum, carnosum, cylindraceum, atque irritabilem polypum esse, atque axem prælongum, inarticulatum modo internum, modo externum, interius possidere: antiquus 
Bohadsk, molum et lucem, quibus pollet polyparium ita explicavit, ut consistat in constrictione quadam peristaltica a nuda ejus extremitate incipiente, et per pennatam quoque partem obsoletius continuata: quasi annulus ruber per stipem ascenderet; stipemque varie curvari, et pinnas horsum moveri, quo molu pinnæ natant.

Ciliatos insuper esse polypos, qui in pennatula hinc inde constituti sunt, observatione constat; qua pariter docemur vesciculas horum polyporum ovula continere, quibus sepositis novæ pennatulce oriuntur. Ad Briozoa itaque pertinere posse posteriora hæc indicant, quamvis plura tum de vasculari systemate, tum de operculis, tum de peculiari incremento pennatulæ, desiderentur.

Pennatulam nunquam in statu fossili reperierunt: diligentia equitis V. Morelli, cujus amicitia benevolentiaque fruor, eam in agro Astensi semel iterumque reperiit.

\section{PENNATULA DILUVII}

\section{NOBIS}

Pennat. stirpe longiuscula; pinnis arcuatis, depressis, contiguis, nudis.

Habitat ... Reperitur in agro Astensi.

Collect. Morelli, Michelotti. 
Denique, amice lector, peractis is, quæe potissimum ad zoophytologice diluviance documenta spectant, harum rerum ordo, operisque brevitas postulat, ut finem ponam.

Non dubito cum Brocchi, qui tam magna laude testaceorum Italice studium prosecutus est, de polypariis asserere, quod ipse de testaceis; plurimas species adhuc esse, quarum cognitionem nobis latuit; at præcipuis, iislemque obviis indictis cæ procul dubio sufficiunt ad furmandam geologicain ætatem, cujus uterque sin pari felicitate, saltem pari alacrique studio, nec dissimilibus vigiliis investigationem ex professo suscepimus.

Universum ferme specimen rei topographicæ consignatum erat, quum fortuua mihi permisit opus claris. Goldf pervolvere; nam antea illud tantummodo, ex aliorum relationibus, potissimum ex auctario Milne-Edwards in 2 edit. operis Lamarck (hist. anim. inv.) cognoscere potui : omnia itaque, quæ passim de Golifi rebus occurrunt, ex aliorum fide metitus sum.

Fatear, ni zoologice rationes in straits supracretaceis peculiaria exposcerent, quemadmodum primus demonstravit $A l$. Brongriart, probavit Studer, defendit Agassiz in Helvetia, Partsch et Screiber's in Austria, Jaziliov, Fischer in Russia (I), alii alibi uti recentissime Huot, qui

(I) Conspect. format. cretac. 1832. vid. vol. 1. Summi autem momenti est consulere ephemeridem G. Leonard et Bronn, uti illam Kefersiein: vehementissime quoque commendo le- 
tres constitutiones sejunclas in hac ætate cernit, ab inceptis me desivisse, tanti nominis opere, uti illud Goldf $i$ est, itinere precluso.

Pauca itaque adjicienda esse putavi, ut quo, meliori fieri possit modo, mendis consulerem in hoc opere relatis, quas ex Goldfi opere eruere potui.

Primum vitrea fractura, ac ramorum clispositio, quæ in antipathe adest, ex peculiari stratorum natura effecit, ut echinorum aculeos pro antipathibus habuerim. Ni longiusculam partem nuper invenissem, quæ mihi probavit veros aculeos, seu spinas echinodermatum, uti loqui amat solertissimus zoologice cultor A. Agassiz, putarem adhuc antiphates corticatam, serialem, hirtam, signa. tam, quum præseferant adjuncta veræ antipathis, hujus generis partem constituere. Quæ inveni fragmenta confirmantur tab. 39 penes Goldfum.

Attende insuper, quam ipse habui pro iurbinolia plicata, eam turbinoliam mitratam Goldfi esse. A pari, quam, uti turbinoliam cuneatum Goldfi citavi, ea vera turbinolia duodecin costata Goldji est.

Placuit Goldfo insuper, tanquam varietatem tur'binolice cuneatce, quam nuncupaverat habere tur'binoliam, quam ego aviculam dixi.

Dubito etiam meam sarcinulam concosden varietatem esse surcinulce auleticon ejuslem aucto-

theam geognosticam Bronn; et Phillips geologix crudimenta. 5. edit. 
ris; nisi, quod mea species pluribus sit radiis signata.

Nota etiam, quod mihi videtur, Goldfum in sua turbinolia cuneata comprehendisse turbinoliam compressam Lamarckii, uti sarcinulam conoideam dixit speciem, quam Linnceus acroporam nuncupavit.

Hæc suni, quæ circa species Goldfi relate ad eas, quas ipse citavi præcipue animadvertenda occurrunt, peculiaria dubia adhuc subsistunt, ordo tanen hujus speciminis omnia enumerare singillatim non patitur.

Quod difficillimam etiam hujus speciminis exarationem redulidit, positum erat in tot novis illis generibus, et speciebus, in tot operum varietate, quod unius privati cognitiones facultatesque superat, et studiosissimi cujusvis conatus ferme iuntiles reddere potest; egregii tamen viri, amicorumque consilia, difficultatum viam æquarunt (I) quibus omnibus publicos grates agere jamdiu desidero.

Si denique grati animi sensum iis signare decet, quorum egregia opera ntimur, quanto magis, supremi Numinis decreta colere debemus,

(x) Inter cæteros memorabo Terver, Lugduno in Gallia degentem, de re conchiolilogica optime meritum. Ipse aliquot ab hinc annis opus generale parat circa testacea ct molluscha terre atque fluminum: raro ingenio, vigili studio, summa pingendi arte, locupleti collectioni, relationum numero suffultus pretiosissinum donum historie naturali temporis progressu afferet. 
scitu enim, "quoniam ipsius est mare, et ipse fecit illud ": quis diligenter colendo naturalem historiam consistere potest, qui cum eodem propheta dicat: " quam magnificata sunt opera tua Domine ! omnia in sapientia fecisti; impleta est terra possessione tua "); proindeque hisce studiis vere addictus, incredulus esse nequit, quidquid contra aut invidia aut ignorantia afferat: incredulitas enim cum philosophia contemplativa conciliari nequit. 



\section{N D E X}

PROOERIUM . . . . . . . . . Pag. I

Sertularia • • • • • • • • • • • • • . " II II

Sericea. Nobis . . . . . . . " I 8

Corallium . . . . . . . . . . . " " 20

Rubrum. Bauh . . . . . . . ” 24

IsIs • . . . • • . • • • • • . " 26

Melitensis. Goldfus . . . . . . " 29

Gorgonia . . . . . . . . . . ” 3 r

Sepulta. Nobis • • . . • . . " 39

Antipathes . . . . . . . . . . . " 40

$\left.{ }^{*}\right)$ Corticata. Lamoroux . . . . . . " 42

$\left.{ }^{*}\right)$ Serialis. Nobis . . . . . . . " 43

Vetusta. Nobis . . . . . . . " ib.

$\left.{ }^{*}\right)$ Hirta. Nobis . . . . . . . . . " ib.

$\left.{ }^{*}\right)$ Signata. Nobis . . . . . . . . " 44

TURbINOLIA

Italica. Nobis . . . . . . . . . ” 5 r

Patellata. Lk. . . . . . . . . " ib.

Armata. Nobis . . . . . . . " 52

Obesa. Nobis . . . . . . . ” 53

Pyramidata. Nobis . . . . . " ib.

Trochiformis. Pallas . . . . . " $5 f$

Nana. Lea . . . . . . . . " 55

Goldfusii. Lea • • . . . . . ” 56

Stokesii Lea . . . . . . . . . " ib.

Maclurii Lea . . . . . . . . " 57

Avicula. Nobis . . . . . . . " 58

(*) Vid. pag. 225. 
Turbinoura Compressa. Lk. . . . . . . Pag. 60

Clavus. $L k . \quad$. . . . . . . . . » 63

Sulcata $L k . \quad$. . . . . . . . » ib.

Pharetra. Lea • . . . . . . " 64

Sinensis. Nobis . . . . . . . " 65

Basochesii. Defrance . . . . . " ib.

Cuneata. Goldfus . . . . . " " 66

Granulata. $L k$. • . . . . . " 67

Cornucopia. Nobis . . . . . " ib.

Prælonga: Nobis . . . . . . " ib.

Raricosta: Nobis . . . . . . . " 68

Konigii. Mantell . . . . . . . . „ ib.

Plicata. Nobis . . . . . . . ” 69

Multiserialis: Nolis . . . . . " 70

Multispina. Nobis . . . . . . " $7 \mathrm{x}$

Cyathus. Solander . . . . . . " 72

Cylındrica. Nobis . . . . . " 73

Calvimontii. $L k$. . . . . . . . ” ib.

Punctata. Nobis . . . . . . . " 74

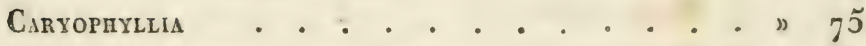

Cariosa. Goldfus • • . . . . ๖ 82

Gracilıs. Goldfus . . . . . . . . ” 83

Cespitosa Linn. . . . . . . . . ” ib.

Reptans. Nobis . . . . . . . ” 85

Amica. Nobis . . . . . . . . " ib.

Truncata: Lamoroux . . . . . ” 86

F ONGIA . . . . . . . . . . . . . . . . . . 88

Japheti. Nobis . . . . . . . " " $9^{2}$

Corounla. Goldfus . . . . . . " 9 ?

Hemisphærica. $L k$, • • • . . ” $9^{6}$

Elliptica. Lk. • • • • • • • . . " 97

Radiata. Goldfus . . . . . . " $9^{8}$

SARCINUla

Perforata. Lk. . . . . . . . " " $10 \tilde{y}$

Costata. Goldfus . . . . . . . "106 
Sarcinula Acropora. Linn. . . . . . . Pag. 106

Plana. Nobis . . . . . . " 107

Punctata. Linn. . . . . . . . . " 109

Faveolata. Solander . . . . . . " וा "

Concordis. Nobis . . . . . . . " ib.

Mirifica. Nobis . . . . . . . . " ib.

Contexta. Nobis . . . . . . . n II2

Geometrica. Nobis . . . . . . " 13

Organum. Linn. . . . . . . . . " 114

Musicalis. Linn. . . . . . . . " 115

Astrea . . . . . . . . . . . . " 118

Interstincta . . . . . . . . " $12 \mathrm{~J}$

Arachnoides. Schroter . . . . . . " 129

Reticularis. $L k$. . . . . . . " 130

Intersepta. Esper . . . . . . . " ib.

Arachnoides. Defrance . . . . . " $13 \mathrm{r}$

Argus, $L k$. . . . . . . . . . " ib.

Favosa. Esper . . . . . . . . " 133

Deformis. Lamoroux . . . . . " ib.

Ananas. Linn. . . . . . . . " 134

Galaxea. Solander . . . . . „ 136

Cavernosa. Schloteim . . . . " ib.

Monticularia . . . . . . . . . " 138

Cuvierii. Fischer . . . . . . " $14 \mathrm{r}$

Mollii. Fischer . . . . . . . " 144

Knorii. Fischer . . . . . . . " ib.

Guettardi. Fischer . . . . . " 1 155

Eorguetii. Fischer . . . . . . " ib.

Testacea. Nobis . . . . . . . " 46

Meandrita . . . . . . . . . . . "147

Labyrinthica. Pallas . . . . . . " 150

Crispa. $L k$. . . . . . . . . . " 152

Crebriformis. Lk. . . . . . . " 154

Dædalea. Solander . . . . . " 155

Filograna. Esper . . . . . . " 157 
Catenipora

Pag. 158

Labyrinthica. Goldfus . . . . . " 162

Pulchella. Nobis . . . . . . . . ” 163

Escharoides. $L k$. . . . . . . . . " ib.

Porites

Aculeata. Nobis . . . . . . . " I68

Complanata. $L k$. ... . . . . " I 70

Clavaria. $L k$. . . . . . . . " $17 \mathrm{I}$

Ornata. Nobis . . . . . . . " " 172

Oculina . . . . . . . . . . . " 174

Rosea. Pallas . . . . . . . " 176

Virginea. Linn. . . . . . . . ” 180

Solanderi. Defrance . . . . . . " 181

MAdRepora . . . . . . . . . . . ” 182

Abrotanoides. Tournefort . . . " 185

Exarata. Nobis . . . . . . . " 186

Lundutes . • . . . . . . . . . " 187

Androsaces. Allioni . . . . . . " I9I

Perforata. Munster . . . . . . " $19^{2}$

Sulcata. Nobis . . . . . . . ” ib.

Intermedia. Nobis . . . . . . . ” 1 93

Enticulata. $L k . \quad$. . . . . . . " 194

Eschara . . . . . . . . . . " 195

Substriata. Munster . . . . . . " 206

Celleporacea. Munster . . . . . . ” ib.

Lata. Milne-Edwards . . . . . . " ib.

Deshaysii. Milne-Edwards . . . " 207

Affinis. Milne-Edwards . . . . . " ib.

Porosa. Milne-Edwards . . . . . ” ib.

(Flustræ) Foliacea. Linn. . . . . . “ 208

Crassa. Desmaret et Lesueur . . . . ” 209

Cretacea. Desmaret et Lesueur . . . "2 2 о

Tesselata. Ll. . . . . . . . . . ” ib.

Contexta. Goldfus . . . . . . "2 2 x

Millepora . . . . . . . . . . . " 212 
Mrlezpora Truncata. Pallas ....... Pag. 215 Tethia . . . . . . . . . . . \$2 216 Asbestella. $L k$. . . . . . . " 218 Cavernosa. $L k$. . . . . . . ” ib. Lyncurium. $L k$. . . . . . . . " 219 Simplex. Nobis . . . . . . . $\gg$ ib. Syphonifera. Nobis . . . . . . " ib. Regularis. Nobis . . . . . . . " 220 Penwatula . . . . . . . . . . . . " $22 \mathrm{r}$ Diluvii. Nobis . . . . . . " 223 


\section{INDUX TABULARUM}

TAE. I.

Fig. r. Isrs - Melitensis. Goldfus

2. Antipates Serialis. Nobis.

3.

Hirta. Nobis.

4.

Signata. Nolis.

5.

Corticata. Lamoroux.

6. Turbinolia Sulcata. Lamarck.

7 .

Trochiformis. Pallas.

8.

Italica. Nobis.

9. Armata. Nobis.

TAB. II.

Fig. r. Turbinolia Compressa. Lk.

2.

3.

4.

5.

6.

7.

8.

9 .
Clavus. $L k$.

Sinensis. Nobis.

Pyramidata. Nobis.

Obesa. Nobis.

Multispina. Nobis.

Multiserialis. Nobis.

Cornucopia. Nobis.

Plicata. Nobis.

TAB. III.

Fig. 1. Turbinolia Plicata. Nobis. variet.

2.

3.

4. Caryophyllia Reptans. Nobis.

5.

Amica. Nobis.
Avicula. Nobis.

Cyathus. Solander. (madrepora) 
Fig. 6. Fungia Japheti. Nobis.

7. Sarcivora Organum. Linnœells. (madrep.)

8. Concordis. Nobis.

TAE. IV.

Fig. I. Sarcindela Mirifica. Nobis.

2 .

Geometrica. Nobis.

3.

Musicalis. Linn. (madr.)

4.

Acropora. Linn. (madr.)

5.

Plana. Nobis.

6.

Punctata. Linn. (madrep.)

\section{TAB. V.}

Fig. I. AstraA Intersepta. Esper. (madr.)

2. Galaxea. Solander. (madrep.)

3. Interstincta. Linn. (madr.)

4. Catemipora Pulchella. Nobis.

5. Dædalea $L k$.

6. Monticularia Guettardi. Fischer.

\section{TAB. VI.}

Fig. 1. Porites Aculeata. Nobis.
2.
Complanata. $L k$.
3. Ornata. Nobis.
4. Oculina Rosea. Pallas.
5. Virginea. Linn.
6. Madrepora Exarata. Nobis.
7 .
Abrotanoides. Tournefort.
8. Millepora Truncata. Pallas. 


\section{TAE. VII.}

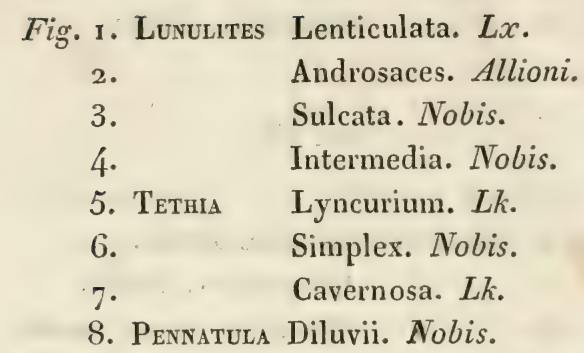

Nota. Nonnulli putant dimensiones lincola apponere debuisse cuique speciei, verum quum major vel minor amplitudo earum ab ætate aliisque adjunctis pendeat, satius duxi talia signa omittere, quæ si adjecissem, paucis tantum individuis, in iisdem adjunctis constitutis, convenire potuissent. 
Lin. $\times 5$ detexerint

I exprimenta

7

12

14

I6

I7

$2 I$

23

25

32

42

41

45

46

46

49

57

57

$6 \mathrm{x}$

6 I

63

6 '

So

$8 x$

87

$9^{\circ}$

112

I 3

I 9

I6 $\mathrm{x}$

$x 63$

I66

I 88

205
25 contrahuntur

I2 prodiri

7 ostendat

I incola

I' lactei

5 minutissimam

I egerut

15 serie

r9 asci

3 sostis

3 simplose

9 turbinolia

23 tentaculos et alibi

Io turbinoliam

Io fulcis

r7 peritus

5 characteri

13 hæc

I4 subaientatæ

25 sentiit

7 orem

26 distinctio

22 alio

I2 meno

8 conjunctique

27 sarcinulis

II tegumentæ

4 flectuare

9 est

ro stellæ

27 quos

27 cambris detegerint

experimenta

contrahunt

prodire

ostendens

incolam

lactis

minutissimum

egerunt

series

axi

costis

simplex

turbinolixe

tentacula

turbinolia

sulcis

penitus

characteres

hæ

subdentatas

sensit

os

distinctionem

aliorumque

nemo

conjunctæque

astreis

tegumenta

fluctuare

esse tradunt

stellas

quæ

cambridgien. 


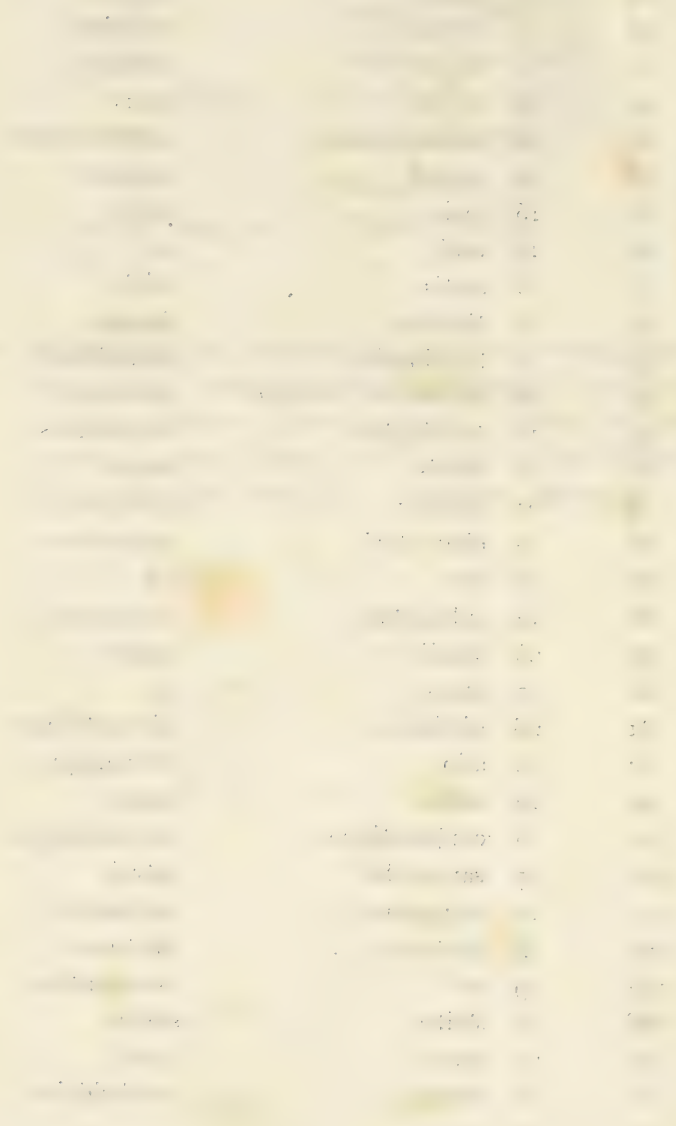




Tab.I.
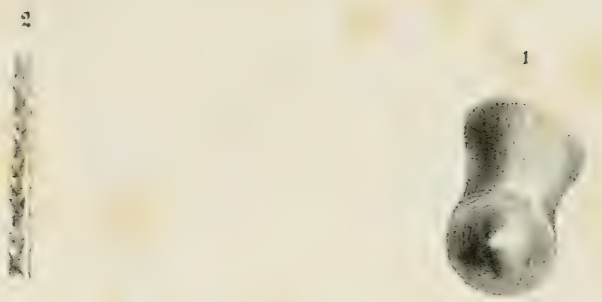

$\boldsymbol{s}$
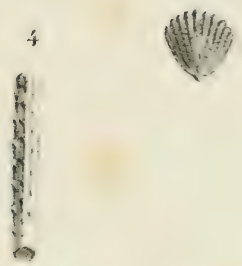

(ำ!le"

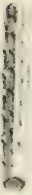

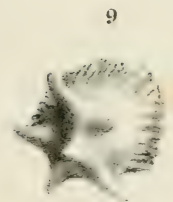

s

6
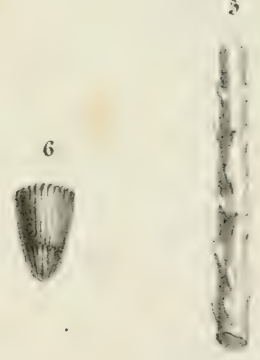

5

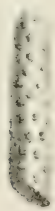




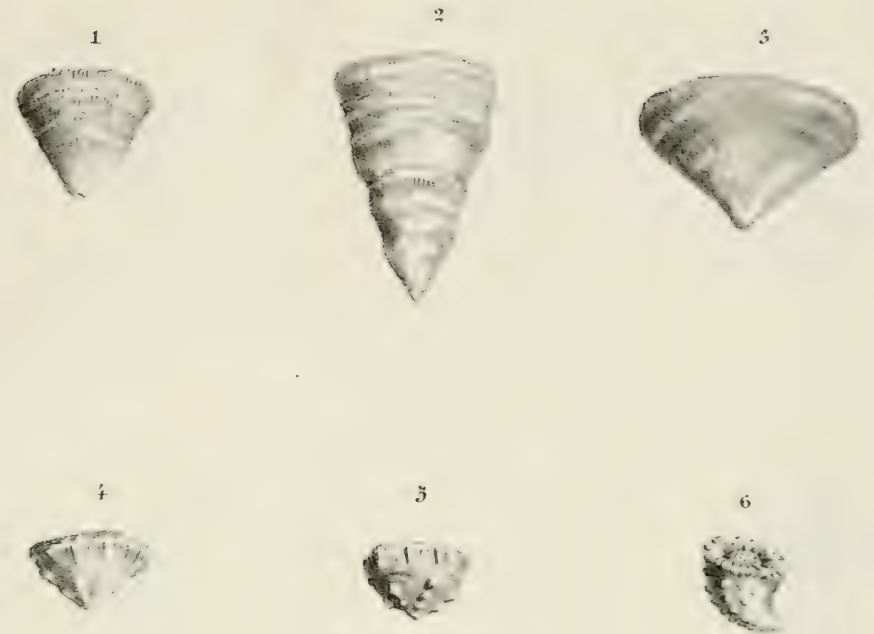

6
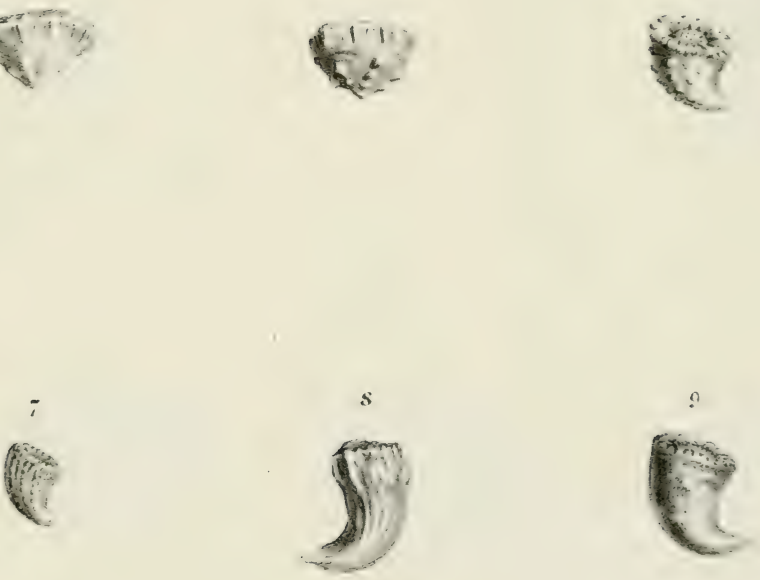

Tab. III.
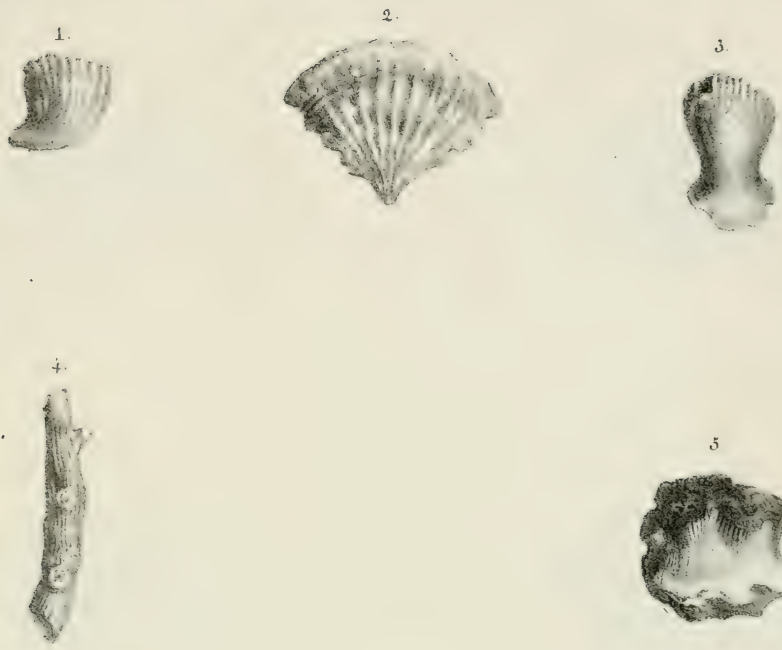

5
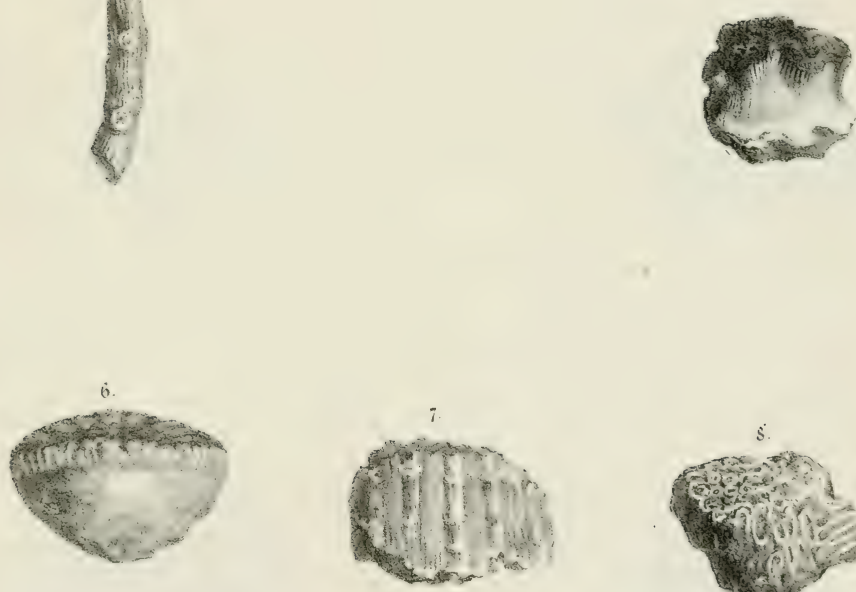

s.

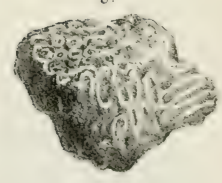





\section{Tab. IY.}
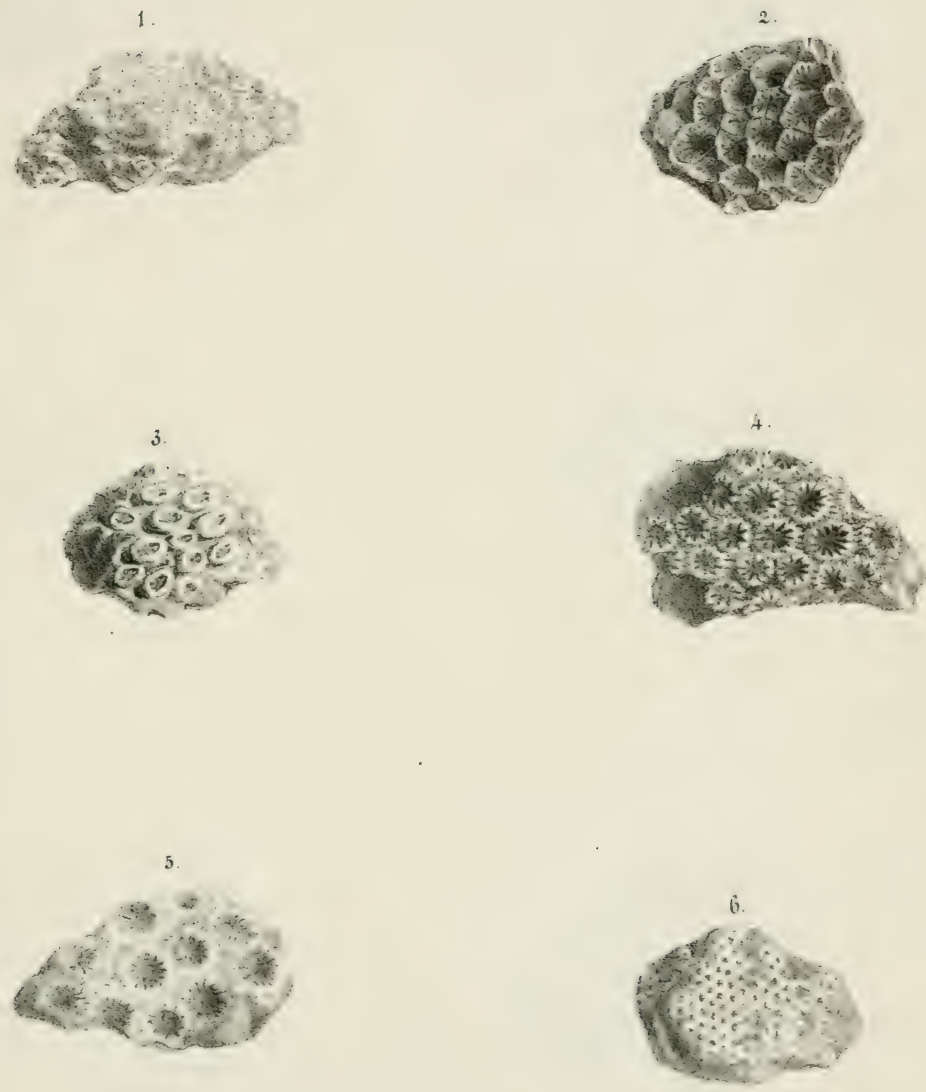



\section{Tab.V.}
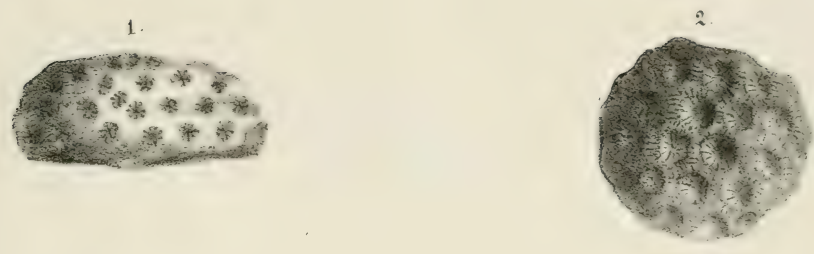

\section{3.}
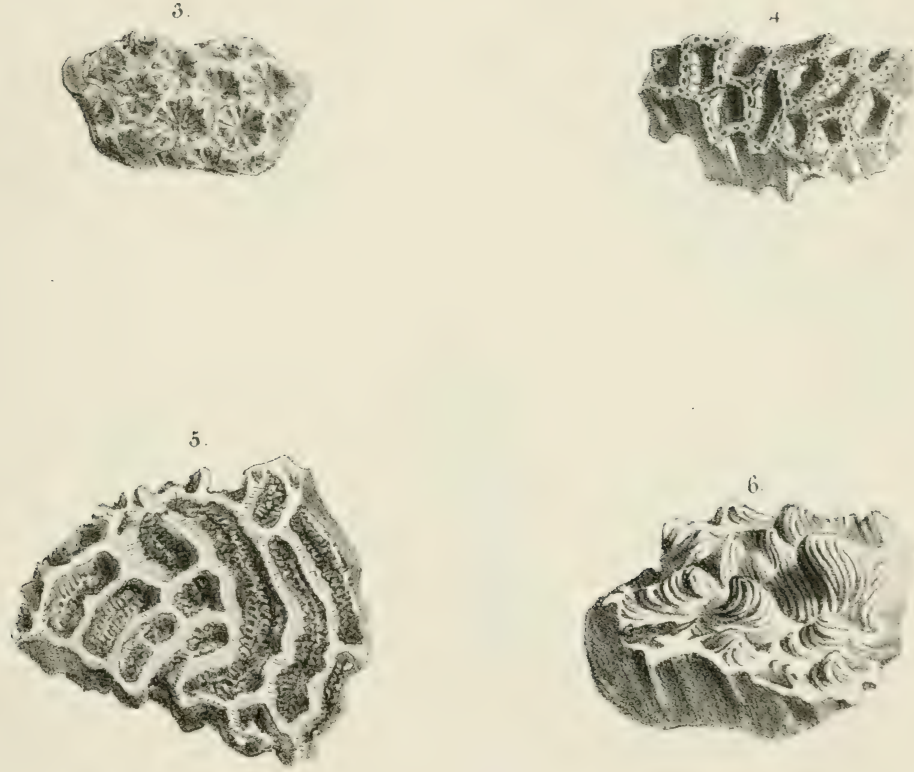

Tab. VI.

1.

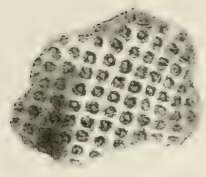

$\therefore$

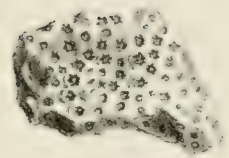

3.

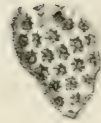

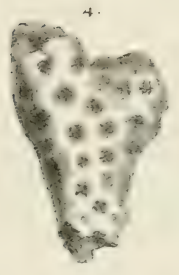
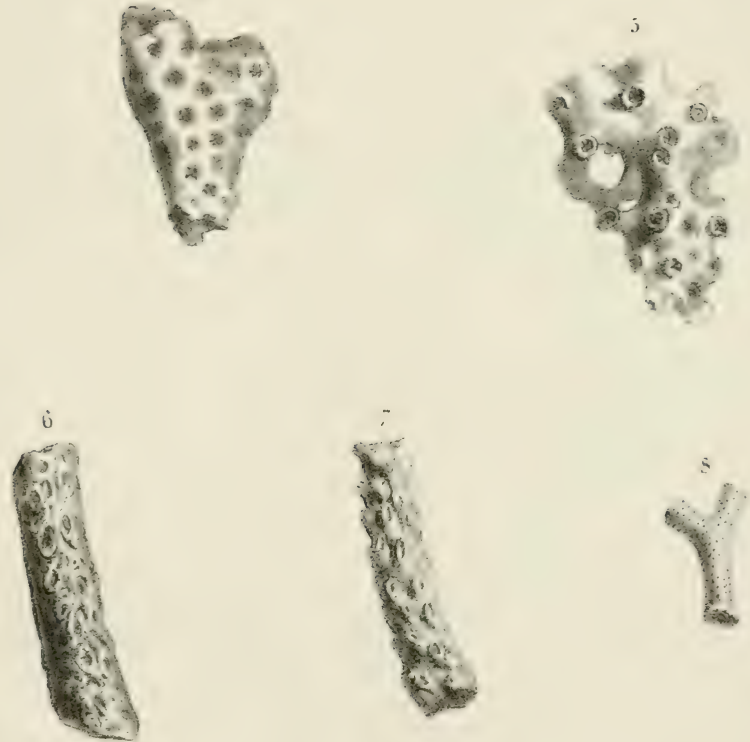

Tab. VII.
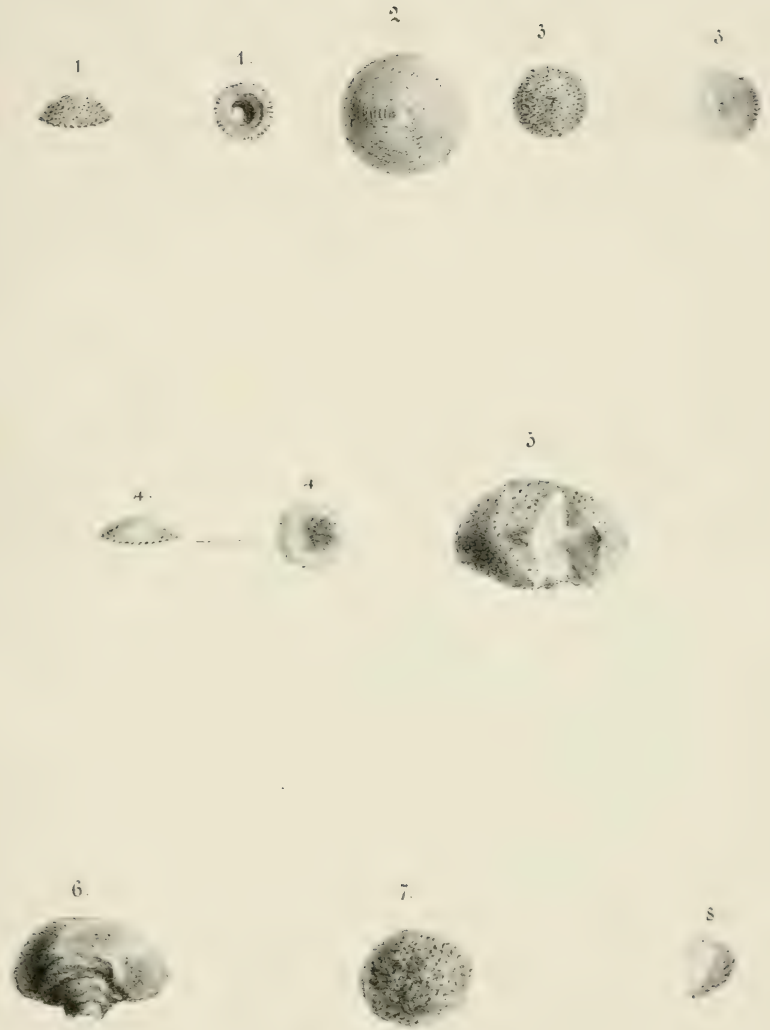




